University of Rhode Island

DigitalCommons@URI

Open Access Dissertations

2021

\title{
A MARKETER'S SYMPHONY: ESSAYS ON THE POWER OF MUSICAL STRUCTURE AND ITS INFLUENCE ON CONSUMERS WITH FOUNDATIONS FOR FUTURE RESEARCH IN AUDIO SENSORY MARKETING
}

Shawn P. Scott

University of Rhode Island, sscott@uri.edu

Follow this and additional works at: https://digitalcommons.uri.edu/oa_diss

\section{Recommended Citation}

Scott, Shawn P., "A MARKETER'S SYMPHONY: ESSAYS ON THE POWER OF MUSICAL STRUCTURE AND ITS INFLUENCE ON CONSUMERS WITH FOUNDATIONS FOR FUTURE RESEARCH IN AUDIO SENSORY MARKETING" (2021). Open Access Dissertations. Paper 1231.

https://digitalcommons.uri.edu/oa_diss/1231

This Dissertation is brought to you for free and open access by DigitalCommons@URI. It has been accepted for inclusion in Open Access Dissertations by an authorized administrator of DigitalCommons@URI. For more information, please contact digitalcommons-group@uri.edu. 


\title{
A MARKETER'S SYMPHONY:
}

ESSAYS ON THE POWER OF MUSICAL STRUCTURE AND ITS INFLUENCE ON CONSUMERS WITH FOUNDATIONS FOR FUTURE RESEARCH IN AUDIO

\section{SENSORY MARKETING}

BY

SHAWN P. SCOTT

\begin{abstract}
A DISSERTATION SUBMITTED IN PARTIAL FULFILLMENT OF THE
REQUIREMENTS FOR THE DEGREE OF
\end{abstract}

DOCTOR OF PHILOSOPHY

IN

BUSINESS ADMINISTRATION

UNIVERSITY OF RHODE ISLAND

2021 
DOCTOR OF PHILOSOPHY IN BUSINESS ADMINISTRATION

OF

SHAWN P. SCOTT

APPROVED:

Dissertation Committee:

Major Professor Lauren I. Labrecque

Christy Ashley

Ian Reyes

Brenton DeBoef

DEAN OF THE GRADUATE SCHOOL

UNIVERSITY OF RHODE ISLAND

2021 


\begin{abstract}
Music surrounds us in our daily lives and lives within us as consumers. It has the power to elicit deep emotions in us. Because of music's power over people, marketers have used music to enhance and direct an emotional response in consumer behavior for decades. These uses of music ranged from ambient forms of music such as in restaurants, at retail, or in public open spaces to more directed forms of music such as in TV commercials or digital advertisements. Despite this expansive use of music used in marketing, this body of research has tremendous opportunity for further exploration. The large body of research from the musical literature, and the research streams of musicology and neuropsychology offer immense opportunity to help explain the deeper context of why marketing researchers see such deep emotional affect in consumers who are exposed to musical stimuli in marketing. Also, by incorporating a multidisciplinary approach to this research though incorporating research from outside of the domain of marketing, subsequently helps to close the gap on many potential marketing research questions.
\end{abstract}

Therefore, the following dissertation is divided into four chapters. The first chapter is an introduction with an overview of and an explanation of the contributions this dissertation makes to the larger body of audio-sensory marketing research stemming from musicology research, psychology research, and marketing research. Chapter 2 explores the specific components of music, how each is outlined and defined in the realm of marketing research, and how other research domains can shed light on additional implications of music's effect on consumers. More specifically, chapter 2 takes us on a journey into multiple components of music such as: how music has been used and researched in marketing, the length of music used, ambient versus targeted forms of music, and under 
researched component aspects of music such as timbre and its power over consumers' emotions. Through exploring these key aspects of music and marketing, a new conceptual framework and map is formed as a foundation for future research.

Chapter 3 outlines musical tension and resolution and tests its effect on consumer attitudes through four empirical studies in support of seven hypotheses. In experiment 1 , it is shown how the tension-build and resolution in musical structure can be paired with advertising to elicit a more powerful consumer reaction and heuristic appeal for the advertised product or service. In experiment 2, a deeper probe is conducted to highlight that this tension build and resolution in the musical structure can vary in its influence on consumer attitudes depending on the location of the tension and resolution structure. Finally, in experiments 3 and 4, underlying factors such as brand familiarity and Need for Cognitive Closure (NFCC) are shown to enhance and attenuate this phenomenon.

Through the exploration of these topics and the research documented through this dissertation, the intent is to expand the conceptual framework, marketing insights, and the methodology that currently exists in the realm of marketing practitioners and marketing scholars in the context of advertising. 


\section{ACKNOWLEDGMENTS}

The decision to leave a lucrative career in industry and pursue my dream to research and teach in higher education has proven to be a difficult yet rewarding journey. I have learned more than I could have even imagined before entering the $\mathrm{PhD}$ program at the University of Rhode Island. This experience has not only changed who I am as a researcher, a teacher and a professional, but has also changed me as a person to the core. As an amateur musician and lifelong marketer, I have always had a passion for music and marketing, and I am so incredibly fortunate to have the opportunity to create a research path out of it. I am grateful and humbled by everyone who has stood by my side through the past four years and offered me both scholastic and emotional support, including my marketing cohort partner P. Dorin Micu for the countless late night and weekend exchanges that kept me sane.

I would like to thank my major professor and advisor, Lauren Labrecque. I realize how incredibly fortunate I am to have met you at the exact time I declared my interest in researching sensory marketing. You have not only been a wonderful teacher and mentor to me, but you have shown me an unbelievable amount of patience and empathy through our time working together.

I also want to thank my other teachers and mentors at the University of Rhode Island, starting with my core committee members, Christy Ashley and Ian Reyes. Christy, you have given me guidance throughout the PhD process and have helped me navigate through some of my toughest times in my four-year journey. I can remember back to the conversations we had before I decided to join the University of Rhode Island and I am so glad I decided to take this direction and work with you. Ian, you have been my music and 
media guru that has kept me on track in my research and kept me true to the multidisciplinary direction that I have taken on in my research. You always made the time for me without question and I truly appreciate all your support. I also want to thank Daniel Sheinin for pushing me to strive for more impactful research and Steven Atlas for teaching me balance.

I would like to thank my friends and family members for all their moral support over the past four years. Most significantly, my father Gerald Scott, who has given me an endless amount of support and love to help get me through this difficult path. Also, my mother Jacqueline Scott, who passed away a month before I started the program. I could feel you by my side every step of the way, looking over me and shining a light on me in my darkest days.

Last but not least, I would like to thank my wife Amanda Scott, my son Thomas Scott and my stepson Samuel Boswell. You all lived at the frontlines of my toughest struggles encouraging me to keep going, and you were there through my biggest milestones and accomplishments celebrating with me. This was most evident in this past year of my PhD journey when we were all quarantined during the pandemic. During this most difficult time, you were all my lifeline that kept me above water. 
TABLE OF CONTENTS

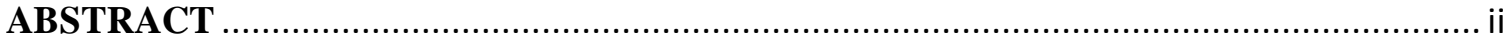

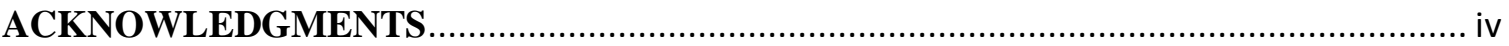

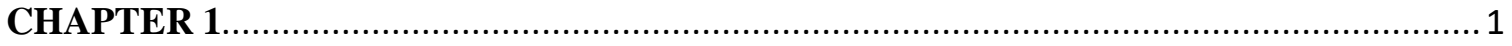

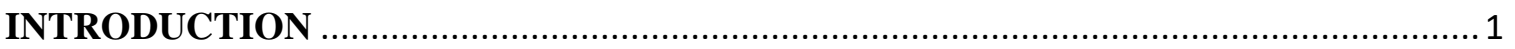

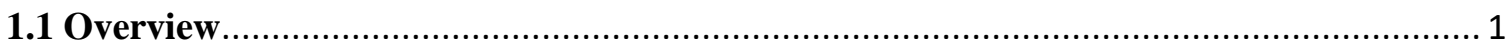

1.2 An Expanded Conceptual Framework Map, and Studies in Musical Tension and

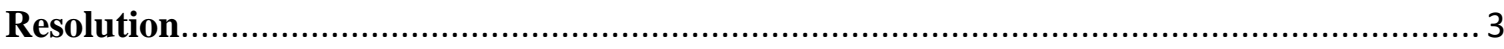

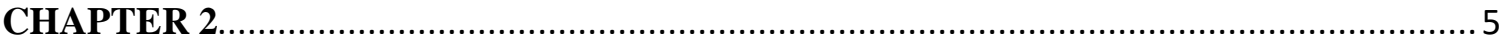

MUSIC DIMENSIONALITY AND INTEGRATION: A MULTIDISCIPLINARY

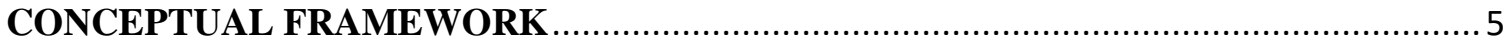

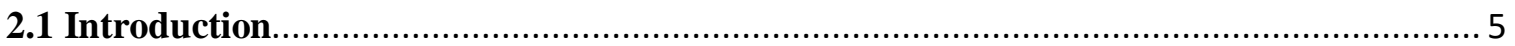

2.2 Beyond Bruner: An updated conceptual framework of time, pitch, and texture ............. 8

2.2.1 Musical Expressions in Marketing ................................................................... 9

2.2.1.1 Time

2.2.1.1.1 Marketing Literature Related to Time ...................................................... 9

2.2.1.1.2 Literature on Time Outside of Marketing Domain ................................... 11

2.2.1.1.3 Future Marketing Research Directions and Managerial Implications on

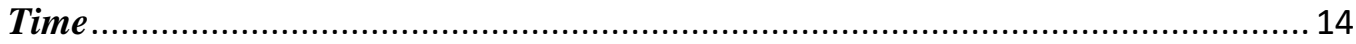

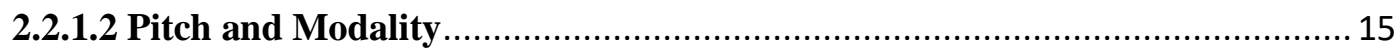

2.2.1.2.1 Marketing Literature Related to Pitch and Modality ................................ 16

2.2.1.2.2 Literature on Pitch and Modality Outside of Marketing Domain ............... 18

2.2.1.2.3 Future Marketing Research Directions and Managerial Implications on

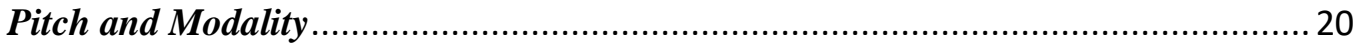

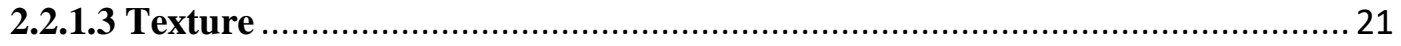

2.2.1.3.1 Marketing Literature Related to Texture …............................................... 22

2.2.1.3.2 Literature on Texture Outside of Marketing Domain ............................... 23

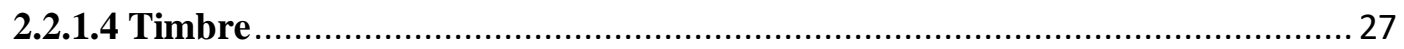

2.2.1.4.1 Marketing Literature Related to Timbre …............................................. 27

2.2.1.4.2 Literature on Timbre Outside of Marketing Domain ............................... 28

2.2.1.4.3 Future Marketing Research Directions and Managerial Implications on

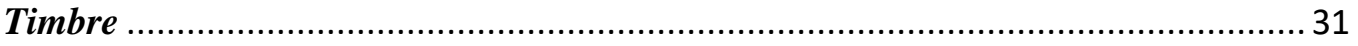

2.2.2.1 Length of Music Used in Marketing ....................................................... 32 
2.2.2.1.3 Future Marketing Research Directions on and Managerial Implications

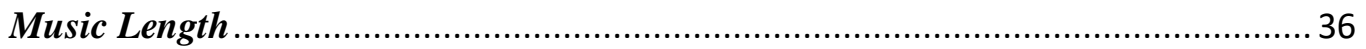

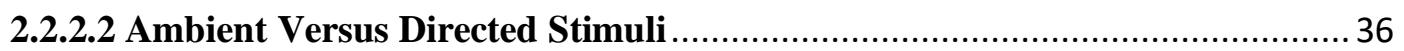

2.2.2.2.1 Marketing Literature Related to Ambient Versus Directed Stimuli ............. 36

2.2.2.2.2 Literature on Ambient Versus Directed Stimuli Outside of Marketing Domain

2.2.2.2.3 Future Marketing Research Directions and Managerial Implications on Ambient Versus Directed Stimuli. 39

2.3 Discussion 40

CHAPTER 3:

GREAT EXPECTATIONS: MUSICAL TENSION AND RESOLUTION'S INFLUENCE

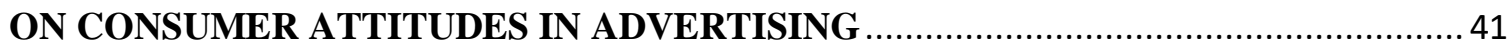

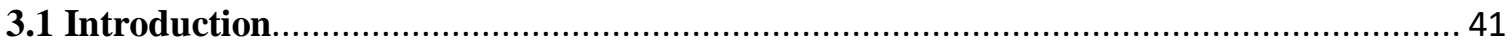

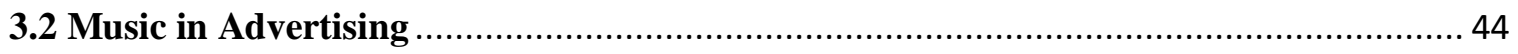

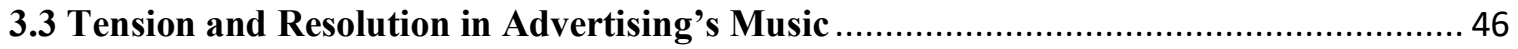

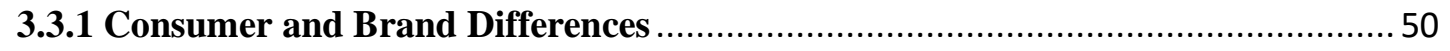

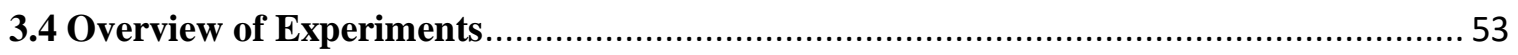

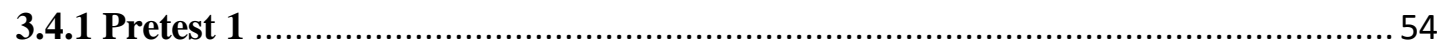

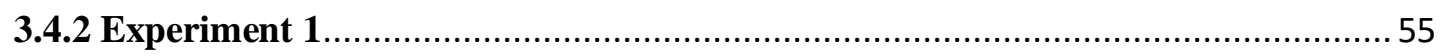

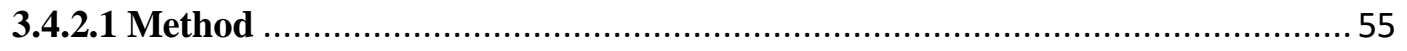

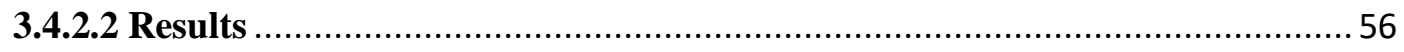

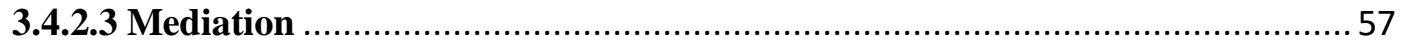

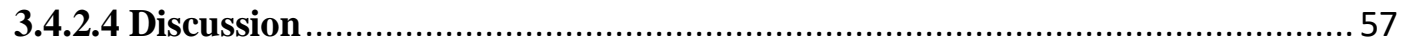

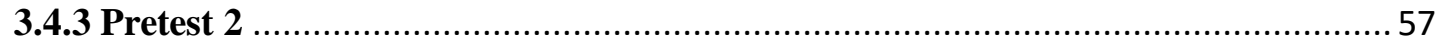

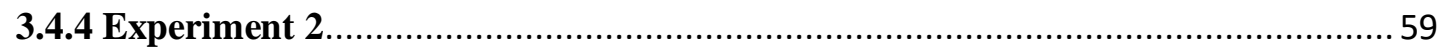

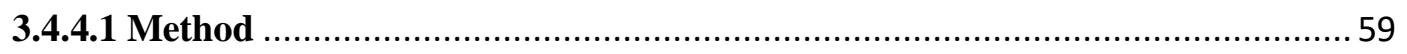

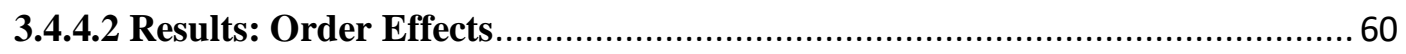

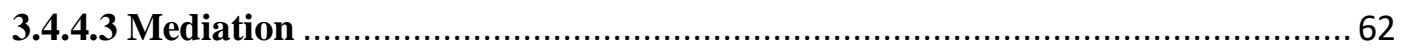

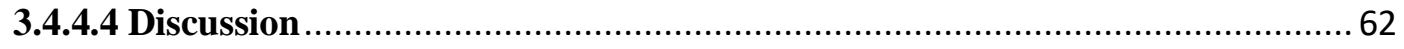

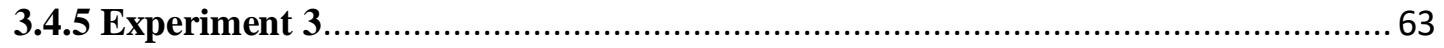

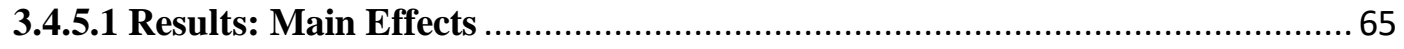

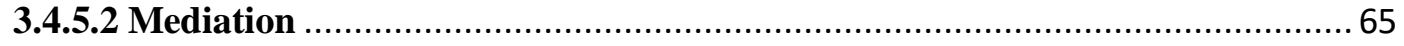




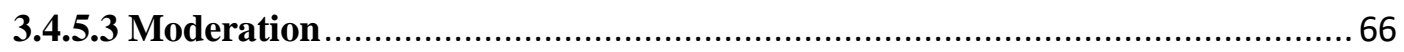

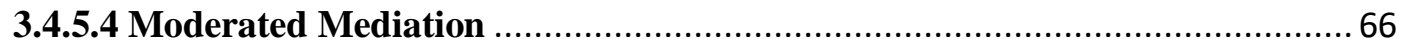

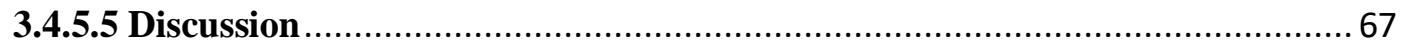

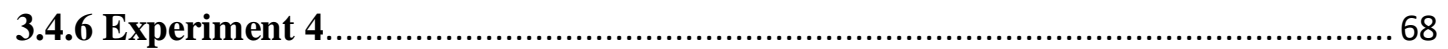

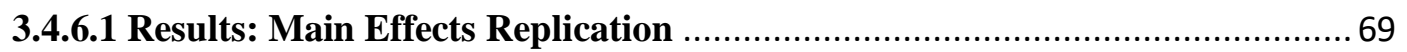

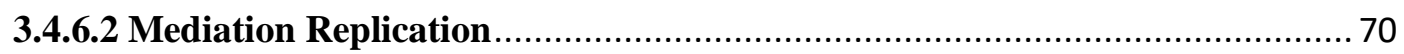

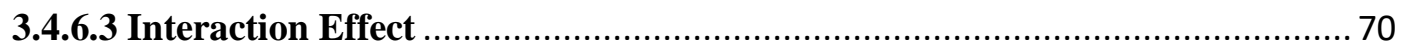

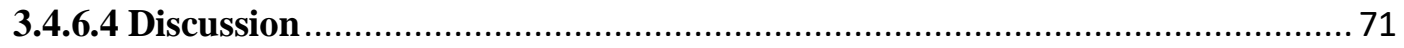

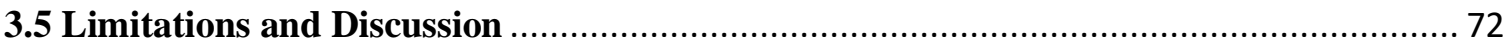

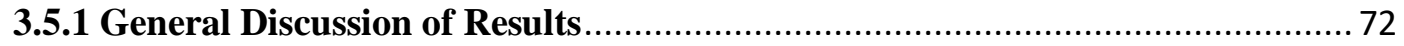

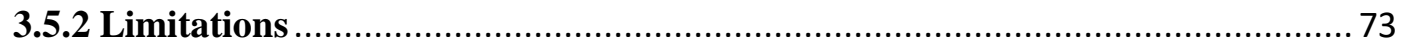

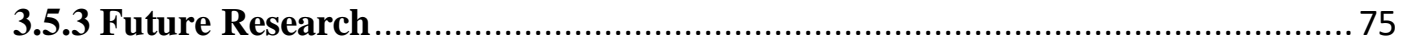

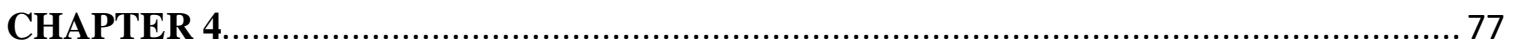

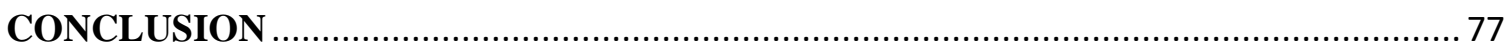

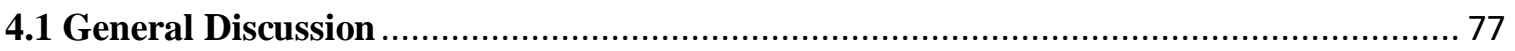

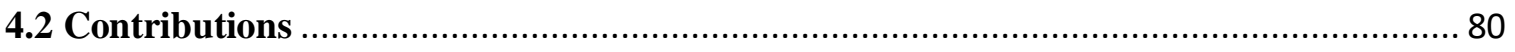

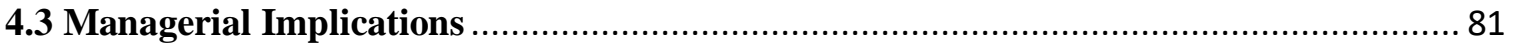

APPENDIX A

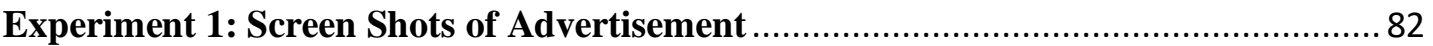

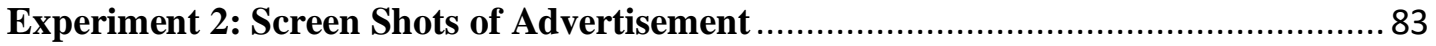

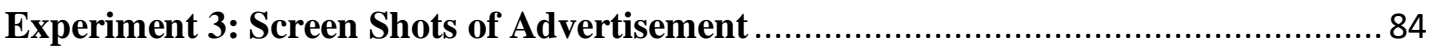

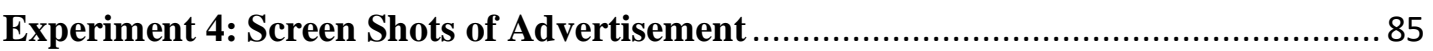

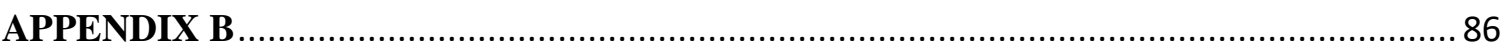

Figure 1: Research Map for the Multidisciplinary Conceptual Framework................. 86

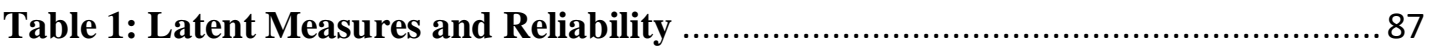

Figure 2: Full Logarithmic Spectral Frequency Display for Clips used in Exp1 .......... 88

Figure 3: Mediation of the Effect of Tension Resolution Structure on Advertisement

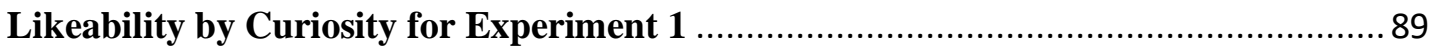

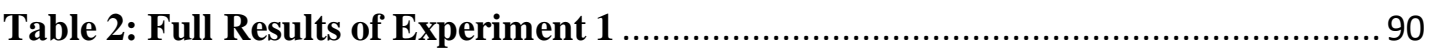

Figure 4: Temporal Slider Scale Output paired with Full Logarithmic Spectral Frequency Display for clips used in Pretest 2 ......................................................... 91

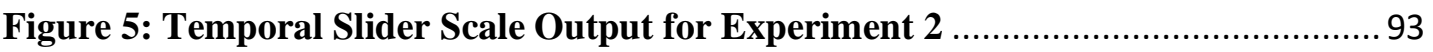

Figure 6: Full Mediation of the Effect of Tension Resolution Structure on

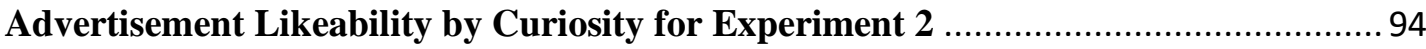




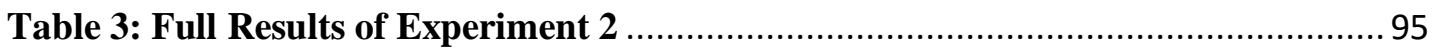

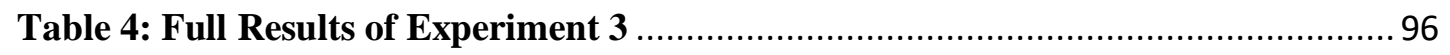

Table 5: Johnson-Neyman Output: Conditional Effect at Values of the Moderator

NFCC on the relationship of the tension resolution structure and ad likeability ..........97

Figure 7: Serial Mediation Model from Experiment 3 …......................................... 98

Figure 8: Moderation Mediation Models from Experiment 3 .................................. 99

Table 6: Johnson-Neyman Output: Conditional Effect at Values of the Moderator

NFCC for Moderated Mediation ..................................................................... 100

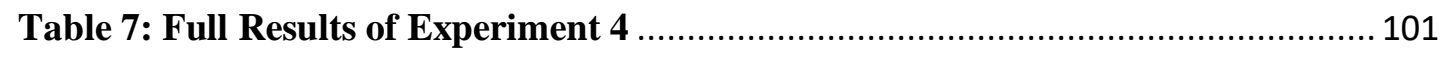

Figure 9: Means Differences Between Conditions in Experiment 4 ......................... 102

APPENDIX C

Table 8: Key Musical Terminology, and Associated Current and Future Research .. 103

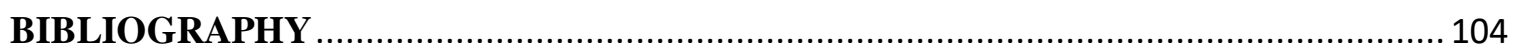




\section{CHAPTER 1 \\ INTRODUCTION}

\subsection{Overview}

In preparation for this dissertation, it became clear when reading various manuscripts from the marketing, neuropsychology, and musicology literature domains, that there is a need to aggregate and create a common musical language for how marketing scholars evaluate music used in marketing, specifically advertising. For example, how scholars define music and even how scholars define the length of music can vary from discipline to discipline.

The landscape of music research has also synthesized over the years in the specific domain called sensory marketing. The areas of sensory marketing are inclusive of all the key five senses: auditory, visual, haptic, olfactory, and gustatory (Biswas, 2019). Recently, the literature has even moved beyond the five senses into areas such as vestibular sensations as an example (Biwas, Szocs, and Abell, 2019). The sensory marketing literature has also explored cross modal correspondences or interactions between the senses (Spence, 2011). Although, within this growing body of literature, there remains a significant opportunity to explore the auditory components.

As a definition of sound and human hearing, science is clear on how humans (and in marketing terms: consumers) process sound. Sound travels to the outer ear, through the fluids in the middle ear, and into the inner ear (cochlea), where the sound waves are processed into neural activity. This process allows humans to perceive sounds between 20 $\mathrm{Hz}$ and $20000 \mathrm{~Hz}$ (Helmholtz, 2013). The concept of what categorizes audio events as 
sound versus music requires a deep examination into the cultural and semiotic nature of audio events. The scope of this dissertation is to focus less on the cultural aspects of music and more on the elements of music which have been established in the marketing, musicology, and neuropsychology literature as having an emotional or physiological effect on consumers.

Specifically, there are elements of music such as time, pitch, texture, and timbre (Bruner, 1990) in addition to a wide range of terminology that can shift in meaning depending on the publication being reviewed. It is not the aim of this dissertation to compare or contrast these differences in full, rather the goal is to synthesize these concepts into one conceptual map of understanding for marketing scholars and practitioners alike. In the following chapters, I intend to create an expanded conceptual framework and uncover new musical effects that contribute significantly to the science of music in marketing. Given that some of the terminology is not central to the marketing domain, Table 8 in Appendix $\mathrm{C}$ highlights key musical terminology along with the associated research within and outside of the marketing research domain to act as a guide to the reader, specifically for chapter 2 . 


\subsection{An Expanded Conceptual Framework Map, and Studies in Musical}

\section{Tension and Resolution}

Music, its complex structure and its effect on the listener, have been studied in marketing, neuropsychology, and musical literature alike. Unfortunately, all three areas of literature have "blind spots," usually focusing only on the specifics germane to their host domain. In Chapter 2, I highlight the most relevant forms of each literature domain and link these theories together in one conceptual map of music's effect on the listener and how this effect shapes consumer attitude.

Music used in advertising has been studied for decades but has not uncovered a significant format in music which is structural and compositional in nature and is a powerful emotive element: that of tension build and resolution. This structural component of music has been written about in musical literature but is lacking in the marketing context. In chapter 3, I posit seven hypotheses that outline the main effects, an underlying mediator, a boundary condition and an attenuating effect of brand knowledge that outlines this phenomenon. It is through these four experiments that I show evidence in support of these seven hypotheses.

Together these two main essays add to the literature of marketing specifically in advertising, in sensory marketing, consumer behavior, and branding. This work adds to marketing literature by adding an updated exploration on the elements of music, an explanation of key terminology, and an expansion of the audio sensory marketing area. By highlighting that tension in advertising's background music can have a positive influence on consumer behavior is a new addition to the existing literature. Finally, this dissertation adds to the consumer and branding literature by uncovering further effects of how 
consumer differences can change the way they react to structures of music and further defining branding boundary conditions. 


\section{CHAPTER 2}

\section{MUSIC DIMENSIONALITY AND INTEGRATION: A}

\section{MULTIDISCIPLINARY CONCEPTUAL FRAMEWORK}

\subsection{Introduction}

Music, which is used as a creative tool in marketing, is a multifaceted discipline which can take many forms such as background music in advertising, sonic branding and can even be attributed to digital ringtones for cell phones. In this way, music as a medium in marketing is intertwined in people's lives and cultures (Keil and Feld, 1994) that connects to emotions and memories (Argo, Popa, \& Smith, 2010). Marketing practitioners have used musical stimuli since the inception of modern marketing. Because of this, consumers are bombarded with musical stimuli, including ambient music and other sounds at retail locations and restaurants; traditional or satellite radio in vehicles; personal audio assistants such as Alexa, Siri, and Google Assistant; streaming podcasts, TV and even on websites. Consumers are responding positively to this increase in music usage as there has been a recent spike in consumers' audio-platform usage over the past decade. The percentage of total audio listening has increased measurably - $122 \%$ since 2014 (Edison Research, 2019). Nielson also recently reported that the average consumer 13 years of age or older listens to over 30 hours of music a week on more than three devices (Nielsen Music 360, 2017). Accordingly, marketers have an ever-increasing opportunity to follow these trends and to attract consumers through music used in marketing.

The challenge in this robust digital landscape is to break through the "audio clutter." For example, consumers lack the time and patience to respond to overt 
marketing; when consumers go online with a purpose or goal in mind, they may perceive digital advertising as intrusive (Li, Edwards, \& Lee, 2002). Because the use of loud video pop-ups on web may have unintended — and negative — effects on consumers (Smith, 2011), marketing practitioners need less overt, more effective communications solutions. Despite extensive research in the music-in-advertising domain (Alpert, Alpert, and Maltz, 2005; Nelson, Meyvis, and Galak, 2009; Oakes 2007; Oakes and North 2006; Park \& Young, 1986), there is opportunity for further refinement. A promising option is to look beyond marketing to the domains of musicology (Aucouturier, Pachet, and Sandler, 2005; Dainow, 1977; Dowling, 1994; Evans, 2005; Fales, 2005; Helmholtz, 1912, 2013; Huron, 1989) and neuropsychology (Bigand, Parncutt, and \& Lerdahl, 1996; Brattico and Pearce, 2013; Gillard and Schutz, 2016; Koelsch, Fritz, Schulze, Alsop, and Schlaug, 2005; Lewis, Beauchamp, and DeYoe, 2000; Möckel, Röcker, Störk, Vollert, Danne, Eichstädt, and Hochrein, 1994; Pearce and Wiggins, 2012; Von Helmholtz, 1912) for further explanation and depth.

In this chapter, a framework of key musical elements and components of musical structure is presented with the intent to produce an expansion on the baseline of Bruner's (1990) work. Although marketing literature highlights these components to a varying degree, the goal of this chapter is to further marketing scholars' understanding of these areas by incorporating research and core concepts from the musical and neuropsychology domains. By synthesizing these domains, opportunities are identified for marketing research into consumer behavior framings and contexts.

In addition, since the goal of this chapter is to aid marketing scholars and practitioners in the expansion of the marketing literature within key musicological areas, a 
table is provided that highlights key musical terminology used in this dissertation accompanied by a brief definition of the terminology, a list of key related research, and proposal outline of future research opportunities for each major element (time, pitch, texture, and timbre) outlined in this chapter (Table 8 can be found in Appendix C). 


\subsection{Beyond Bruner: An updated conceptual framework of time, pitch, and}

\section{texture}

In 1990, Bruner established a framework between various components of music (such as time, pitch, and texture) and marketing which provided an overview of the impact of each musical component. He cites three dimensions of musical structure which encompass these musical components: physical, emotional, and preferential. Bruner (1990) identifies many components of music that are ascribed to emotional states and are therefore potential variables for study. For example, happiness can be expressed through faster tempos, major modes, or higher keys, while strength, seriousness, and force can be expressed through firm rhythms, rising pitch, or crescendos. Bruner (1990) outlines such characteristics for three categories of musical expression: time-related, pitch-related, and texture-related.

Expanding on Bruner's work, each of the following sections are: (1) an outline of research from marketing literature which establishes a core framework of three key music components: time, pitch, and texture; (2) research highlighted from other domains which helps to expand our knowledge of these three components; (3) an attempt to resolve differences in how these musical components are defined between these distinct literature streams; and (4) an exploration of future research possibilities in the marketing literature. In addition to expanding on the components of music used in marketing, the context of exposure is also explored. Specifically, important factors in song length and in ambient versus directed exposure to music are outlined. Both of these exposure factors have significant implications to marketing research yet are rarely discussed in academic publication. Figure 1 presents a map for this conceptual framework. 


\subsubsection{Musical Expressions in Marketing}

\subsubsection{Time}

The definition of time in the context of music used in marketing varies by publication source. In the context of marketing research, Bruner (1990) highlights key time-related components of musicology when he identifies fast tempos as having animation and expressing happiness, and he argues that firm rhythms express seriousness. However, moving beyond marketing literature to expand the definition into the mechanics of musical time reveals that there is more to time-related expression than tempo such as rhythm.

\subsection{Marketing Literature Related to Time}

Previous marketing literature shows that some time-related elements, such as tempo, have salience and cause arousal of the human senses (Mattila and Wirtz, 2001). Tempo not only affects arousal, but also how this effect is moderated in hedonic (emotional) and not utilitarian (functional) product settings (Ding and Lin, 2012). In addition, these consumer attitudes and feelings such as brand attitude and mood states can extend beyond the advertisement being viewed and can change consumer sentiment of a brand (Stewart and Koh, 2017), which is driven by a need for emotion.

Upon investigation of the two dimensions of tempo, that of faster and slower tempo significant differences are seen in consumer behavior in the marketing literature. For example, a slower tempo has been shown to influence consumer emotional states by increasing satisfaction and relaxation levels (Oakes, 2003), and change temporal perception and impatience (Kim and Zauberman, 2019). Conversely, research has found that faster tempo music drives consumers to become more impatient due to judging temporal distance to be longer (Kim and Zauberman 2019). Eroglu, Machleit, and Chebat 
(2005) found similar results in retail settings, where slower tempo music increased hedonic (emotional) responses and even approach tendencies. Patterns of causality emerge from these pieces of research which show that slower tempo relaxes consumers and therefore has potentially positive downstream effects at retail such as spending more time in-store, likelihood of entering a store, and purchasing more product. A slow tempo can also have a positive influence on math anxiety for pricing decisions (Feng, Suri, and Bell, 2014). These results extend to other consumer-based environments and areas as well and can be seen in advertising research where slower tempo music to enhance ad recall (Oakes and North, 2006). Slower tempo had an influence in consumption and purchasing in restaurants (Septianto, 2016).

Tempo does not exist in a vacuum. There are other musical components at play. Despite consumer sentiment, tempo didn't change downstream sales in a retail environment when a major mode (a collection of musical notes that sound bright or happy) was played (Knoferle, Spangenberg, Herrmann, and Landwehr, 2012). Conversely, slower tempo did have a positive effect on sales when paired with a minor mode (a collection of musical notes that sound sad). The interaction of other musical dimensions are not the only factors that need to be considered. Recent research has shown tempo to change consumers' taste perceptions in restaurant settings (Pantoja and Borges, 2017). These authors showed evidence that patrons had evaluated their food for favorably and overall more positive hedonic (emotional) experiences in a restaurant when fast tempos were played. These research results highlight a particularly important component of tempo in marketing research: that of context. For example, referencing back to research on tempo and modality (Knoferle et al., 2012), the congruency of the tempo and how happy or sad the music 
sounds can contextually be of significant importance. Looking outside of the marketing research domain, an expansion and further clarity to this concept is found beyond how time is represented in the marketing literature.

\subsection{Literature on Time Outside of Marketing Domain}

Scholars in the musicological and psychological literature explore the concepts of tempo and rhythm and uncover components that can benefit marketing researchers and practitioners alike. For example, the neuropsychology literature shows evidence for deeper effects of tempo and rhythm and how these elements of time appear in the brain. When people listen to beats or rhythms, they process the sounds in the motor parts of their brains (Grahn and Brett, 2007). Even more complex structures of rhythm, such as meter and pattern, elicit activity in other parts of the brain not related to motor activity (Thaut, Trimarchi, and Parsons, 2014). This suggests that auditory working memory and pattern recognition are activated in the brain in both metered time and clock time processing (Kuck, Grossbach, Bangert, and Altenmüller, 2003).

Looking beyond the scope of the marketing literature, differences in how tempo affects decision making are revealed. For example, earlier in this chapter it was established that marketing research showed how slower tempo helped math anxiety on pricing decisions (Feng, Suri, and Bell, 2014). There was research outside of marketing that had already established how faster tempo music increased accuracy of decisions (Day et al., 2009). These two results together help to frame out the effect that tempo has on consumers more completely by not focusing on simply marketing-specific outcomes. This is especially important to consider depending on the desired strategy that a marketer is trying

to employ. It is through understanding these underlying mediating factors of a listener's 
emotional state which can benefit marketing scholars and practitioners alike. For example, anticipation can play into the listener's perception of the music through what they call "the theory of predictive coding" which further separates the heard rhythm and the perceived meter (Vuust, Gerbauer, and Witek, 2014). This further uncovers more about how consumers perceive musical time and gives marketers a specific tool to apply to their tactical execution. For example, by changing the time-related components of music in an advertisement, which in turn change a consumer's anticipation, marketers can potentially change consumer attitudes or direct their attention in an advertisement.

Although tempo and rhythm may be dimensions that are prevalent in research inside and outside of marketing literature, one of the most unresolved arguments of musical time in marketing research is the difference between metered time and clock time. Where clock time is evident in all our daily lives as a measurement of the passage of incremental time, meter time is different in the context of music. Metered time measures patterns in the music such as beats of a rhythm or bars which are comprised of a specific clustering of notes and rests that follow a tempo. These two concepts could be similar depending on the arrangement of the music and tempo, but are usually vastly different. These two aspects of musical time have been argued for centuries as music sets the stage for the passage of time, "Technological developments such as the mechanical clock and the marine chronometer helped to reshape a wider public's notion of temporal passage" (Grant, p.60, 2009). At its base, musical time is not bound by a physical anchor, rather it is multidimensional (Pressing, 1993). Furthermore, it pulls from many other factors such as interpersonal interaction, the environment which it is experienced, and even culture. 
The representation of time in music has significant implications for marketing researchers. For example, if you had two musical stimuli against the backdrop of an advertisement, one had a faster tempo but had the same clock time exposure and saw statistically significant differences in dependent variables. The researcher in this case could attribute causality back to tempo speed arguing that the exposure "time" was the same. There lies the challenge. Musical theorists would disagree. They would say that, despite the same clock time between the two stimuli, the condition that had the faster tempo had a greater musical exposure, so, in this case it was the greater exposure that drove the downstream differences. In marketing research, equal exposure of a stimulus between conditions is a critical factor that must be accurately measured and reported for independent variables. Examples of this can be seen in attribute research and digital advertising (Vermeulen and Beukeboom, 2016), and more traditional forms of advertising (Raja, Anand, and Allan, 2019).

As a concrete example using musical time as the independent variable, in the context of notated structure, a melodic quarter note at 60 beats per minute plays for the same length of clock time as a half note at 120 beats per minute (Gabrielsson and Lindström, 2010). Unfortunately, these two clock time examples can sound vastly different to the listener depending on what other elements accompany the melody. When the dynamics of syncopation and time changes that are prevalent in modern music (Temperley, 1999) and advertising are added to the framework, the concept of time-related effects in musical stimuli become vastly complex beyond clock time and must be considered in marketing research. 
These effects can be tied back to the perception of time, which were prevalent in the marketing literature discussed earlier in this chapter. Systematic changes in attention occur in the brain while listening to music, as measured through eye tracking (Day, Lin, Huang, and Chuang, 2009). These changes are linked to large-scale properties of musical structure that are found in music. Meter is a property of musical structure that can change our perception of time in music (London, 2012). These examples show that there are significant opportunities for exploration of time elements and their effect on music used in marketing.

\subsection{Future Marketing Research Directions and Managerial Implications on Time}

As noted earlier, meter and clock time as components of musical time have been debated for centuries. The challenge for audio-based sensory marketing researchers is to remove or minimize any potential confounds in their musical stimuli. One way to resolve these differences in clock time and metered time is by suggesting that clock time should be brought into the equation (along with metered time) when measuring music in research (Clercq, 2016). Metered time can vary greatly in not only the number of notes but also in the perception of length. If the rhythm in a song is double time (suddenly increased in pace by two times), it can throw off perception for the laymen (Clercq, 2016). Therefore, when conducting research, both metered time and clock time should be considered and implemented when possible. To leave one aspect out of the measurement and reporting of results, leaves out an important dynamic of temporal exposure. It is proposed that by reporting these elements of musical time separately, a deeper understanding of how the structural components effect consumer behavior is achieved. In addition, the solution that is offered when researching time elements of music, is to develop and use stimuli that 
adheres to both concepts, perceptually. Put simply, in situations where the researcher wants to hold time constant between stimuli and conditions, they should keep to similar clock time while also giving the "perception" of the same metered time. This is easiest to achieve in monophonic musical structures. This is because in monophonic musical structures single notes of a melody are heard without the accompaniment of other notes or rhythmic structures. It is the overlapping nature of these other musical components which could interfere with the perception of time. Specifically, these separate musical structures could be perceived by the listener to have a different time structures, thus creating confounds in the research.

Research outside of the marketing domain highlights many opportunities for marketing scholars and practitioners alike. Research on rhythm components of musical time could lend to interesting research streams ranging from smart phone swiping (Carah and Shaul, 2016; Mulcahy and Riedel, 2020) to cross-modal interactions with color (Elliot

and Aarts, 2011; Kaltcheva and Weitz, 2006). Also, given that time-based music structures can alter memory and attention in consumers, further research exploring how tempo interacts with and can expand our understanding of the elaboration likelihood model is an opportunity for exploration (Petty and Cacioppo, 1986).

\subsubsection{Pitch and Modality}

Looking back to Bruner's (1990) work, he also discusses pitch-related elements of musicology and their emotional effects, including rise and fall of intensity, key signatures, happiness or sadness, modality, positivity, and harmonic complexity. Modality affects both behavioral intent and arousal (Kellaris and Kent, 1993). The concept of pitch through melody, and its effects on consumers is notably more complex than general measures of 
rise and fall, key signatures, or modality. For example, intervals (which are differences in pitch between notes) are a critical part of pitch; they can create consonance and dissonance (Krumhansl, 2000). Taken together, these pitch-related elements form complex, rich melodic structures. More research is needed to understand their potential for marketing. For example, if modality, key signatures, and interval interactions affect how people process melody, could these elements be paired with other sensory components? Pitch is processed partly in the language centers of the brain (Levitin and Menon, 2003). In this part of the chapter, the question of why pitch can have such a powerful effect on listeners, namely consumers, is revealed. Is it purely salience, or is there another factor present that ties back to the neurochemistry of our brain driven by how humans are hardwired anthropologically? Could it also simply be a factor of culture and popular music influence? For example, could the processing of melodic form in the language center of the brain strengthen or attenuate the effects of verbal communications such as text, taglines, and even fonts?

\subsection{Marketing Literature Related to Pitch and Modality}

As discussed earlier in this chapter, structures of music can influence the perceptions of time. This phenomenon of time perception can also be found in melodic qualities of music. Music with a major modality increased perception of time and atonal music decreased perception of time (Kellaris and Kent, 1992). This is counter to conventional wisdom because in earlier research, they also found that modality played a part in appeal in an ambient setting as a major mode was the most appealing (Kellaris and Kent, 1991). One would think that music that is more appealing would pass time quicker as "time flies when you are having fun." In a service setting, positively-valenced music 
(music with a positive and upbeat tone) triggers a more positive emotional response to the wait time in a service environment and a stronger approach behavior towards the service organization (Hul, Dube, and Chebat, 1997). Positively valenced music also increases perceived wait duration. These changes in behavior and perception driven by pitch and modality can be even more powerful when used with tempo. When music that was played in a retail environment had a minor modality, it was significantly more effective at driving positive consumer behavior when played at a slower tempo (Knoferle et al., 2012).

The effects that pitch and modality have on consumers can extend beyond the structural and melodic components of the music and can also include how the listener interprets the music. Outside of the behavioral aspects of marketing, pitch and modality in music are used to drive a narrative within the story (Huron, 1989). Deeper narrative meanings communicated in music can be both referential (descriptive) and hedonic (emotional) in nature (Meyers-Levy and Zhu, 2010). In this research, female respondents described music heard in both ways, while males who scored high on a need for cognition scale only were sensitive to the descriptive meaning. These gender-difference results start to highlight that pitch and modality differences may be driven by some other underlying mechanisms. For example, there are cross-modal interactions between pitch in background music and the sound of a person's voice (Lowe and Haws, 2017). These authors found that a lower pitch in a voice or melody drove consumer perceptions of a product to be larger in size, which the authors attribute to mental imagery facilitated by the sonic stimuli, but attenuated by actually seeing the product. Pitch can drive preference as well. In a similar study which was done a few years earlier that showed how in a radio spot context, the choice of voice (gender and pitch) can have a significant effect on cognitive and affective 
perceptions from the listener (Martín-Santana, Muela-Molina, Reinares-Lara, and Rodríguez-Guerra, 2015). Their research revealed that a low-pitched voice was shown to score higher on listener's attitudes towards the radio personality and this effect was stronger for female voices.

Another phenomenon created by pitch is its ability to change the perception of social distance. Lower pitched music increased perceptions of distance, were congruent with products (artwork in a gallery) that signified far psychological distance through abstractness, and messages that were more abstract (Sunaga, 2018).

\subsection{Literature on Pitch and Modality Outside of Marketing Domain}

While marketing researchers have significantly studied pitch and modality over the past three decades as discussed in the previous section, clarity is added to these research areas when looking at literature outside of the marketing domain. Specifically, more insight is found in the areas of cross-modal interactions with other senses, gender differences in perception and affect, and differences in frequency in relation to the instrument sound used.

As do other characteristics of music, pitch can span the senses in a cross-modal way. Sweeter and brighter smells such as that of candied orange and iris flowers were matched with music that had a higher pitch (Crisinel, Jacquier, Deroy, and Spence, 2013). Similar research showed that high-pitched notes were associated with sweet and sour tastes (Crisinel, 2010). Conversely, low pitched notes were associated with bitter and umami (savory) tastes. These interactions can result in interesting marketing studies.

Building on previous research (Meyers-Levy and Zhu, 2010), lower pitched music was deemed less pleasant, but arousal (psychological states of mind) scores were higher (Joquet, Danuser, and Gomez, 2014). The pleasantness effect was stronger in women, 
while arousal effects were stronger in men. Expanding on these two gender difference studies, and that of Meyers-Levy and Zhu (2010), low voice pitch in men is more attractive to female listeners, who associate it with other attractive male physical features and signals of sexual maturity. These reported attributes have roots in deeper coding in our brain that stems from anthropological, semiotic, and cultural roots. These cultural anchors are at the core of how listeners perceive pitch. These authors dial back to ancient Greece to explain how music's perceived consonance and dissonance is tied to cultural familiarity (Parncutt and Hair, 2011). More specifically, consonance and dissonance structures that stem from pitch and tonal passages are based on the learning of certain cultural pitch patterns in speech and music and judged against the recognition of those patterns. Put simply, consonance occurs when familiar pitch patterns are heard, and dissonance has a "roughness" that deviates from the pitch expectations.

As with other musical characteristics, culture plays a significant role in pitch and modality. Research in relation to modality and pitch in the context of song key showed that when listener sentiment was cross referenced with historic popularity of songs that used key signatures more recognizable in popular music seemed more celebratory, fun, and subsequently were more popular during positive social and economic times, while songs with key signatures that were less recognizable were perceived to be more reflective and serious, therefore more popular during social and economic bad times (Pettijohn, Eastmen, and Richard, 2012). Cultural and semiotic context can not only set how an individual thinks about pitch and modality, but more importantly, can establish a reference point of expectation. By deviating from that expectation, a form of dissonance can occur (Steinbeis, Koelsch, and Sloboda, 2006). These authors found an increase in tension, emotionality, 
and electrodermal activity when music with high levels of unexpected harmonic variation.

Effects of pitch can affect perception in the listener as well (McLachlan, 2016). There are basic auditory functions at play when pitch and timbre are involved, which stem from auditory vibrations and how the brain translates them (McLachlan, 2016). He intertwines the two concepts of pitch and timbre as he explains how pitch could be explained as timbre mapped along a temporal space. He explains how dissonance is created when there is poor auditory information processing in pathways in the brain and lack of neural plasticity. Timbre will be discussed later in this chapter, although this research does start to uncover the phenomenon on how the listener "fills in" the elements of music that they cannot hear. This is not only present in the pitch of an individual melody or instrument, but in the overall frequency of the musical sound as a whole. When experimenting with the overall frequency and pitch of a musical piece, researchers found that changes in pitch to $528 \mathrm{~Hz}$ and recorded a decrease in oxytocin, cortisol, and self-reported measures of stress and tension (Akimoto, Hu, Yanaguchi, and Kobayashi, 2018). These pitch-related areas of research present opportunities to marketing scholars and practitioners alike.

\subsection{Future Marketing Research Directions and Managerial Implications on Pitch}

\section{and Modality}

When examining the work in culture, overall frequency distribution, and cross modal interactions of the senses, some promising answers to common marketing problems that still remain unanswered are seen. Pitch and modality can potentially be modified to change the cultural connection with the listener. This could be significantly impactful for a domestic brand that wants to expand globally. Pitch also has the opportunity to interact with other musical factors (i.e. tempo, etc.), and other senses (i.e. taste, color, etc.), which 
opens opportunities for further research in the marketing domain. Finally, the findings discussed earlier in this chapter from Sunaga (2018) suggest that lower frequencies could potentially interact with construal level theory (Liberman, Trope, and Wakslak, 2007). In a retail setting, this could potentially decrease the feeling of being crowded and increase the time spent in a store. As an example, by simply changing the overall frequency distribution/reverberation level of the music, the sense of social distance is given. It is important to note that this example is different from the varying pitch changes that occur throughout a musical piece. By changing the overall frequency/pitch distribution of a musical piece, the song's texture can also be affected, which is explored in the next section and can be seen in a full logarithmic spectral frequency display output (as exhibited in Figures 2 and 4 in Appendix B).

\subsubsection{Texture}

Exploring Bruner's (1990) work on texture-related expressions creates an opportunity to bring in research from other domains. Bruner (1990) characterizes texture according to loudness, movement of volume (e.g., crescendo, dimuendo), and timbre. These three components diverge greatly in their elements of texture; loudness and movement of volume have similarities, but timbre has many more complex components. Therefore, loudness and movement of volume is compared and discussed in this section of the chapter, then address timbre in the subsequent section of this chapter. In addition, volume is only one component of musical texture. A deeper explanation of texture and a comparison of two large distinctions is found outside of the domain of marketing literature, that of monophonic and polyphonic music, both of which are discussed in this section. 


\subsection{Marketing Literature Related to Texture}

Researchers have studied music volume extensively and revealed its strong effects on consumers in retail store contexts (Beverland, Lim, Morrison, and Terziovski, 2006; Milliman, 1982; Yalch \& Spangenberg, 1990), though few investigations consider its effects in other settings. With the value of wireless earphone sales anticipated to double to \$2.5 billion from 2017 to 2022 (All Ears: 27, 2019), and prevalent use of earbuds today, it is of significant interest to marketers to understand how volume levels affect behavior in areas outside physical retail, such as online shopping or through social media advertising on mobile devices. Volume level as it relates to ambient sound or directed sound is addressed later in this chapter, although the use of headphones or earbuds may have a distinctive change on volume levels which is of significant interest in the context of texture.

Bruner's explanation of loudness is limited to animation, tranquility, and proximity.

He also describes the movement of volume in the contexts of force and power. Because these emotional interpretations exist in the confines of musical elements, they do not encompass the totality of research in the area of musical volume. The marketing literature has a significant gap when the concept of musical texture is examined. More recently, researchers also studied how volume can influence consumers (Biswas, Lund, and Szocs, 2019). They showed how lower volume music increased healthy eating behavior through relaxation and higher volume music drove unhealthy food choices due to the enhancement of excitement. As mentioned earlier in this section musical volume, change in volume, and volume dynamics are only a few components that make up on dynamic of texture. To map out a more complete picture of musical texture, examination of the literature outside of the marketing domain is helpful. 


\subsection{Literature on Texture Outside of Marketing Domain}

Beyond the marketing domain, researchers have uncovered substantial effects of music volume on task performance (Wolfe, 1983), arousal and behavior (Smith and Curnow, 1966), alcohol consumption (Guéguen, Hélène, and Jacob, 2004), and exercise intensity (Edworthy and Waring, 2006), according to individual differences in musicality (Geringer, 1995) and age (Smith, 1989).

Outside the marketing literature resides a gap in the textural concepts of monophonic and polyphonic music structures. When musical texture is examined, there are more than just these two distinctions. There are also homophonic and heterophonic musical structure. The focus on monophonic and polyphonic music structures is qualified because structurally and culturally they are more relevant in music used in marketing today. Monophonic music structures are found in quite simple, single melodies. An example of this can be heard in cell phone rings. Polyphonic music structures are more complex usually with more than one melody playing at the same time. This type of music is mostly found in advertising and popular music.

By expanding beyond monophonic and polyphonic structures, our discussion would move into a different dimension of musical texture. In homophonic music, a melody accompanied by a harmonic component is found. In popular western music this is most prevalent. One example would be a piano or guitar playing a chord structure behind a melody. Heterophonic music is rare in western music styles as it usually layers similar melodies usually one with more embellishment than the other. Given that homophonic and heterophonic are so culturally dependent, they fall out of the scope of the research focus for this chapter. Yet, marketing research would benefit from the examination of these two 
musical structures as they are under researched and could lend significant insight to music used in marketing when a global cultural and semiotic layer is added.

Monophonic may seem simplistic in characteristics, but it lends itself well to marketing research in a few ways. By being more simplistic, researchers can focus on less variables, thus producing more causal results. In addition, there is less room for error in reporting, and confusion from participants. Monophonic music has been described as more primitive in nature and is most widely used in research with children, given its simplicity (Matsunaga, Hartono, and Abe, 2015).

As mentioned earlier, monophonic music structures are present in marketing and society today through consumer products. One example of how monophonic music can be used effectively to shape consumer attitude is with cell phone ringtones. A cell phone ring tone is more than just an identifier that a call is coming in. It allows a consumer to customize and personalize based on their feelings, the caller, their personal music tastes, or even their need for a mood enhancer (Gopinath, 2016). Ringtones have attained a new social connective medium with consumers (Licoppe, 2008). Looking back at the first days of cell phones, the cell phone ring tone was mainly an indicator of social status and has evolved today into a deeper expression of one's self (Schneider, 2009). A deeper understanding of how this effect is processed is gained when cell phone rings are tested with musically trained (vs layman) participants. A study on cell phone ringtones and university students was conducted with both musical students and non-musical students. The authors found that non-musical students had stronger positive opinions about melody and rhythm in the ringtones, while to music students cell phone ring tone preference ranges 
across descriptors to more obscure characterizations as tone color and density (Ying, Lung, Chait, and Hee, 2013).

It is also known that monophonic musical structures are processed differently in our brains. A model was derived from research on music, language, and the effects each have on the brain (Brown, Martinez, and Parsons, 2006). Their model shows parallels of music and language in neural systems as complex sound structures regardless of their content of information. In similar research, evidence to how monophonic music is processed and why it is so effective is revealed (Koelsch and Jentschke, 2010). Their research findings show how a simple melody is processed earlier in the brain and with somewhat different neural mechanisms than more complex harmonic music. It is also worth noting that the more complex harmonic music was processed in the frontal parts of the brain (as the simpler melodies) mainly due to the melodic content within the more complex harmonic structures. Put simply, whether you are playing a simple melody or a more complex structure that contains a melody, the melodic component is activating the frontal brain normally activated in language activity. An overlapping phenomenon of melody recognition in polyphonic music structures can be seen through research in monophonic melodic structures when the research participants identified that pitch or timbre were different (Gregory, 1990).

Polyphonic music is different from monophonic as it adds a layer of complexity to the sound. Examples of polyphonic music are heard when listeners are exposed to harmonies in popular music. Another example of polyphonic music can be heard when through songs in a round as in children's music. As monophonic music is simpler, it can be used to teach toddlers phonics, and has ties back to more primal aspects of human 
development, polyphonic music is multi-tonal and is processed in more parts of the brain (Patel, 2014). In research, polyphonic music training has been shown to challenge the brain, combined with the emotive quality of polyphonic music, more complex melodic harmonies enhance neural plasticity and cognitive processing mechanisms in the brain (Patel, 2014). For example, auditory research has shown that instrumental musical training can influence speech (Patel, 2014). Patel attributes this phenomenon beyond the musical ear-training itself and points to the deeper mechanics of musical training which include emotional rewards, frequent repetition, and focused attention which activates neural plasticity. The differences between simpler melodic structure in monophonic music and more complex melodic harmonies of polyphonic music can be seen in a full logarithmic spectral frequency display output as seen in Figures 2 and 4 in Appendix B. In addition, the full logarithmic spectral frequency display is used in these figures as part of audio research stimuli measurement later in chapter three.

\subsection{Future Marketing Research Directions and Managerial Implications on Texture}

When the historical marketing literature definition of texture is expanded beyond volume and loudness, not only a more complete picture of musical textures is revealed, but also opens research opportunities in the marketing domain. For example, as discussed earlier in this section, polyphonic ringtones are more appealing in nature, yet monophonic ringtones have stronger ties to other primal parts of our brains. If so, could these simpler tones elicit quicker motor responses? Meaning, even though someone might prefer a polyphonic ringtone (attitude) would they respond to a monophonic tone more quickly (behavior)? 
Research in this area is not without its challenges. As with other complex structures of music, the inability of non-music students to report texture has been researched and reported for decades (Bamberger and Brofsky, 1978). Therefore, scholars could investigate and report on how musical texture changes behavior or sentiment. Although, uncovering mediators will be more challenging.

\subsubsection{Timbre}

Although timbre, as a textural component of musicology, has been studied, most work has focused on the finite level of individual notes and their associations with instruments. Bruner (1990) shows that through timbre, brass instruments convey cold, hard force, whereas reed instruments can produce lovely, melancholy tones. Although Bruner's (1990) work is a critical foundation for understanding timbre, a deeper more practical approach is necessary; timbre's complexity, and its effects opposite to those described by Bruner (1990), are apparent when listeners hear the soft, comforting tones of a French horn or the bubbly, whimsical nature of a clarinet.

\subsection{Marketing Literature Related to Timbre}

Fales (2005) explains timbre in more detail than Bruner (1990), using three main components: production, acoustics, and perception. Production refers to the physical creation of sound, and acoustics relates to the composition and transmission of the sound, which stems from its creators. Fales (2005) describes perception in the context of sensation, noting that timbre can have a significant effect on the heuristic (emotional) nature of listeners. The author maintains that not only can consumers fill in missing notes within musical structures through backward revision, but they also can fill in sentiment from their default schema, just as they interpret imagery from Ruben's goblet (Alpers, 1967). For 
example, consumers might describe music or instruments as sounding "sad" (Fales, 2005). It is also worth noting that "perception" would be more appropriately positioned as "active interpretation" from the listener. Music used in marketing can also involve multiple instruments, exposing consumers to many notes, both successive and overlapping, in various chord structures (Aucouturier et al., 2005). Recent research on timbre has shown to induce feelings of security and drove consumers to rate products advertising more positively (Sunaga, Meng, and Zhuang, 2020). Timbre was even found to change consumer's perceptions of products to match closer to the characteristics of the instrument's timbre (Melzner and Raghubir, 2019). In addition, when certain instruments are used in an advertisement, congruity of the sound was found to have a significant impact on ad attitudes and recall (Oakes and North, 2006). Despite recent research on timbre, the opportunity to frame out the gaps in the literature lie outside of the marketing domain.

\subsection{Literature on Timbre Outside of Marketing Domain}

It is also important to note that since timbre has such powerful emotive qualities, it is also burdened with the categorization of congruity. It was found that timbre affected the listener's perceptions of emotions in the music (Hailstone, Ormar, Henley, Frost, Kenward, and Warren, 2009). If there is a mismatch of timbre and emotive intent, incongruent affect has the potential to occur. Further evidence of congruity was shown in another study (Trainor, Wu, and Tsang, 2004). They showed that songs learned by infants lacked preference response when played back to them with a different instrument timbre. Valence and energy inherent in musical timbre could also have effects on a listener's perceptions (Eerola, Ferrer, and Alluri, 2012). 
The research discussed so far establishes that timbre of a specific instrument cannot be varied. Musical scholars would disagree and say that timbre is more than a specific tonal quality as it relates to a specific instrument. Instruments can have multiple timbre qualities (Parncutt, 2013). For example, it was found that instrument sounds that were short expanded emotive descriptors not previously captured in research and explored features of timbre such as decay and correlated them with emotional characteristics (Chau, $\mathrm{Wu}$, and Homer, 2014, 2015). For example, they found plucked string instruments raised emotive qualities of sadness and depression in the listener, while percussive tones sounded happier and heroic.

Timbre can also cross other musical textural or structural boundaries. For example. one significant quality of timbre was found to be holistic and absolute in nature, especially when compared to pitch. Listeners could distinguish small variations of pitch across a similar timbre, but not the opposite (Krumhansl and Iverson, 1992). Timbre can also vary across other textural components, such as loudness, which was discussed earlier in this section. This quality of being distinguishable outside of loudness is exhibited when listening to an orchestra, where the instruments are playing at the same loudness. Regardless of the similar loudness, melody, or pitch, the listener can still distinguish between the timbre qualities of the different instruments (Risset and Wessel, 1999). Helmholtz described timbre of an instrument to be defined as a sound with a steady "state" (Helmholtz, 1912, 2013), but Risset and Wessel (1999) expand this thinking to have differences in attack and decay as well.

Timbre has significant qualities that can not only be distinguished on a spectral centroid (Russo, Ammirante, and Fels, 2012), but have also raised debate on the proper 
ways to measure timbre through the perceptual nature of timbre (Hajda, Kendall, Carterette, and Harchberger, 1997). Even more complexities arise when the listener is factored in: the listener's perception of the qualities of the music and sound, how it is received, and even how the brain processes timbre. A critical quality of timbre was its proportion of energy and the duration of decay, depending on the scales used (Gregory, 1994). Therefore, timbre has cross categorization dependencies with other musical factors and cannot be defined by one attribute. When studying these physical versus perceptual qualities of timbre, inconsistencies arise. For example, as with other elements of music, such as pitch and rhythm, timbre also exhibits qualities that are shared with language (Wallmark and Kendall, 2018).

Regardless of how listeners self-report their perception of timbre, there is a significant activity in multiple parts of the brain when processing timbre. Research shows that both hemispheres of the brain are used in timbre processing. More specifically, the Heschl's gyrus (as part of the auditory cortex) is activated, along with the posterior and superior temporal sulcus (which are found to be active in cross modal sensory research), and the circular insular sulcus (which is attributed to emotional valence) (Menon, Levitin, Smith, Lembke, Krasnow, Glazer, Glover, McAdams, 2002). Using fMRI to understand where timbre is processed in the brain, they found timbre to be processed in the cerebrocortical area as expected as that area processes auditory responses, but surprisingly the cerebellum (which is central to movement). 


\subsection{Future Marketing Research Directions and Managerial Implications on}

Timbre

Timbre has significant implications to marketing research. As shown in recent research, consumers associate timbre to descriptors of ruggedness (guitar) and sophistication (violin) which have the potential to influence consumer's attitudes and perceptions of products (Melzner and Raghubir, 2019). These consumer attitudes have downstream effects of purchase intent. Other elements of timbre such as congruity and emotive qualities need to be considered when conducting marketing research.

By understanding the complexities of timbre, researchers and marketing practitioners can find answers to many common marketing and branding problems. For example, could simply changing the instrument (and thus the timbre) of a jingle modify a consumer's perceptions of a brand, or potentially modify the deeper connections with the brand? This would allow practitioners to create a significant change in perception for their brand without significantly changing the deeper brand meaning inherent in their sonic logo or jingle per se. Also, understanding how timbre can cross sensory boundaries, such as language or movement, has significant implications in various forms of advertising and in restaurant or retail store environments. As noted in the earlier section on texture, a full logarithmic spectral frequency display can qualify differences in timbre for researchers and aid in visually identifying structural changes in the music's timbre (as seen in figures 2 and 4 in Appendix B and used in research documented in chapter 3).

\subsubsection{Musical Exposure}

Throughout my journey to uncover the key contextual components identified by both marketing and non-marketing researchers, and through my investigation of key 
journals and more recent topics of concern to both scholars and practitioners suggests two additional contextual components of musical exposure. First, the length of musical exposure is important. For practitioners, shorter forms of musical stimuli offer ways to change consumer behavior in today's digital age; for scholars, there is a need to agree on a definition of musical length. Second, music as marketing stimuli can be either direct (e.g., headphones, earbuds) or ambient (e.g., in a retail store or restaurant). In the following sections, These two key contextual components are explored with the intent of creating a more synergistic and complete conceptual framework that can be used in future marketing research.

\subsubsection{Length of Music Used in Marketing}

\subsection{Marketing Literature Related to Music Length}

Music used in marketing has been explored in the context of broader musical structures and forms, through the context of jingles (Bronner, 2008), to background music in advertising (Park and Young, 1986).

Sonic logos have been used since the original NBC chime triad notes of "G-E-C" aired on November 29, 1929 (NBC News, 2015). A study of sonic logos by Krishnan, Kellaris, and Aurand (2012) revealed that shorter forms of musical structure have significant impacts on consumer behavior such as willingness to pay. Krishnan et al. (2012) explore how certain design characteristics of auditory cues can modify customers' willingness to pay. They highlight two key contributions: Bruner's (1990) finding that musical sound is characterized by pitch, time, and texture, and Dowling's (1994) finding that pitches can be characterized by their quantities. Krishnan et al. (2012) develop their hypotheses according to these two characteristics and the foundation of processing fluency; 
their conceptual model links the quantity of tones in a sonic logo to consumers' willingness to pay in a nonlinear inverted-U relationship. Their research offers evidence of this relationship, finding that compared with six tones, three tones and nine tones elicit lower willingness to pay. Moreover, both musical literature and practice show that sound sentiment can be communicated by modality (Bruner, 1990), either as major or minor modes within the confines of a simple musical triad (Helmholtz, 1912, 2013). Through merely these two points alone (note structure and note count) can result in significant consumer behavior changes. In addition, more research needs to be done on this topic to understand if there is an optimal count or format for sonic logos or if it varies by context. For example, some of the more popular and recognizable sonic logos do not fit the tonal count that Krishnan et al. (2012) researched. Could the NBC 3-tone chime benefit from repeating its sonic logo or should the T-Mobile sonic logo add a note so they both fit the 6-note optimization?

Interesting findings in other sensory domains also may have applications to the music used in marketing domain. For example, the exposure time of an olfactory cue changes consumer behavior: Shorter exposures to stimuli increase desire by reminding consumers of their appetites, whereas longer exposures decrease desire by reminding them that their need for food has been satiated (Biswas, Lund, and Szocs, 2019). Do these findings hold true for audio stimuli too? Could short forms of music, in the form of sonic logos, have the same effects as long forms of music? These questions are explored and are expanded on through the concept of shorter musical exposure. Interestingly, regardless of the importance of the length of musical exposure as highlighted in the "time" section earlier 
in this chapter, there is extraordinarily little written about or research published in peer reviewed marketing journals on this topic.

\subsection{Literature on Music Length Outside of Marketing Domain}

When studying short musical exposure specifically, finding self-reported data is limited unless we look outside of the marketing domain. For example, through fMRI analysis when visual logos (for brands that have recognizably strong sonic logos as part of their brand identification) were shown, auditory imagery parts of the brain (i.e. superior temporal gyrus, etc.) showed activity even through no sounds were played (Sung, Choi, Chung, and Kim, 2011). This evidence supports how sounds can become a significant part of a consumer's memory of a brand's attributes. Recent research explored whether familiarity had an impact on encoding (Manchón, 2019). The results from this research were interesting, as participants reported the sonic logos were more familiar to them when played over brands that were more familiar to them. The critical part of this research study was that the sonic logos played were never part of that brand's identity. This transfer of familiarity shows evidence of how malleable and adaptable sonic logos can be in attaching to a brand's identity. Sonic logos are unique as a directed form of advertising. They have the ability to convey emotion and sentiment, while at the same time have a subliminal quality similar to ambient music (van Leeuwen, 2017).

Since there is little research on this matter, to understand further about sonic logos and their short note form, looking to research that examines musical triads and short note sequences are revealing. When looking at musical triads and their emotional connotations researchers showed happy, sad, and neutral faces and recorded brain activity when these faces were played against the backdrop of major and minor triad chord structures (Baaker 
and Matrin, 2015). These authors found that despite their significantly short exposure time, these chord triads possess emotional meanings in the brain and very quickly when the faces were congruent with musical modality (as quick as $200 \mathrm{~ms}$ ).

In addition, research has shown that not only emotive qualities can be processed in the human brain with little exposure, but also the ability to discriminate small differences can be distinguished with little exposure. Even infants can distinguish one semitone difference in a 5-note sequence (Cohen, Thorpe, and Trehub, 1987). Similar results were found in a separate study with adults and triad chord structures (Howard, Rosen, and Broad, 1992), but only yielded significant results in musically trained individuals.

Further research revealed that both infants and adults can identify a downward semitone change (Trainor and Trehub, 1993). In their research, these authors showed that both infants and adults performed significantly better when major (versus minor) triads were played. Further investigation revealed that a triad's perfect fifth was the main identifier in detecting differences (even in when non-western music was played), thus showing why the major triad yielded stronger results.

Not only emotional sentiment, but also recognition has been shown to be present in short note sequences. As with pitch, modality, melody, and texture, cultural components must be considered. Note recognition increased in shorter sequences are exhibited when culturally congruent musical styles are observed (Dalla Bella, Peretz, and Aronoff, 2003). These note length structures were shorter for musicians (between approximately 4-9 notes) but were also shorter for non-musicians as well (between approximately 5-10 notes). 


\subsection{Future Marketing Research Directions on and Managerial Implications Music Length}

Whether looking into the marketing domain or further out into the musical literatures, shorter musical stimuli can be found to have significant outcomes when presented to the listener in several ways. First, shorter musical structures can convey emotion. Gaps in research still exist as to how short of an exposure can still convey certain emotions. Scholars do not fully understand how shorter musical exposure interacts with other sensory stimuli such as imagery or smells. In addition, it is also worth exploring how shorter musical stimuli can be moderated by other musical components. It is known that emotion can be conveyed in pitch and modality, but understanding how rhythm or timbre changes the effect of shorter musical exposures would bring light to potential boundary conditions. It would be of significant importance to marketing scholars and practitioners alike to explore these areas and answer these questions.

\subsubsection{Ambient Versus Directed Stimuli}

Listeners can experience music in either directed ways, or in ambient and atmospheric ways. A determining factor in how this changes consumer perception is whether the music becomes salient or subconsciously passes through the listener. Music can be influential, no matter how it is experienced, but it is important for practitioners and researchers to understand differences in consumer processing for both scenarios.

\subsection{Marketing Literature Related to Ambient Versus Directed Stimuli}

An example of directed music is the use of repetitive melodies in a television ad (Argo et al., 2010). Despite its salience, this kind of directed stimulus can have a profound effect on listeners, including physiological effects that vary from increased heart and 
metabolic response rates (Edworthy and Waring, 2006) to relaxation responses (Möckel et al., 1994). Moreover, directed music can have powerful psychological effects that drive consumer choice (Gorn, 1982; Kellaris and Cox, 1989).

Although these types of directed effects are useful tools for marketers, consumers have fast-paced lifestyles; it is not always possible to direct messages to them. Fortunately, ambient music/sound also can be powerful, with profound effects on consumer choice (Chebat, Chebat, \& Vaillant, 2001), due to its ability to modify consumer processing. For example, it can drive customers to choose healthier foods (Biswas et al., 2019) and make people feel safer (Sayin, Krishna, Ardelet, Decré, and Goudey, 2015) by taking on anthropomorphic characteristics. It even can change the length of time consumers spend in stores (Morrison and Beverland, 2003). In some circumstances, consumers use ambient sound as their own control mechanism, to block out the relentless barrage of marketing or unwind in unlikely spaces, such as their cars (Bijsterveld, 2010).

Ambient music can have significant downstream positive effects as well. A field study on ambient music was conducted and it was found that when congruent classical music was played (versus top 40 music) in a wine store, patrons spent more money (Areni and Kim, 1993). Specifically, patrons bought more expensive wine. Similarly, recent research showed that patrons purchased healthier food when the ambient music volume was low (Biswas et al., 2019). Despite these research studies in marketing on ambient music, marketing researchers have not examined the differences between directed versus ambient stimuli. Therefore, looking beyond of the marketing literature is required to find answers. 


\subsection{Literature on Ambient Versus Directed Stimuli Outside of Marketing Domain}

Looking outside of the marketing literature, scholars frame the ambient versus directed music domain as headphones versus speakers. There are significant differences to a listener's perceptions, affect, social distance, movement and even fatigue when hearing music through headphones versus through ambient speakers. Distinct differences between speaker versus headphone listening have been found (Kallinen and Ravaja, 2007). Listening through headphones was preferred over speakers and elicited more positive responses to stimuli. Those that listened through speakers, had higher attention scores, scored higher in sociability scores, and had higher physiological responses.

More recently, researchers looked at how even body movement changes when the listeners were exposed to the same music either through headphones or through speakers (Zelechowska, Gonzalez-Sanchez, Laeng, and Jensenius, 2020). Their results showed that those participants who used headphones moved more but reported more fatigue from the research.

Outside of the movement of the listener, other research looked at the emotional valence (happy versus sad music) and social distance (Tajadura-Jiménez, Pantelidou, Rebacz, Västfjäll, and Tsakiris, 2011). Their results showed that those who wore headphones and listened to happy music moved closer in proximity to others, while those who listened to music through speakers increased their personal space when the music sounded sad. These differences in how listeners are exposed to music have significant marketing and social effects. It is shown through research that listening to someone through headphones increases an individual's connection and positive attitudes when communicating to others (Lieberman, Amir, and Schroeder, 2016). 


\subsection{Future Marketing Research Directions and Managerial Implications on Ambient Versus Directed Stimuli}

Despite the significant research conducted over the past few decades on ambient music and its effect on retail and restaurant environments, musical stimuli received through headphones is an under-researched area that demands attention. Consumers take in media through their phones at an ever-increasing rate with $37 \%$ of American adults who use their mobile devices more often when accessing the internet (Anderson, 2020) and 67\% who use headphones when on their smartphone (Kunst, 2019).

The use of headphones opens many opportunities as an independent variable in marketing research, but it also must be a measured and reported variable. There are significant sociological responses and psychological distance effects which marketers would benefit from understanding, but also must be ruled out in research as potential confounding effects. 


\subsection{Discussion}

With the recent increase in attention to sensory marketing, opportunities for marketing science to move towards a deeper understanding how the components of sound and music elicit intended consumer behaviors is even more apparent. By synthesizing marketing with musicology and neuropsychology domains into a new conceptual map, gaps in the marketing literature are highlighted which sets the foundation for future research. These foundational elements are central to advertising, branding, and marketing communication.

My research offers substantial opportunity for contributions to the marketing domain, specifically in relation to explorations of musical time, melodic structure, texture, and timbre. Table 8 included in Appendix $\mathrm{C}$ highlights language that is central to musicology, but not necessarily readily used in marketing literature. In addition this chapter highlights additional gaps in marketing publications with concepts explored outside of marketing, such as short and long forms of musical stimuli, and targeted versus ambient exposure to musical stimuli.

The conceptual framework map outlined in this chapter organizes each of these key areas of opportunity into a format that highlights each of the three main components of research. The first component consisted of a complete review of core marketing literature within each area of interest. The second component synthesized research from outside the marketing domain, primarily from the musicology and neuropsychology areas. The third component offers future implications for marketing practitioners and research opportunities for marketing scholars. 


\section{CHAPTER 3:}

\section{GREAT EXPECTATIONS: MUSICAL TENSION AND RESOLUTION'S INFLUENCE ON CONSUMER}

\section{ATTITUDES IN ADVERTISING}

\subsection{Introduction}

Music has been used as an emotive element to drive consumer behavior above and beyond what a simple advertising message can conjure (Alpert and Alpert 1989; Bruner 1990). It can even drive product choice (Gorn, 1982), persuade us (Kellaris and Cox, 1989), increase involvement (Park and Young, 1986), and is an ever pervasive and influential element in consumers' lives driven through pop culture (Brackett, 2016). Within these areas, research has shown that positive elements such as faster tempo (Kellaris and Kent, 1993), higher timbre, major modes (Bruner, 1990) and congruity (Oakes, 2007) create positive outcomes and are sought after by marketers. Conversely, research has shown that although emotive elements such as tension can elicit strong emotive responses (Ruan, Hsee, and Lu, 2018), and can also result in negative consumer evaluations (Webster and Kruglanski, 1994).

Tension is a universal element to music as it exists in the narrative of the composition (Krumhansl, 1996; Lerdahl, 1996; Lerdahl and Krumhansl, 2007), as well as film, literature, and many aspects of our lives inclusive of pop culture and media at large (Brackett, 2016). It is understood from the music literature that tension is a powerful musical effect that can increase a listener's attention and change their cognitive state (Bigand et al., 1996). Lerdahl and Krumhansl (2007) frame out musical tension in the 
context of musical elements such as rhythm, tempo, dynamics, and density. It is these elements that can create a juxtaposing dynamic of stability and instability in the music. This instability is referred to in both a cognitive and sensory way as "dissonance".

"A representation of hierarchical (prolongational) event structure, a model of tonal pitch space and all distances within it, a treatment of surface (largely psychoacoustic) dissonance, and a model of voiceleading (melodic) attractions (Lerdahl and Krumhansl, 2007).”

One method for increasing attention in advertising, is the use of silence or breaks in musical flow. Music has been manipulated in radio advertisements with the addition of silence (no background music) to accentuate specific parts of an ad; In doing so, recall is increased for those targeted areas (Olsen, 1995). This can even be replicated in instrumental and vocal versions of music (Roehm, 2001). These all set the stage for an experience and transference of knowledge between the creator and listener of music (Pearce and Wiggins, 2012). In this way musical tension can also elicit many kinds of responses from the listener. These responses can encompass physical and motor responses such as increased heart rate, respiration, galvanic skin resistance, and muscle tension (Dainow, 1977), that can occur as the music naturally progresses (Möckel et al., 1994) or with a change in music volume (Edgeworthy and Waring 2006).

Despite these positive effects tonal "tension and resolution" has in the confines of a musical domain, little is known about how its prevalence in music influences consumer perceptions of advertising. In addition, research has shown that advertising executives may choose music to accompany advertising focusing on the artist versus the effect the music has on consumers (Anglada-Tort, Keller, Steffens, and Müllensiefen, 2020). Therefore, 
there remains a significant gap in knowledge for how the tension and resolution structures in music can potentially influence consumer attitudes.

These specific components are outlined in the following theoretical framework and will show evidence through four main experiments that the "tension and resolution" structure of music increases overall consumer attitude for an ad. Experiment 1 shows that this effect is due to an underlying element of curiosity caused by the anticipation of the tension resolution. Experiment 2 illustrates how an earlier tension build in the advertisement has a stronger positive influence on consumer evaluations. In addition, a boundary condition is uncovered in experiment three. Those consumers that have a high level of the individual difference variable Need for Cognitive Closure (NFCC) showed a lower attitude score for the advertisement when the music lacked resolution, while those with a lower NFCC score rated the ad higher when the music lacked resolution. The final experiment, experiment 4, shows how brand knowledge can interact with the "tension and resolution" structure of music, where an unknown brand elicits higher consumer positive attitudes when resolution doesn't exist.

These findings contribute to the music and advertising literature in many ways. First, this research adds to the existing theories on music in advertising by highlighting positive outcomes from elements previously seen as negative in advertising. Second, this research adds to the musical literature by outlining boundary conditions inherent in a consumer individual difference variable. Finally, the science behind the tension and resolution mechanism that can be effectively used in advertising in order to draw a consumer's attention is highlighted. 


\subsection{Music in Advertising}

Music in advertising has been both widely used by marketers as an agent of influence and studied extensively by researchers for decades. Seminal research uncovered that by merely increasing our attention through different types of preferred music in advertising, marketers can drive behavior to a target and attributed this result to the classical conditioning model (Gorn, 1982). From the development of this literature stream, marketers and researchers alike now understand how music can have a profound positive influence on consumer's attitude towards advertising (Park \& Young, 1986), alter the listener's mood (Alpert and Alpert, 1989), and have identified specific components of music that result in very different behavioral outcomes and emotional states (Bruner, 1990). Individual components of music also interact with one another in the context of musical structure (Alpert et al, 2005), and can modify consumers' mood, but can also increase attention and memory (Allan, 2006). This stream of research in music and advertising not only highlights the complexity of musical dynamism, but also brings to light why researchers need to dive deeper into how music drives consumer behavior in this way.

In order tobecome more efficient and elicit stronger responses in shorter temporal frames, marketers need a deeper understanding of the mechanics of music and its different aspects can be used to increase the effectiveness of even greater targeting. Some recent research has looked deeper into memory, retrieval cues and congruency (Hwang and Kim, 2015) as well as product perception and choice (North, Sheridan, and Areni, 2016). Similarly, other researchers have explored areas such as music in advertising (Oakes and North 2006, Oakes 2007), retail background music (Chebat et al, 2001; Morrison and 
Beverland, 2003; Beverland et al, 2006), and background noise (Biswas et al., 2019).

Core to music and songwriting is the concept of musical tension and resolution (Evans, 2005) or sensory dissonance, which has yet to be explored in depth. This concept is paramount to music composition as it is the mechanism that brings the listener along on a journey of highs and lows, setting points of tension and reflection. This concept and its relationship to advertising is further explored in the proceeding section. 


\subsection{Tension and Resolution in Advertising's Music}

Huron (1989) explained that in the thirty seconds of a television commercial, music can enhance the narrative intent of the marketer, creating forces such as dynamic tension, climax and resolution (denouement). Of specific interest to this research is how the tension and resolution structure can cause change in our affect and behavior.

Tension and resolution in music has significant outcomes that can be observed in our neurochemistry. Orthogonal dimensions of dissonance and consonance (tension and resolution) were introduced in research and showed specifically how each affects the brain (Brattico and Pearce, 2013). They explain how this one example of tension and resolution "stimulating neighboring hair cells in the basilar membrane and causing neurons in the cochlear nucleus and brainstem to fire" until the musical dissonance is resolved. Conversely, the soothing effect of consonance that follows is "an active process involving reward centers in the brainstem." Irregular chords activated certain parts of the brain that tie to auditory working memory, processing of musical syntax and musical meaning, and potentially emotional aspects of music processing, with some variability dependent on the subject's musical training (Koelsch et al., 2005). Increased blood oxygen levels in the orbitofrontal cortex and amygdala (areas of the brain used for decisions and choice) during periods of musical tension have also been shown in research (Lehne, Rohrmeier, and Koelsch, 2013).

The elements of tension and suspense are used in many storytelling and narrative art forms such as film, video and music (Lehne and Koelsch 2015). One example of this structure can be taken from the classic model of narrative storytelling in Freytag's Pyramid (Freytag, 1863). This 3-act storytelling structure starts with a setup, moving to a rising 
action in the storyline to confrontation, and then a falling action to resolution (or dénouement). In this structure the tension builds the anticipation in the storyline and is paired with the critical resolution of the story to create a more powerful story arc. These tension elements are so powerful because the tension elements trigger "predictive processes directed at future events of emotional significance" (Lehne and Koelsch (2015). The increase in consumers' experience through suspense and uncertainty can also be seen in research on video games (Klimmt, Rizzo, Vorderer, Koch, and Fischer, 2009), and watching competitive sports (Knobloch-Westerwick, David, Eastin, Tamborini, and Greenwood, 2009).

Information teasing and suspense generation is conceptually related to the "tension and resolution" mechanism. By teasing information and temporarily keeping participants in suspense, Ruan et al (2018) were able to get participants to remember trivia information at a higher level, and better enjoy the test taking experience. In further experiments these authors showed an increase in viewer's attitude and willingness to try advertised products when they were first prompted to guess what product advertisement they would see next.

Tension is only one part of the structure that in music. With each tension structure is a paired resolution structure in music and it is this pairing that results in a net positive hedonic (emotional) response (Lehne and Koelsch 2015). Without the resolution, there is only dissonance which will modify the listener's reaction to the music and accompanying advertisement, thus resulting in a net negative response on all measures due to demands on the listener's cognitive processes (Bonin and Smilek, 2016). Therefore, I posit that:

$\mathbf{H}_{1}$ : An advertisement with a "tension and resolution" background musical structure (versus a "tension and no resolution" background 
musical structure) will have a higher overall consumer attitude towards the advertisement.

The "teasing effect" is attributed to the creation and resolution of uncertainty, and its net positive outcomes and increased hedonic (emotional) response is due to an increase in curiosity (Ruan et al 2018). Just as the end hedonic response is amplified when the "teasing effect" is used, the same "teasing effect" can be seen in music. The "teasing effect" increases the net hedonic experience and highlights the area of delineation (increases salience). Want versus need creates a state of tension in a consumer's impulses. Motivation resolves that tension. The tension created by the tonal structure builds up the potential reward which is the anticipated resolution of the musical tonal structure. It is through this build of tension that curiosity is enhanced.

When researchers turn to musical literature, these same tension and curiosity structures emerge. The musical form of tension builds expectations and curiosity (Magala, Mantere, Sillince, and Hämäläinen, 2007). Further research into musical tension adds to this phenomenon of how as listeners, expectations of information about to come is built (Huron, 2006), and these expectations change the way listeners process memory and emotions and are hard-wired to our reward structures (Pearce and Wiggins, 2012). These pre-programmed processes are a key element underlying tension and suspense in the media society consumes as these processes help us predict and anticipate what will come (Lehne and Koelsch 2015). Therefore, I posit:

$\mathbf{H}_{2}$ : An advertisement with a "tension resolution effect" background musical structure (versus no resolution and just a "tension" background musical structure) will show a higher consumer curiosity level. 
Order effects have been shown in research to have significant effects on consumer attitudes. We know that first impressions are important in marketing communication and can have a lasting effect on behavior (Anderson and Hubert, 1963). An example of this effect is exhibited when consumers click on the first website link they see (Murphy, Hofacker, and Mizerski, 2006). These order effects can also vary based on whether the stimuli related to products that were desirable, as desirable products resulted in a higher primacy effect (Biswas, Grewal, and Roggeveen, 2010). In the context of tension and resolution structures in music, primacy and recency can also be a factor as the presence or absence of music can drive positive or negative affect (discussed in $\mathrm{H}_{1}$ ). In musicology research, it was shown how participants recalled moments of the music they listened to that exhibited higher levels of intensity and the most recent moment (Rozin, Rozin, and Goldberg, 2004). In addition, tension in music has been shown to increase in intensity depending on the tension's peak from the root tone, which is also present in the resolution of a tonal tension and resolution structure (Toiviainen and Krumhansl, 2003). Given these prior studies, when the tension and resolution structure is at the beginning of the advertisement, the tension peak should be less salient as it is less recent and allow the resolution (which immediately follows the tension) to be more salient. Conversely, when the tension peak is at the end of the advertisement, the peak will be more salient as it is more recent (and subsequently the resolution less salient). The recency and salience of the tension peak will in turn drive a difference in consumer attitudes towards the advertisement due to the subsequent increase or decrease in attention to the resolution. Therefore, I posit:

$\mathbf{H}_{3}$ : Consumer attitudes toward the advertisement will be more positive 
when the "tension and resolution" musical structure is in the first half of the advertisement (versus second half of the advertisement).

\subsubsection{Consumer and Brand Differences}

When considering the nature of these experiments and the structural composition of the "tension and resolution" for the accompanying music proposed, a potential boundary condition emerges. Need for Cognitive Closure (NFCC) is an individual difference variable and latent measure scale that has been researched over the decades. The original scale was developed as a 47-manifest construct (Kruglanski, Atash, De Grada, Mannetti, and Pierro, 2013), which found that those with a high level of need for cognitive closure exhibit a desire for predictable situations, prefer order and structure, are linked to close-mindedness, are more decisive, and dislike ambiguity (Webster and Kruglanski, 1994). Later research revealed that NFCC can not only drive the way people perceive and judge social groups, but can also influence what people remember (Dijksterhuis, Van Knippenberg, Kruglanski, and Schaper, 1996). In addition, it was even found that those with a high NFCC prefer less cognitively demanding media (Vermeir and Geuens, 2008). Originating from social cognition literature, this construct linked to close-mindedness and decisiveness, has also shown that individuals having a high level of NFCC to dislike ambiguity. Time span reduction for the tension structures before resolution increases stability conditions and results in a lower account of tension (Lerdahl, 1996). More recent research shows that curiosity had a negatively correlated relationship with those individuals that had a high need for cognitive closure (Kashdan, Stiksma, Disabato, McKnight, Bekier, Kaji, and Lazarus, 2018). 
Given this difference, a musical tension without resolution structure will have a greater negative impact on those that score high on an NFCC scale, as these individuals will exhibit less curiosity, and will have a lower positive attitude for the advertisement compared to an advertisement with a tension and resolution musical structure. Therefore, I posit that NFCC will moderate the effect of tension and resolution on ad likeability and also moderate the mediation of curiosity's effect on the relationship of tension and resolution on ad likeability:

$\mathbf{H}_{\mathbf{4}}$ : Those with a high (versus low) Need for Cognitive Closure score, will perceive a commercial with a "tension and no resolution" musical structure as less (versus more) appealing and have a lower (versus higher) ad likeability.

$\mathbf{H}_{\mathbf{4}}$ : Those with a high (versus low) Need for Cognitive Closure score, will perceive a commercial with a "tension and no resolution" musical structure as less (versus more) appealing and have lower (versus higher) curiosity level and subsequently have a lower (versus higher) ad likeability.

Researchers have shown that curiosity is not a linear process that increases in intensity, which is known as the "curiosity gap" (Kang, Hsu, Krajbich, Lowenstein, McClure, Wang, and Camerer, 2009; Loewenstein, 1994). Curiosity has a U-shaped curve driven by knowledge (Kang et al., 2009; Kidd and Hayden, 2015; Berlyne, 1954). This forms a "Goldilocks Zone", meaning if there is too little information consumers lack interest and consumer interest increases as more information is present. When there is too much information consumers will lose interest. Of specific interest to my study is the concept of 
"epistemic curiosity" as it drives people to fill knowledge gaps (Berlyne, 1954). The less consumers know about something, curiosity is piqued fueling the thirst learn more. Conversely, the more consumers know about something they will approach the "Goldilocks Zone", our curiosity is satiated.

This can result in interesting consumer interactions that have significant implications to my research. As previously outlined, the "tension and resolution" effect should increase overall feelings of curiosity in consumers when resolution is present. In accordance with prior research and literature, brand knowledge should have an interaction effect with the "tension and resolution" structure of music.

Specifically, an ad for a known brand containing a tension structure with no resolution should drive both a lower curiosity level and subsequently result in lower ad likeability. Conversely, an unknown brand will have more curiosity and satisfaction levels which is an inverse relationship to a music structure without resolution, thus attenuating this effect. Therefore, I posit:

$\mathbf{H}_{\mathbf{5}}$ : An advertisement with an unknown brand (versus known brand) will have a higher curiosity level.

$\mathbf{H}_{5 \mathbf{5}}$ : An advertisement with a known (versus unknown) brand will have lower (versus higher) curiosity level for an ad that has a tension and no resolution musical structure (versus an ad with a tension and resolution structure), thus result in a lower (versus higher) ad likeability.

This is of particular interest to marketing practitioners, as it highlights how important the tension and resolution structure is to an advertisement of a known (versus unknown brand) brand. 


\subsection{Overview of Experiments}

I conducted two pretests and four experiments to test the seven hypotheses outlined in my theoretical framework. In the two pretests, the tension and resolution structures required for the subsequent four experiments were created and qualified. In experiment 1 the first two hypotheses were tested to show significant main effects for tension and resolution on ad likeability as well as mediating effects of curiosity. In experiment 2 the location of the tension and resolution structure of music was shown to change the effect on consumers' ad likeability. In experiment 3 the individual difference variable of Need for Cognitive Closure (NFCC) was introduced and showed how the level of a consumer's NFCC moderates the relationship of tension and resolution has on ad likeability. In the final experiment brand familiarity was shown to moderate the effect tension and resolution structures have on consumer curiosity and ad likeability levels as well as the mediation of curiosity and excitement on those main effects.

For the purpose of this research, the construct of "tension and resolution" is explored as a whole with the construct either present as a "tension and resolution" pair or not present as "as tension without resolution" (versus smaller discreet elements and variations of tension build).

It is also important to note that mood can be a potential covariate in sound studies and needs to be both measured and controlled for in order to rule it out as a potential confound. More specifically, the reason for including mood in this research is to make sure that the causal chain can stem back to the audio stimuli versus an individual's mood at the time they take the survey. 


\subsubsection{Pretest 1}

In order to choose the proper stimuli to be used in experiment 1,3 , and 4 , a pretest was conducted ( $n=39, M_{a g e}=21$ years, $44 \%$ male). This pretest was conducted with students from the college of communication who had at least some level of music training. This sample of respondents were chosen because according to the literature on measurement of musical tension, students without musical training were not able to identify tension structures reliably (Krumhansl, 1996; Toiviainen and Krumhansl, 2003; Lerdahl and Krumhansl, 2007). Eight clips were tested for the tension and resolution structure. For the tension measure, it was explained that "Less tension corresponds to a feeling of relaxation or resolution, while more tension corresponds to the building of anticipation", then instructed participants to "Please use the slider below to rate the amount of tension in the musical clip you just heard" using a 0-100 sliding scale.

An ANOVA revealed significant differences in tension between the clips (F ( 7 , $157)=3.571, \mathrm{p}=.001)$. The final two clips that were chosen both had a high tension score $\left(\mathrm{M}_{\text {clip1 }}=63.76, \mathrm{M}_{\mathrm{clip} 2}=78.61\right)$. To measure resolution, the participants were also asked "Did the tension within the music resolve itself?" (yes/no). A chi-square test revealed significant differences in resolution between the clips $\left(\mathrm{X}^{2}(7,165)=58.750, \mathrm{p}=.000\right)$. The final two clips that were chosen had different resolution scores, $\left(\mathrm{M}_{\text {clip1 }}=1.14, \mathrm{M}_{\text {clip2 }}=1.89\right)$.

The two final clips were 30 second clips developed from a song by the musical artist Jason Ross, one clip with the tension resolution and the other clip without resolution. For the clip with tension resolution, a 30 second clip was selected from the song that included this tension and resolution musical structure. To create the condition with tension and no resolution, the same 30 second clip was used and the resolution portion from the 
end of the clip was removed. In order to keep the two clips at the same 30 second length (exposure), a repeated portion of the beginning of the clip was duplicated. These modifications were done to ensure that the only difference between the pair of music clips in my experiment was solely the presence vs. absence of resolution. Full logarithmic spectral frequency display outputs for both clips can be seen in Figure 2 of Appendix B.

\subsubsection{Experiment 1}

\subsubsection{Method}

In experiment 1 , both hypotheses 1 and 2 were tested. In doing so, the two 30 second musical stimuli from the first pretest were layered into the audio track of an online advertisement. The advertisement that was created shows a mini refrigerator and highlights its many features (see Appendix A for screen shots of advertisement). The features are displayed in the advertisement one at a time over the 30 second timeframe. The visual aspects of the advertisement are identical between the two conditions. In this experiment there are two distinct audio conditions, one with a "tension and resolution" musical structure and the other with only the tension musical structure (a 2 x 1 between-subjects design) and measure overall likeability for the ad. The participants' involvement with the product category in the ad and overall mood were measured in order to rule out potential confounds.

For the first experiment, 80 student participants were recruited (average age 21 years, $53 \%$ male), all of which received class credit for participating in the 10-minute survey. Critical to any auditory research where participants are exposed to stimuli by using their own devices, all participants were tested to ensure that the participants had audio enabled on their device and that it was at a level that would allow them to hear the audio 
stimuli. Therefore, participants were presented with an auditory word "hello" that they had to play and then enter into the survey in order to determine if they had their sound on and at a level that they could hear properly. Five participants were rejected because they could not complete this task or failed the attention check asked halfway through the survey thus lowering the number of participants $(\mathrm{n}=75)$. Following the audio test task, the participants watched and listened to one of the two 30 second video advertisements (randomly assigned) and answered a series of questions to measure likeability of the advertisement (Homer, 1990), and curiosity and whether their curiosity was satisfied (Ruan, Hsee, Lu, 2018), along with involvement (Coulter, Price, and Feick, 2003) and mood (Lisjak, Bonezzi, Kim, and Rucker, 2015) as potential covariates.

\subsubsection{Results}

An MANCOVA revealed that there was a statistically significant difference in consumer attitudes based on the tension and resolution structure of the advertisement's background music, $(\mathrm{F}(3,69)=4.688, \mathrm{p}=.005$, Wilk's $\Lambda=.831, \eta 2=.169)$. Further analysis into the dependent variables indicated a statistically significant higher likeability of the advertisement measure $\left(\mathrm{F}(1,74)=10.395, \mathrm{p}=.002, \eta^{2}=.128\right)$ with the clip that had resolution $\left(\mathrm{M}_{\mathrm{res}}=4.6071\right)$ over the clip without resolution $\left(\mathrm{M}_{\text {nores }}=3.9306\right)$ supporting $\mathrm{H}_{1}$. In addition, the results showed a statistically significant higher curiosity score $(F(1,74)=$ 9.974, $\left.\mathrm{p}=.002, \eta^{2}=.123\right)$ with the clip that had resolution $(\mathrm{M}=3.20)$ versus the clip without resolution $(\mathrm{M}=2.46)$ and statistically significant higher satisfaction score $(\mathrm{F}(1,74)=$ $\left.11.702, \mathrm{p}=.001, \eta^{2}=.141\right)$ with the clip that had resolution $(\mathrm{M}=3.15)$ versus the clip without resolution $(\mathrm{M}=2.37)$. These results incorporated involvement and mood as covariates. Although involvement ( $\mathrm{p}=.261)$ and mood $(\mathrm{p}=.915)$ were not significant, they 
were incorporated in the multivariate analysis given their importance in prior research. When these two covariates were not used, separate ANOVA revealed significant ad likeability $(\mathrm{F}(1,74)=5.044, \mathrm{p}=.028)$, curiosity $(\mathrm{F}(1,74)=4.395, \mathrm{p}=.04)$ and satisfaction $(\mathrm{F}(1,74)=4.608, \mathrm{p}=.035)$ measures, although the results for these dependent variables were more significant when these two covariates were incorporated. For a full list of latent measures and reliability, see Table 1 (Appendix B).

\subsubsection{Mediation}

Upon further investigation, curiosity was revealed as a mediator by running a Hayes Mediation Process Model 4 (Hayes 2017) using 5,000 bootstrapped samples. The relationship between the tension and resolution structure and the advertisement likeability score was fully mediated by curiosity since the confidence interval $(\mathrm{CI})$ excludes zero $(\mathrm{b}=-$ $.424,95 \%$ CI $[-.844,-.014]$ ) supporting $\mathrm{H}_{2}$. Figure 3 (Appendix B) illustrates these mediation results and Table 2 (Appendix B) includes a full table of results from experiment 1.

\subsubsection{Discussion}

These initial results from experiment 1 support $\mathrm{H}_{1}$ and show how the presence or absence of resolution paired with tension can greatly change the outcome of consumer attitudes, namely ad likeability. Furthermore, this effect was fully mediated by curiosity supporting $\mathrm{H}_{2}$ and adding to the literature on curiosity showing that not only a marketing message or question can tease curiosity (Ruan et al., 2018), but tension and resolution structures in music can do so as well.

\subsubsection{Pretest 2}

In the second pretest, 30 seconds of music from a longer piece of music were 
isolated into two different 30 second musical clips (similar to the procedures outlined in the first pretest). Separately from pretest 1 , the tension build and resolution were included in both 30 -second audio clips. The two 30 second audio clips were edited to order the tension build and resolution to either the first half of the 30 second clip or the second half of the 30 second clip. This process was repeated for two artists in order to create four clips total for pretest. The first artist was "Skrillex" and the song was "Bangarang," and the second artist was the "Foo Fighters" and the song was "All My Life." All four clips were the same length in order to maintain the same level of exposure length.

Similar to the first pretest, the second pretest was conducted with students from the college of communication who had at least some level of music training ( $\mathrm{n}=52, \mathrm{M}_{\mathrm{age}}=21.46$ years, $61.5 \%$ male). These respondents were chosen because according to the literature on measurement of musical tension, students without any musical training were unable to identify tension structures reliably (Krumhansl, 1996; Toiviainen and Krumhansl, 2003; Lerdahl and Krumhansl, 2007). Since the key to my second pretest was to verify that the tension build and resolution structure was either in the first half or the second half and also identify which artist had the strongest contrast in these two conditions, using students with some musical training was even more critical in this second pretest.

As with the first pretest and experiment, a sound comprehension test was used to qualify that the respondents had their volume levels in an audible range. The critical part of this pretest was to determine where the tension built up in the song and where the resolution began. In order to measure this, a temporal slider scale that was used in previous musicology literature was implemented (Krumhansl, 1996, p.408). Before students were exposed to the musical clip and asked to use the temporal slider, the students were asked 
to watch a short two-minute video explaining the slider and how to use it This would ensure that the students understood the task and minimized errors. The students were then asked to listen to the clip and move the slider scale up if they hear more tension and move the slider down as they heard the tension in the song decrease. The results from this pretest confirmed that the two clips with the tension build in the first half were recognized as such by the students' output of the temporal slider scale, and the two clips with the tension build in the second half were recognized as such by the student responses using the output temporal slider scale. Average output on the temporal slider scale and logarithmic spectral frequency display output for all four clips can be seen in Figure 4 in Appendix B.

\subsubsection{Experiment 2}

One explanation for the potential results of experiment 1 may be that the results observed are due to the location of the tension and resolution structure in the advertisement. For example, prior research has shown (Mackenzie, 1986; Anderson and Hubert, 1963) that the primacy or recency of an attribute could affect preference. This was addressed by counterbalancing the order of the product attributes to remove any primacy or recency effects (Biswas, Grewal, and Roggeveen, 2010).

\subsubsection{Method}

In experiment 2 , hypothesis 3 was tested. To add generalizability to the results of experiment 1, a different product category for experiment 2 was used. The advertisement that was created shows a microwave oven and highlights its many features (see Appendix A for screen shots of advertisement). The features are displayed in the advertisement one at a time over the 30 second timeframe. The visual aspects of the advertisement are identical between the two conditions, although the order of the features was switched 
between the first and second half to rule out order effects of the feature presentation. In addition, in this experiment three distinct audio conditions are present, one with the long tension build and resolution in the first half of the ad, a second with the long tension build and resolution in the second half of the ad, and a third condition with no music. Therefore, the design of the experiment is a 2 (feature order) x 3 (resolution) between-subjects design. Likeability for the and curiosity were measured as main dependent variables and also the participant's involvement with the product category in the ad and overall mood were measured in order to rule out potential confounds as was done in the first experiment.

240 student participants were recruited (average age 20.41 years, 55\% male), all of which received class credit for participating in the 10-minute survey. A total of 11 respondents were removed from the analysis because they either failed the attention checks or audio comprehension checks. Therefore, a total of 229 respondents were used in the final analysis $\left(\mathrm{n}_{\text {feature order } 1}=115, \mathrm{n}_{\text {feature order } 2}=114, \mathrm{n}_{1 \text { st half }}=72, \mathrm{n}_{2 \text { nd half }}=80\right.$, and $\left.\mathrm{n}_{\text {no music }}=77\right)$. Following the audio test task, the participants watched and listened to one of the six 30second video advertisements (randomly assigned) and answered a series of questions to measure likeability of the advertisement (Homer, 1990), curiosity and satisfaction level (Ruan, Hsee, Lu, 2018), and category involvement (Coulter, Price, and Feick, 2003) and mood for potential covariates (Lisjak, Bonezzi, Kim, and Rucker, 2015). These students also used the temporal slider to measure their curiosity level.

\subsubsection{Results: Order Effects}

A MACNOVA was conducted to analyze the main effects of the tension resolution condition, the order effects condition, and any potential interaction effects on my dependent variables of ad likeability, curiosity, and satisfaction with the incorporation of 
involvement and mood as covariates. The MANCOVA revealed that there was a statistically significant difference in consumer attitudes based on the tension and resolution condition, $(\mathrm{F}(6,438)=3.796, \mathrm{p}=.001$, Wilk's $\Lambda=.904, \eta 2=.049)$, a non-significant result on the order condition $(\mathrm{F}(3,219)=1.439, \mathrm{p}=.232$, Wilk's $\Lambda=.981, \eta 2=.019)$, and no interaction was present between the two conditions $(\mathrm{F}(6,438)=0.297, \mathrm{p}=.938$, Wilk's $\Lambda$ $=.992, \eta 2=.113)$. Further analysis into the dependent variables revealed as predicted that there were no significant main effects for feature order on ad likeability $(\mathrm{p}=.939)$, curiosity $(\mathrm{p}=.17)$, or satisfaction $(\mathrm{p}=.744)$. There also were no significant interaction effects on ad likeability $(\mathrm{p}=.918)$, curiosity $(\mathrm{p}=.862)$, or satisfaction $(\mathrm{p}=.880)$. Although there were significant main effects on the tension resolution condition for curiosity $(F(2,228)=6.439$, $\left.\mathrm{p}=.002, \eta^{2}=.055\right)$, and satisfaction $\left(\mathrm{F}(2,228)=10.747, \mathrm{p}=.000, \eta^{2}=.089\right)$, but only marginal significance for ad likeability $\left(F(2,228)=2.444, p=.089, \eta^{2}=.022\right)$. When involvement and mood were not incorporated into the multivariate analysis the results remained similar with curiosity $(\mathrm{p}=.004)$ and satisfaction $(\mathrm{p}=.000)$ showing significance, and ad likeability $(\mathrm{p}=.08)$ showing marginal significance.

Upon further analysis with a multiple comparisons LSD test on the tension and resolution condition revealed a significant difference for curiosity between the $1^{\text {st }}$ half $(\mathrm{M}=3.415)$ and the $2^{\text {nd }}$ half $(\mathrm{M}=2.869) \mathrm{p}=.009$, the $1^{\text {st }}$ half $(\mathrm{M}=3.415)$ and no music $(M=2.695) \mathrm{p}=.001$, but not between the $2^{\text {nd }}$ half $(\mathrm{M}=2.869)$ and no music $(\mathrm{M}=2.695)$ $\mathrm{p}=.393$. The analysis for satisfaction revealed a significant difference between the $1^{\text {st }}$ half $(\mathrm{M}=3.272)$ and the $2^{\text {nd }}$ half $(\mathrm{M}=2.625) \mathrm{p}=.002$, the $1^{\text {st }}$ half $(\mathrm{M}=3.272)$ and no music $(M=2.344) \mathrm{p}=.000$, but not between the $2^{\text {nd }}$ half $(\mathrm{M}=2.625)$ and no music $(\mathrm{M}=2.344)$ 
$\mathrm{p}=.160$. The results for ad likeability were only significant between the $1^{\text {st }}$ half $(M=4.041)$ and the no music $(\mathrm{M}=3.691) \mathrm{p}=.031$ conditions.

These results from experiment 2 reveal that the main effects of a consumer's curiosity and satisfaction for an ad diminishes when there isn't enough time for resolution in the ad. This is evident by the results showing higher curiosity and satisfaction scores for the condition which had the resolution in the $1^{\text {st }}$ half (versus $2^{\text {nd }}$ half) and supports $\mathrm{H}_{3}$.

\subsubsection{Mediation}

As in experiment 1, curiosity was examined as a mediator by running a Hayes. Mediation Process Model 4 (Hayes 2017) using 5,000 bootstrapped samples. The relationship between the tension and resolution structure and the advertisement likeability score was fully mediated by curiosity since the confidence interval (CI) excludes zero (b=$.068,95 \%$ CI [-.119, -.026]). Figure 6 (Appendix B) illustrates these mediation results and Table 3 (Appendix B) includes a full table of results from experiment 2.

\subsubsection{Discussion}

The results from experiment 2 expand on the results from experiment 1 showing evidence for the effect of a tension and resolution music structure on consumer attitudes depending on where the tension and resolution structure resides in the musical clip in the ad. An analysis for order effects reveals that when the tension and resolution structure is at the beginning of the 30 second advertisement, consumer attitudes, as well as curiosity and satisfaction levels, are higher. Conversely, when the tension and resolution structure is at the end of the 30 second advertisement consumer attitudes, curiosity, and satisfaction levels are lower. These results can be attributed to the length of time to process the resolution as evident on the curiosity temporal measurement output (see Figure 5 in Appendix B). These 
results add more evidence and contribution to the tension in music literature as well as the tension in marketing communications literature showing where the optimal point for placing tension peaks are located.

\subsubsection{Experiment 3}

In the third experiment, hypotheses $4 \mathrm{a}$ and $4 \mathrm{~b}$ were tested, which pertain to the measure of the Need for Cognitive Closure as an moderating variable. To add generalizability to the results of experiment 1 and 2, a different product category for experiment 3 was used. The advertisement that was created shows a coffee maker and highlights its many features (see Appendix A for screen shots of advertisement). As in experiment 2, the features are displayed in the advertisement one at a time over the 30 -second timeframe. The visual aspects of the advertisement are identical between the conditions. In experiment 3 , two distinct audio conditions are present using the same audio clips used in experiment 1 . One of the conditions has a tension build with resolution and the second condition has the tension build without the resolution.

In addition to the measures administered during the previous experiments, the Need for Cognitive Closure (NFCC) scale was added into the survey to analyze the respondents across their NFCC score. As noted earlier, this measure can be found in the Need for Cognitive Closure (NFCC) literature (Kruglanski et al, 2013; Vermeir and Geuens, 2008; Dijksterhuis et al, 1996; Webster and Kruglanski, 1994), which highlights that those with a high level of this individual difference variable preferred less complex, mentally stimulating media, and had lower memory and judgement when presented with more complex structures. Given this difference, those that score high on the NFCC scale (see table 1 for latent scale manifest variables) will find the more complex tension and no 
resolution structure less appealing, and therefore will have a lower attitude for the advertisement and lower recall of the messaging being highlighted. For simplicity in administering the survey and to reduce potential survey fatigue, a 9-point adaptation of the original 47-point latent scale was used (Kashima and Loh, 2006). In addition, curiosity was measured as in the first two experiments as a potential mediator.

Therefore, the design of the experiment is a 2 (tension) x 1 between-subjects design with the measured variable of NFCC as a moderating variable. Likeability was measured for the ad as the main dependent variable and measured the participants' involvement with the product category in the ad and overall mood in order to rule out potential covariates as was done in the first two experiments. Finally, given the literature on NFCC, those with a high NFCC do not like excitement, therefore, excitement was measured to further tease out the relationship with NFCC as used in previous research (Kruglanski et al, 2013).

One hundred and forty-one student participants were recruited (average age 20.08 years, $52.7 \%$ male), all of whom received class credit for participating in the 10 -minute survey. A total of 10 respondents were removed from the analysis because they either failed the attention checks, audio comprehension checks, or didn't complete the survey. Therefore, a total of 131 respondents were used in the final analysis $\left(\mathrm{n}_{\text {res }}=65, \mathrm{n}_{\text {nores }}=66\right)$. Following the audio test task, the participants watched and listened to one of the two 30 second video advertisements (randomly assigned) and answered a series of questions to measure likeability of the advertisement (Homer, 1990), curiosity and satisfaction level (Ruan et al., 2018), along with category involvement (Coulter et al., 2003) and mood as potential covariates (Lisjak et al., 2015). In addition, participants completed the 9-point adaptation of the original 47 point latent NFCC scale (Kashima and Loh, 2006). 


\subsubsection{Results: Main Effects}

The MANCOVA revealed that there was a statistically significant difference in consumer attitudes based on the tension and resolution condition, $(\mathrm{F}(3,127)=4.468, \mathrm{p}=$ .005 , Wilk's $\Lambda=.905, \eta 2=.095)$. Further analysis into the dependent variables revealed a statistically significant higher likeability of the advertisement measure $(F(1,129)=6.545$, $\left.\mathrm{p}=.012, \eta^{2}=.048\right)$ with the clip that had resolution $\left(\mathrm{M}_{\mathrm{res}}=4.644\right)$ over the clip without resolution $\left(\mathrm{M}_{\text {nores }}=4.152\right)$ further supporting $\mathrm{H}_{1}$. In addition, the results showed a statistically significant higher curiosity score $\left(F(1,129)=11.889, p=.001, \eta^{2}=.084\right)$ with the clip that had resolution ( $M=3.662)$ versus the clip without resolution $(M=2.833)$, and showed a statistically significant higher satisfaction score $\left(F(1,129)=4.131, p=.044, \eta^{2}=\right.$ .031) with the clip that had resolution $(\mathrm{M}=3.585)$ versus the clip without resolution $(\mathrm{M}=3.091)$. Both of the covariates of involvement $(\mathrm{p}=.110)$ and $\operatorname{mood}(\mathrm{p}=.131)$ were not significant. Although when involvement and mood were incorporated into the multivariate analysis the results were less significant with curiosity $(\mathrm{p}=.004)$ and ad likeability $(\mathrm{p}=.037)$ remaining significant, and satisfaction $(\mathrm{p}=.129)$ showing as not significant.

\subsubsection{Mediation}

Upon further investigation, curiosity and excitement were shown as mediators by running a Hayes Mediation Process Model 6 (Hayes 2017) with 5,000 bootstrap samples to test for serial mediation. The relationship between the tension and resolution structure and the advertisement likeability score was fully mediated by curiosity since the confidence interval (CI) excludes zero ( $b=-.138,95 \%$ CI [-.292, -.036]), further building on $\mathrm{H}_{2}$. Figure 7 (Appendix B) illustrates all the mediation results from experiment 3. 


\subsubsection{Moderation}

In order to test for $\mathrm{H}_{4 a}$, how the NFCC score moderates the relationship of the tension resolution structure on ad likeability and curiosity, was examined by running a Hayes Mediation Process Model 1 (Hayes 2017) using 5,000 bootstrap samples. It was found that both the direct relationship of Tension and Resolution on Ad Likeability ( $\beta=$ $1.417,95 \%$ CI $[-.505,3.339], \mathrm{t}=1.459, \mathrm{p}=.147)$ and NFCC on Ad Likeability $(\beta=.052$, $95 \%$ CI $[-.013, .118], \mathrm{t}=-1.589, \mathrm{p}=.114)$ were not significant, yet the interaction $(\mathrm{F}(1,127)$ $\left.=4.051, \mathrm{p}=.046, \eta^{2}=.029\right)$ was significant, suggesting moderation. Upon further investigation the Johnson-Neyman output reveals that NFCC significantly moderates the relationship between tension/resolution and ad likeability at the NFCC score of 41.77 and higher. These results support $\mathrm{H}_{4 \mathrm{a}}$ as the participants with a lower NFCC score are less significantly affected by the tension and resolution structure of music, but as the NFCC score increases the results cross over and the high NFCC participants rate the ad likeability significantly lower. These results support $\mathrm{H}_{4 \mathrm{a}}$ and further explain the effect of $\mathrm{H}_{1}$. Table 4 (Appendix B) includes the moderation results and table 5 (Appendix B) includes the results of the Johnson-Neyman output for NFCC moderation.

\subsubsection{Moderated Mediation}

In order to test for $\mathrm{H}_{4 \mathrm{~b}}$, how the NFCC score moderated the mediators curiosity and excitement, a Hayes Mediation Process Model 14 (Hayes 2017) with 5,000 bootstrap samples was conducted. It was found that the direct relationship of Tension and Resolution on Ad Likeability $(\beta=.006,95 \%$ CI $[-.290, .303], t=.0421, p=.997)$, Curiosity on Ad Likeability $(\beta=.053,95 \%$ CI $[-.584, .689], \mathrm{t}=.164, \mathrm{p}=.87)$, and excitement on ad likeability $(\beta=-.328,95 \%$ CI $[-.767, .112], \mathrm{t}=-3.208, \mathrm{p}=.143)$ were not significant, yet the 
interaction in the model at excitement and $\operatorname{NFCC}\left(F(6,124)=5.834, p=.0172, \eta^{2}=.023\right)$ was significant, suggesting a crossover effect of NFCC at the mediating relationship of excitement to ad likeability. Upon further investigation, the Johnson-Neyman output shows evidence that NFCC significantly moderates the mediation relationship at the NFCC score of 38.3861 and higher. As the participants with a higher NFCC score are more significantly affected by the tension and resolution structure of music through an increase in excitement and rate the ad likeability significantly lower, these results support $\mathrm{H}_{4 \mathrm{~b}}$ and further explain the mediating relationship of $\mathrm{H}_{2}$. Figure 8 (Appendix B) illustrates all of the results in the moderated mediation model, Table 4 (Appendix B) includes the mediated moderation results and Table 6 (Appendix B) includes the results of the Johnson-Neyman output for the NFCC moderated mediation.

\subsubsection{Discussion}

The results from experiment 3 replicate the results from experiment 1 showing evidence of higher consumer attitudes for ads with tension and resolution structures in their background music versus those advertisements without resolution, further supporting $\mathrm{H}_{1}$. In addition, the results from experiment 3 also replicate the full mediation of these main effects through curiosity, further supporting $\mathrm{H}_{2}$. Of specific interest in experiment 3 is the introduction of the individual difference variable NFCC. This self-reported variable was shown to moderate the main effect and the mediators, curiosity and excitement, when NFCC scores were high, supporting hypotheses $\mathrm{H}_{4 a}$ and $\mathrm{H}_{4 b}$.

These results further add evidence to the literature on curiosity in both musicology and marketing literature in a number of ways. First, the variable excitement is added to the variable of curiosity and was show to serial mediate the main effect of downstream 
consumer attitudes. In addition, by introducing the results of the NFCC measure, a greater understanding is added to both literature streams in understanding more about how consumers process tension and resolution and what consumer personality attributes react to these stimuli. The results from this experiment also add to the NFCC literature by adding the musical component of tension to our understanding of this individual difference variable.

\subsubsection{Experiment 4}

In experiment 4 hypothesis 5 was tested to determine the impact of brand familiarity (known versus unknown brand) on the tension and resolution structure of the music clip in the advertisement. To add generalizability to the results of my previous experiments, a different product category for experiment 4 was used. The advertisement that was created shows video footage from chocolate manufacturing (Art-Numeric Mazy Réginald., 2010). Features of high-quality chocolates were layered onto the video footage and placed on both of two brands (one real and one fictional). For the real brand "Godiva Chocolatier" was used and for the fictional brand "Gorero Chocolatier" was used. As in previous experiments, the features are displayed in the advertisement one at a time over the 30 second timeframe. The visual aspects of the advertisement are identical between the conditions (see Appendix A for screen shots of advertisement). In experiment 4, two distinct audio conditions used the "Skrillex" song used in experiment 2. However, the clips were modified slightly. As hypothesis 5 tests for the presence and absence of resolution from the tension build in the song, two versions were created: one with resolution and one without. Both audio clips that were layered into the commercial visuals were 30 seconds in length, therefore had the same exposure time. Given these two distinct conditions, a 2 
(tension and resolution) x 2 (known versus unknown brand) between-subjects design was used.

In addition to the measures administered during the previous experiments, a selfbrand connection measure was used as a covariate. All latent measures are listed with their scale reliability in Table 1 (Appendix B).

Two hundred and nineteen student participants were recruited (average age 20.41 years, $57.1 \%$ male), all of whom received class credit for participating in the 10-minute survey. A total of 58 respondents were removed from the analysis because they either failed the attention checks, audio comprehension checks, or didn't complete the survey. Therefore, a total of 161 respondents were used in the final analysis $\left(n_{\text {knownbr }}=79\right.$, $\left.\mathrm{n}_{\text {unknownbr }}=82, \mathrm{n}_{\text {res }}=79, \mathrm{n}_{\text {nores }}=82\right)$. Following the audio test task, the participants watched and listened to one of the four 30-second video advertisements (randomly assigned) and answered a series of questions as noted earlier.

\subsubsection{Results: Main Effects Replication}

A manipulation check was conducted on the known versus unknown brand condition using the brand familiarity dependent variable. The results showed a successful manipulation of the independent variable $\left(F(1,159)=129.570, p=.000, \eta^{2}=.449\right)$ with the familiar brand scoring higher in brand familiarity $(M=4.592)$ than the fictitious brand $(\mathrm{M}=2.345)$.

The MANCOVA revealed that there was a statistically significant difference in consumer attitudes based on the tension and resolution condition, $(\mathrm{F}(4,156)=5.762, \mathrm{p}=$ .000 , Wilk's $\Lambda=.871, \eta 2=.129)$. Further analysis into the dependent variables revealed a statistically significant higher likeability of the advertisement measure $(F(1,160)=8.898$, 
$\left.\mathrm{p}=.003, \eta^{2}=.053\right)$ with the clip that had resolution $(\mathrm{M}=5.646)$ versus the clip without resolution ( $M=5.112)$ further supporting $\mathrm{H}_{1}$. In addition, the results showed a statistically significant higher curiosity score $\left(F(1,160)=15.482, p=.000, \eta^{2}=.089\right)$ with the clip that had resolution $(\mathrm{M}=4.71)$ versus the clip without resolution $(\mathrm{M}=3.82)$, and showed a statistically significant higher satisfaction score $\left(F(1,160)=7.975, p=.005, \eta^{2}=.048\right)$ with the clip that had resolution $(M=4.72)$ versus the clip without resolution $(M=4.01)$. Given that this experiment involved known versus unknown brands, Self Brand Connection was used as a potential covariate throughout as this measure was also significant $(F(1,160)=$ 5.373, $\left.\mathrm{p}=.022, \eta^{2}=.033\right)$. Results without including SBC as a covariate were also significant for ad likeability $(\mathrm{p}=.001)$, curiosity $(\mathrm{p}=.000)$, and satisfaction $(\mathrm{p}=.001)$.

\subsubsection{Mediation Replication}

Upon further investigation, curiosity was examined as a mediator by running a Hayes Mediation Process Model 4 (Hayes 2017) using 5,000 bootstrapped samples. The relationship between the tension and resolution structure and the advertisement likeability score was fully mediated by curiosity as in all the previous experiments since the confidence interval (CI) did not include zero (b=-.276, 95\% CI [-.457, -.125]), further supporting $\mathrm{H}_{2}$. Table 7 (Appendix B) illustrates all the mediation results from experiment 4.

\subsubsection{Interaction Effect}

In order to test $\mathrm{H}_{5}$, a MANCOVA was used testing the interaction between the tension condition and the brand condition. Although the interaction was only marginally significant on curiosity $\left(F(1,160)=3.445, \mathrm{p}=.065, \eta^{2}=.022\right)$ and satisfaction $(\mathrm{F}(1,160)=$ $\left.2.960, \mathrm{p}=.087, \eta^{2}=.019\right)$, it was significant on ad likeability $(\mathrm{F}(1,160)=8.089, \mathrm{p}=.005$, 
$\eta^{2}=.049$ ). To understand these results further, a pairwise comparison across all four conditions was used in order to identify the points of significance. When ad likeability was examined, the most notable differences were between the known brand without resolution $(\mathrm{M}=4.803)$ condition compared to the other three conditions which were: the known brand with resolution $(\mathrm{M}=5.727) \mathrm{p}=.000$, and the unknown brand with resolution $(\mathrm{M}=5.489)$ $\mathrm{p}=.003$, and the unknown brand without resolution $(\mathrm{M}=5.437) \mathrm{p}=.004$. Results were similar for curiosity with the most notable differences between the known brand without resolution $(\mathrm{M}=3.487)$ condition compared to the other three conditions which were: the known brand with resolution $(\mathrm{M}=4.664) \mathrm{p}=.000$, the unknown brand with resolution $(\mathrm{M}=4.647) \mathrm{p}=.000$, and the unknown brand without resolution $(\mathrm{M}=4.197) \mathrm{p}=.010$. Results were also similar for satisfaction with the most notable differences between the known brand without resolution condition $(\mathrm{M}=3.725)$ compared to the other three conditions which were: the known brand with resolution $(\mathrm{M}=4.713) \mathrm{p}=.001$, the unknown brand with resolution $(\mathrm{M}=4.620) \mathrm{p}=.004$, and the unknown brand without resolution $(\mathrm{M}=4.357) \mathrm{p}=.034$. Figure 9 (Appendix B) shows three graphs illustrating these conditional differences.

\subsubsection{Discussion}

The results from experiment 4 replicate the results from experiment 1 and 3, further supporting hypotheses $\mathrm{H}_{1}$ and $\mathrm{H}_{2}$. These results also show evidence that known brands are more impacted when musical tension isn't resolved in an advertisement. This can be attributed to the results showing that known brands have lower curiosity levels as does music with a tension and no resolution structure supporting $\mathrm{H}_{5 \mathrm{a}}$. In addition, this additive effect can be detrimental to the likeability of an advertisement of a known brand. The 
results are very different for an unknown brand as there is little difference between the tension with resolution and tension without resolution condition and support $\mathrm{H}_{5 \mathrm{~b}}$.

Results from experiment 4 add further contribution to the literature on tension in music and in marketing communications. In addition, by introducing this brand component, the results show how the effects observed in the prior experiments can also transfer beyond consumer attitudes for the advertisement and attach to consumer sentiment for a brand. More specifically, we now have a better understanding and have contributed to the literature on branding to known versus unknown brands. This is particularly useful for marketing practitioners to understand as tension structures in music can have a substantially greater negative effect on known brands versus new brands when resolution of the tension isn't present.

\subsection{Limitations and Discussion}

\subsubsection{General Discussion of Results}

In experiment 1, the mere presence or absence of resolution of a musical tension build was shown to shape consumer attitudes. How this relationship was fully mediated by curiosity and excitement was also shown. By resolving the tension, consumer attitudes increased for the advertisement, specifically with ad likeability. These initial results were replicated in the subsequent three experiments using different music and product categories for generalizability.

Experiment 2, showed how the resolution structure influenced positive attitudes more when the build and resolve occurred in the first half of the ad, thus leaving time for the resolution. When the resolve was in the second half, there was less time for the resolution and therefore lower positive effects on consumer attitude. 
In experiment 3 an important individual difference variable, Need for Cognitive Closure (NFCC), was introduced and was shown to moderate the influence that tension and resolution structures of music have on attitudes. Evidence showed how those consumers who have a higher NFCC score exhibited significantly lower attitudes towards an advertisement with tension and no resolution along with lower satisfaction and curiosity scores. Those with low NFCC scores, had little change between the conditions of tension with resolution and without resolution.

Finally, experiment 4 showed that the tension and resolution structure of music has a greater influence on consumer attitudes for known brands versus unknown brands. Specifically, known brands had a significantly lower consumer attitude towards the ad when the ad used music with tension and without resolution. For the unknown brand, there was little effect, thus giving advertisers more latitude when using tension structures in music on a new and unknown brand.

\subsubsection{Limitations}

As with many forms of sensory marketing research, the robustness of the data is dependent on the measurement devices. Albeit the devices and methods described in the methodology are clearly used in many published and cited sensory marketing research and can clearly show main effects of music on consumers, more sophisticated technology would produce far superior fidelity such as fMRI machines, wireless oximeter (to measure heart and oxygen levels), and skin current sensors (to measure GSR - galvanic skin response).

As outlined in the introduction of this paper, there are many ways to create musical tension. For the purposes of the four studies outlined in this research, tonal tension was 
used. Therefore, there is opportunity to further explore other types of tension such as rhythm and tempo, volume, or breaks and pauses in music altogether. Each of these types of tension could lead to different effects on consumer attitudes. Also, given the many different kinds of music genres and the added layer of culture or semiotic components of music, there remains unanswered research questions around how different kinds of music offer up tension and how that effects people from different cultures.

Apart from limitations due to technology and scope, while conducting the experiments, there were also limitations in sampling and methodology. For all of the experiments conducted in this chapter students completed the self-administered surveys and recruited through a link using the Qualtrics online survey service. Each participant in every experiment was asked to play a sound file at the beginning of the study and type the word they heard. This acted as a qualifying element to the study to ensure that the students had the volume on and up to a level that allowed them to discern language and sound. This method had to be used due to COVID-19 restrictions and the lack of opportunity to bring students in large numbers into a lab setting. What this method did not account for were a number of factors. First, it didn't qualify whether students took the survey on their laptop, desktop, or mobile device. The sound quality of their device speakers could have a significant variability which could account for some of the marginal effects reported. In addition, the methodology did not account for whether students used headphones or earbuds, or even used high quality speakers. As outlined in chapter 2 , this could have had a significant effect on the results. 


\subsubsection{Future Research}

The research conducted in my four experiments is limited to the downstream effects of consumer attitude (ad likability). It would be of considerable interest to understand how these attitudes, influenced by the tension and resolution structures of music, shape consumer behaviors such as willingness to pay and product choice. My research also focused on how tension and resolution structures drove consumer attitude in the context of directed advertising. There is opportunity to expand on the literature of music at retail in order to further understand how tension and resolution structures in ambient music can change behaviors in a retail field setting.

Furthermore, given the different types of musical tension and the cultural or semiotic nature of music, there remains many opportunities for future research exploring these areas. Specifically, one of the challenges that marketers face is developing advertising that resonates globally. By understanding how musical tension effects different cultures would benefit marketers globally.

Outside of consumer attitudes, there remains opportunity to expand the methodology to measurement beyond consumer attitudes to other dependent variables. For example, understanding how brand attitudes are altered by tension and resolution structures of music should be explored further outside of the one experiment that was conducted on known versus unknown brands. In addition, experiment 4 had significant results, although these results were counter to some of the main effects in the first three main experiments conducted. In experiment 4, there was no significant difference in the unknown brand condition. This is of particular interest, because the products used in the first three experiments were also unbranded. On possible explanation for this is may be the category 
of products used. In the first three experiments, the products were utilitarian products, where the product used in experiment 4 was a hedonic product. This highlights a particular difference that could be explored further. This can be accomplished by running experiment 4 again with a utilitarian product and running one of the first three experiments again with a hedonic product.

Also, as noted in the limitations section, conducting these new experiments and controlling for the device used and audio speakers used will add to the validity of the results from the first four experiments. It is also of interest to determine if there are cross modal correspondences (Spence, 2011) initiated by using different devices. 


\section{CHAPTER 4 \\ CONCLUSION}

\subsection{General Discussion}

The two main essays preceding this chapter start by outlining a broad spectrum of key auditory sensory marketing areas, highlight gaps in the marketing literature, present answers from research outside of marketing publications, and offer potential areas of research within the marketing domain. Addition topics of the length of music used in marketing as well as the significance of ambient versus directed musical stimuli are also presented and addressed. Also, through a deeper exploration of the theoretical framework of musical tension and resolution structures, and the execution of four empirical studies, a deeper understanding of musical tension and resolution is achieved.

In chapter 2 the exploration of key musical expressions of time, pitch, texture, and timbre are introduced. Through highlighting key research in the marketing domain along with adding components of research outside of the marketing domain (i.e. musicology research, psychology/neuropsychology) a more complete conceptual map is updated. As an added dimension on musical exposure, two other concepts are explored in chapter 2 which add to the context of music used in marketing. These areas of the length of music and the ambient versus directed nature of the stimuli offer more opportunity for future research and publication. In addition, it is understood that marketing practitioners and scholar may not frequently use musical terminology, so a table is included at the end of this dissertation which outlines these terms, key research completed inside and outside of the marketing domain and future research opportunities for each musical expression. 
In chapter 3 a deeper understanding the effect musical tension and resolution structures have on consumer attitudes is achieved. Through two pretests and four experiments seven hypotheses are tested and confirmed. The results from these experiments achieve insight into a number of aspects of how tension and resolution musical structures can influence consumer attitudes.

First, one important factor or this musical structure is highlighted which is the resolution of tension. The mere presence of the resolution of tension can change consumer attitudes significantly. Secondly, it is through the anticipation of the resolution and the curiosity caused by that anticipation that is the key mediating factor exhibited in this phenomenon. Thirdly, through experiment 2 more fidelity is achieved in understanding tension build and resolution's effect on consumer attitudes depending on its location in an advertisement. By having the tension and resolution structure at the beginning of the advertisement and allowing for a longer resolution of the tension, more positive consumer attitudes were achieved. In addition, by introducing the individual difference variable of Need for Cognitive Closure (NFCC) into experiment 3, a deeper understanding of the specific underlying mechanism behind this phenomenon is uncovered. As an individual's NFCC is high, so is their sensitivity to tension structures in music and advertising when resolution is not present. Finally, a practical managerial perspective is proposed and tested through how tension and resolution structures of music can change in consumer influence depending if they are used on the backdrop of a familiar brand or new (unknown brand). That is, unknown brands create their own level of curiosity which counters the effect of tension and resolution resulting in little change between structures with or without 
resolution. Conversely, familiar brands carry information that attenuate curiosity thus are negatively affected by advertising that used musical tension without resolution. 


\subsection{Contributions}

This dissertation contributes to both the marketing literature and practice in a number of ways. In chapter 2, the research outlines and expands the current conceptual framework within the marketing literature domain in four ways. First, by bringing in the research and conceptual insights from neuropsychology and musical literature into the marketing literature. This new aggregated conceptual map adds context to the marketing literature and practice alike. Second, expansion of contextual aspects of music such as the timbre literature in marketing are achieved, thus adding to the importance of this textural component of music. Third, through the exploration of the finite nature of musical structure and its potential to guide consumers' emotions, chapter 2 conceptualizes how some emotive elements may be easier to process than others in a shorter form which contributes considerably to the emotive effect that music has on consumers.

In chapter 3, the concept of tension and resolution within music is applied to the backdrop of advertising. More specifically, it was shown how this musical structure can be used as a powerful tool to change consumer attitudes and uncovers the mediating effect of curiosity that drives those consumer attitudes. These results contribute to the theoretical areas of marketing communications, specifically the "teasing effect". In addition, the contribution to the understanding of how consumer experience tension and resolution in music is amplified. An additional contribution is achieved in our theoretical understanding of the individual difference variable Need for Cognitive Closure (NFCC). Finally, a contribution is added to our understanding of known versus unknown brands and the factors that can attenuate curiosity and excitement in advertising that uses tension and resolution structures in music. 


\subsection{Managerial Implications}

Marketing professionals spend a considerable amount of time and money developing new music or matching existing popular music to enhance their advertising or as a brand attribute. Unfortunately, little has been written on this subject to pull all of the conceptual elements of music together in a way that can serve as a marketer's "musical toolbox" in order to create the product, attribute, or brand sentiment that marketers are aiming for.

From a research forensic perspective, marketers potentially choose elements of music or specific musical scores because of their own personal sentiment (Webster and Kruglanski, 1994). In addition, scholars have shown research and cautioned against musical tension (Anglada-Tort et al., 2020) which could potentially misdirect marketing practitioners who do not possess a broader understanding of tension and resolution structures in music.

The work in this dissertation serves as both a "toolbox" of key elements that can be used to create very specific sentiments and consumer attitudes, and a "roadmap" to why musical tension and resolution structure elicit certain consumer attitudes. 


\section{APPENDIX A}

\section{Experiment 1: Screen Shots of Advertisement}
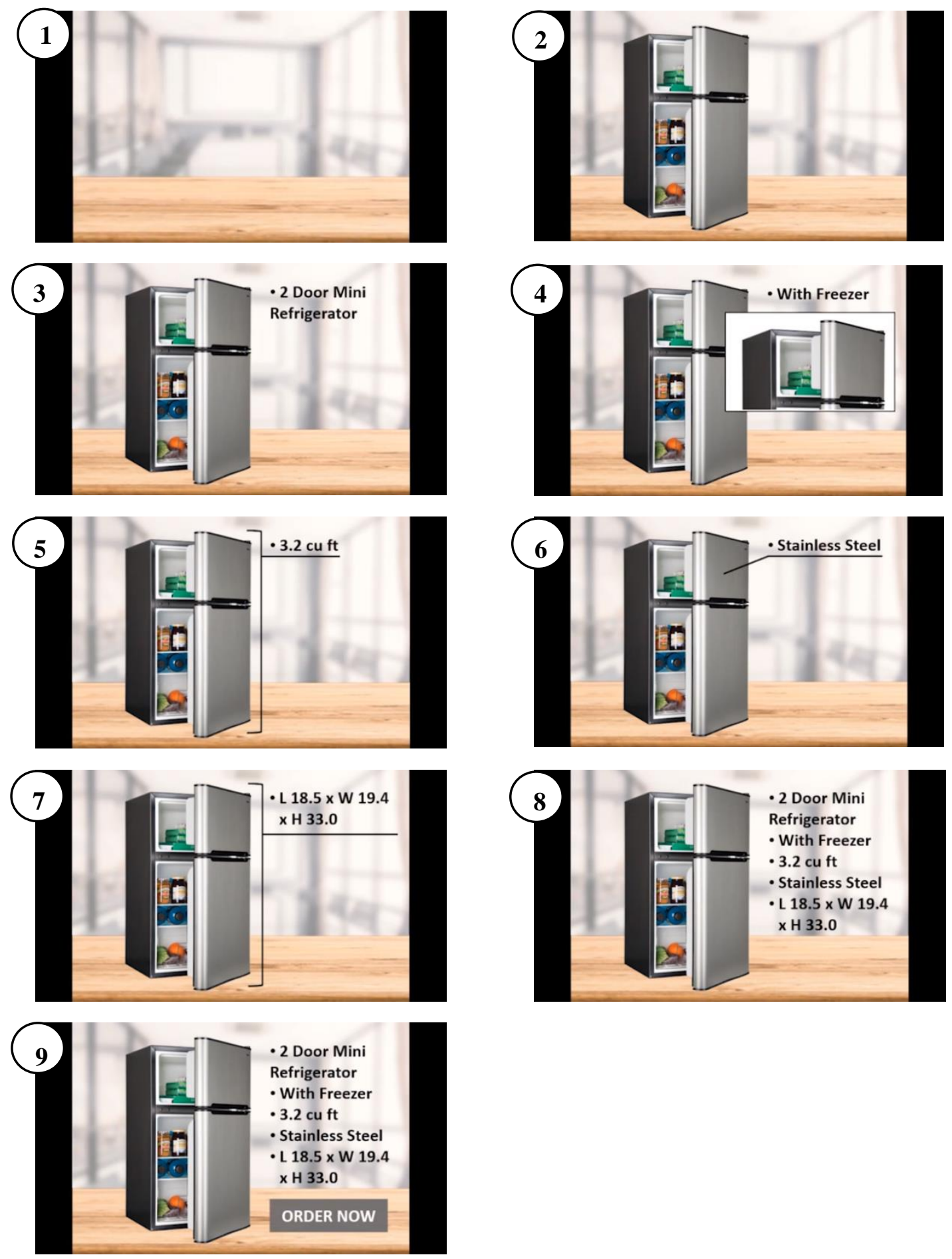

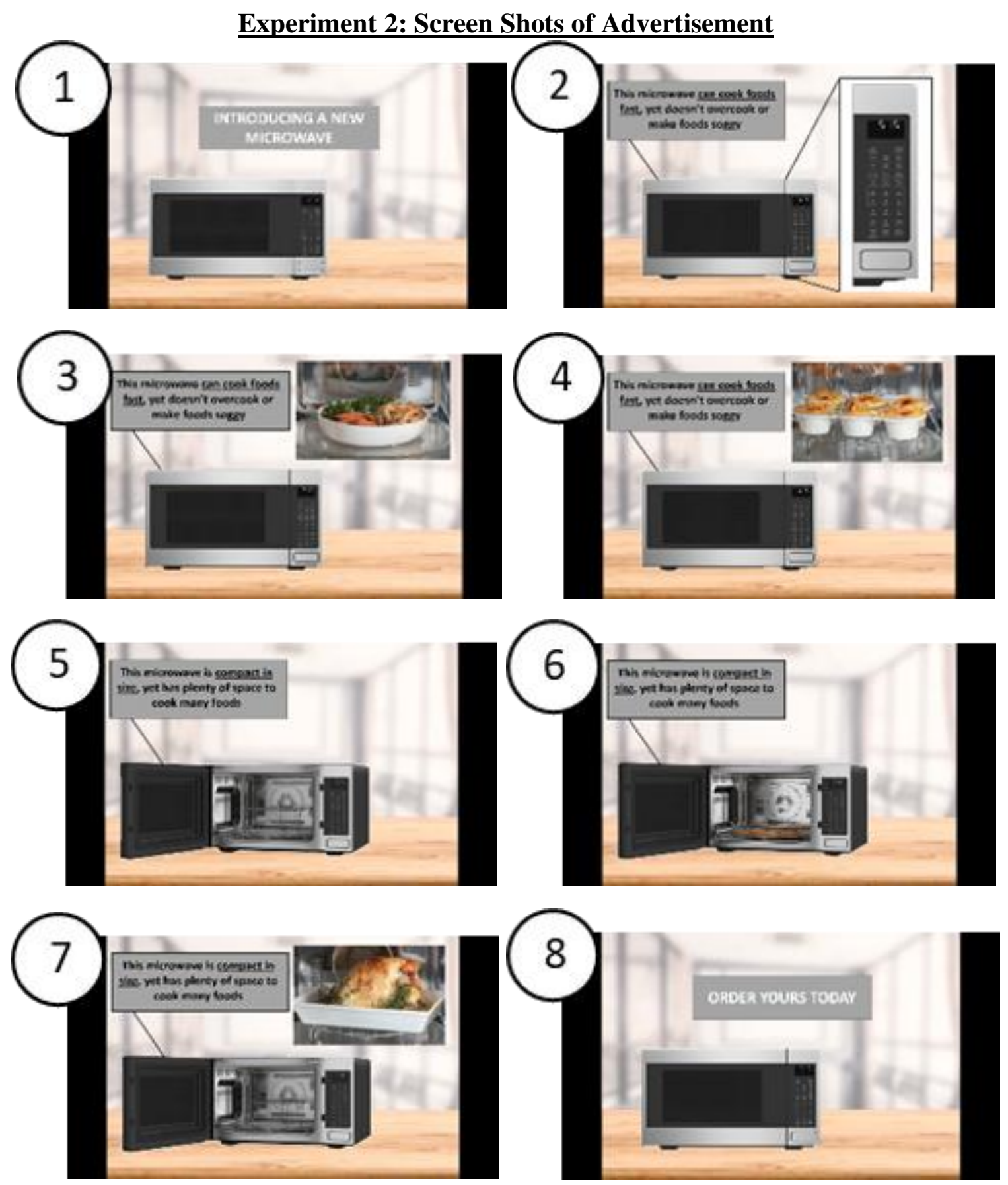

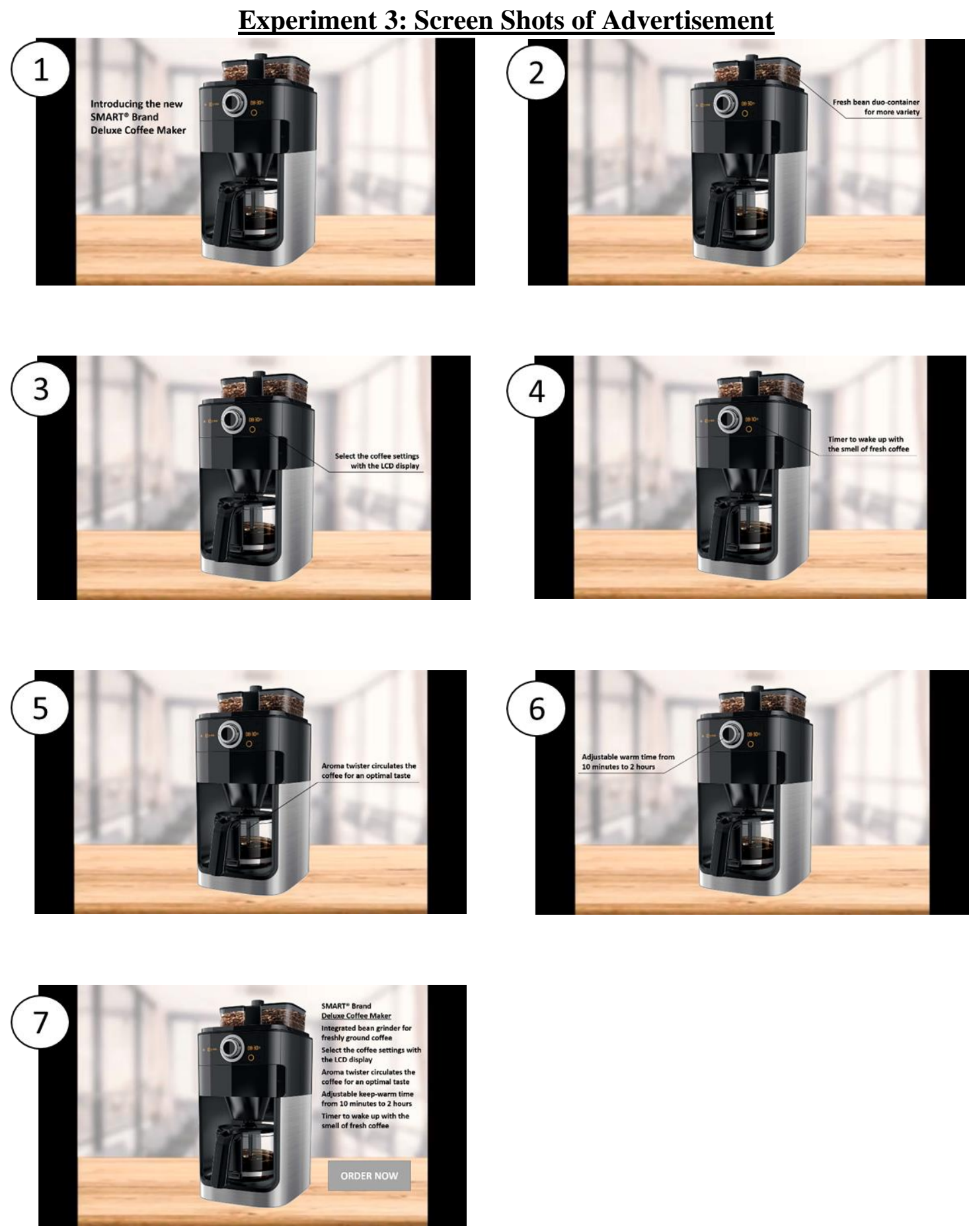


\section{Experiment 4: Screen Shots of Advertisement}
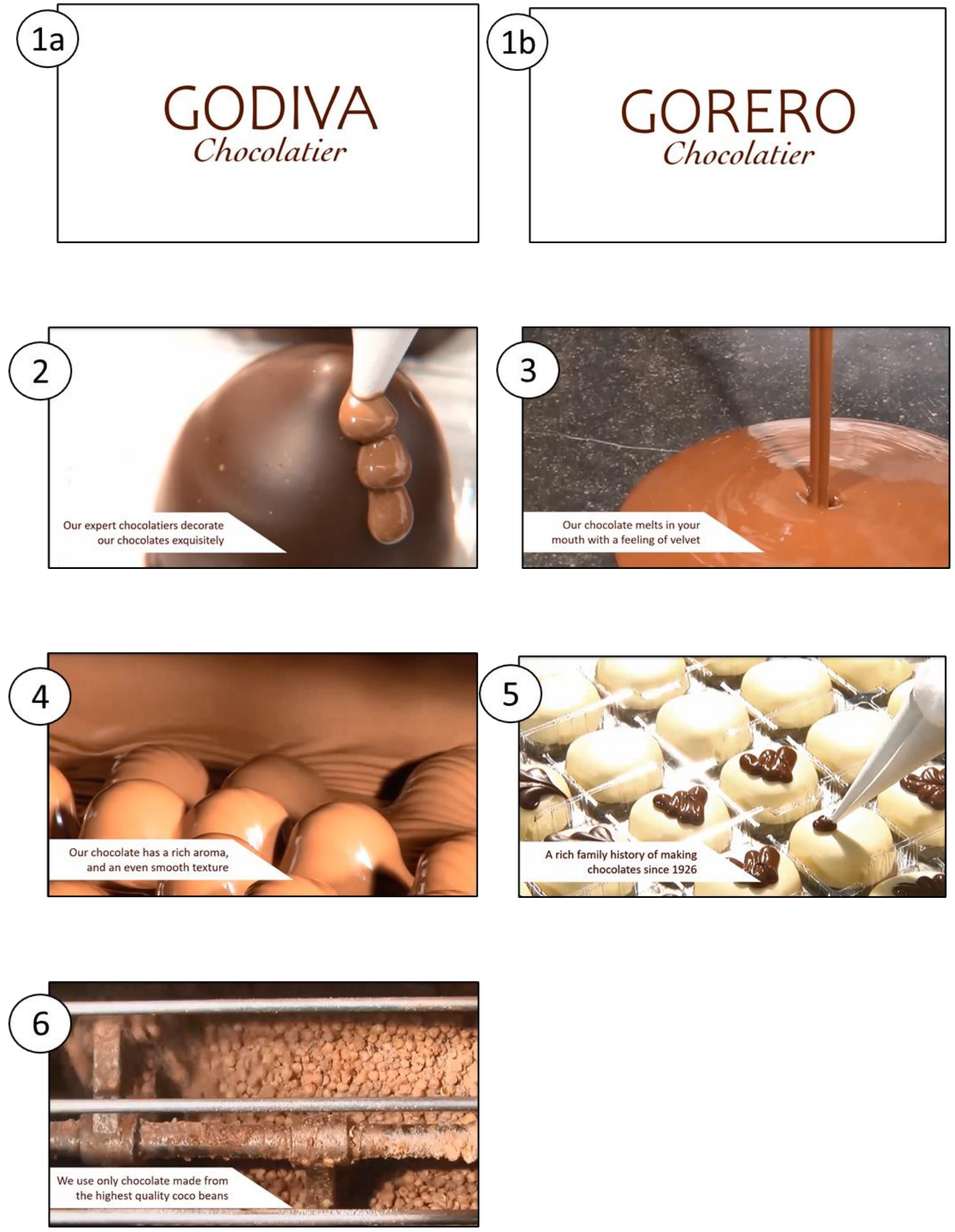


\section{APPENDIX B}

Figure 1: Research Map for the Multidisciplinary Conceptual Framework

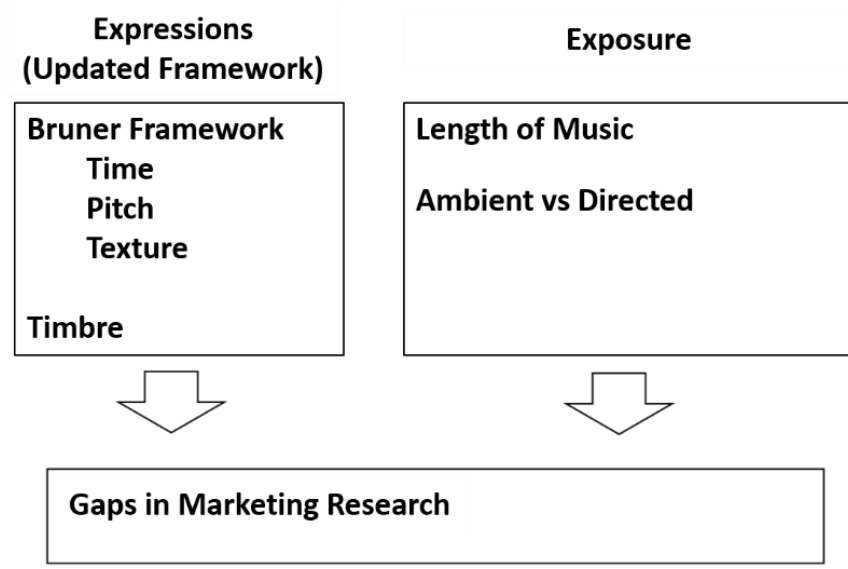

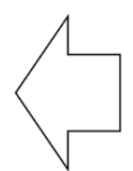




\section{Table 1: Latent Measures and Reliability}

\begin{tabular}{|c|c|c|c|}
\hline Latent Measure & Item & $\alpha$ & Source \\
\hline Ad Likeability & $\begin{array}{l}\text { Please describe your overall feelings about the Advertisement you just watched. } \\
\text { Negative/Positive } \\
\text { Good/Bad } \\
\text { Unfavorable/Favorable } \\
\text { Boring/Interesting } \\
\text { Deceptive/Credible } \\
\text { Exagerated/Factual } \\
\text { Unappealing/Appealing }\end{array}$ & 0.917 & $\begin{array}{l}\text { Modification of: Homer, P. M. (1990). The mediating role } \\
\text { of attitude toward the ad: Some additional evidence. } \\
\text { Journal of Marketing research, 27(1), 78-86. }\end{array}$ \\
\hline Involvement & $\begin{array}{l}\text { In general, I have strong interests in this product category } \\
\text { This product category is very important to me } \\
\text { This product category matters a lot to me } \\
\text { This product category means a lot to me }\end{array}$ & 0.940 & $\begin{array}{l}\text { Modification of: Coulter, R. A., Price, L. L., \& Feick, L. } \\
\text { (2003). Rethinking the origins of involvement and brand } \\
\text { commitment: Insights from postsocialist central } \\
\text { Europe. Journal of consumer research, } 30 \text { (2), 151-169. }\end{array}$ \\
\hline Mood & $\begin{array}{l}\text { At this moment I am feeling: } \\
\text { Bad/Good } \\
\text { Unpleasant/Pleasant } \\
\text { Sad/Happy } \\
\text { Negative/Positive }\end{array}$ & 0.962 & $\begin{array}{l}\text { Modification of: Lisjak, M., Bonezzi, A., Kim, S., \& Rucker, } \\
\text { D. D. (2015). Perils of compensatory consumption: Within- } \\
\text { domain compensation undermines subsequent self- } \\
\text { regulation. Journal of Consumer Research, 41(5), 1186- } \\
1203 .\end{array}$ \\
\hline Curiosity & How curious did you feel when viewing the advertisement? & N/A & $\begin{array}{l}\text { Single item measure: Ruan, B., Hsee, C. K., and Lu, Z. Y. } \\
\text { (2018). The teasing effect: An underappreciated benefit } \\
\text { of creating and resolving an uncertainty. Journal of } \\
\text { Marketing Research, 55(4), 556-570. }\end{array}$ \\
\hline Satisfaction & How much did the advertisement satisfy your curiosity? & N/A & $\begin{array}{l}\text { Single item measure: Ruan, B., Hsee, C. K., and Lu, Z. Y. } \\
\text { (2018). The teasing effect: An underappreciated benefit } \\
\text { of creating and resolving an uncertainty. Journal of } \\
\text { Marketing Research, 55(4), 556-570. }\end{array}$ \\
\hline Excitement & $\begin{array}{l}\text { After watching the advertisement I felt: } \\
\text { Excited } \\
\text { Stimulated }\end{array}$ & 0.849 & $\begin{array}{l}\text { Adapted from: Gorn, G. J., Chattopadhyay, A., Yi, T., \& } \\
\text { Dahl, D. W. (1997). Effects of color as an executional cue } \\
\text { in advertising: They're in the shade. Management science, } \\
\text { 43(10), 1387-1400. }\end{array}$ \\
\hline NFCC & $\begin{array}{l}\text { When I am confused about an important issue, I feel very upset. } \\
\text { I don't like situations that are uncertain. } \\
\text { I don't like to go into a situation without knowing what I can expect from it. } \\
\text { I hate to change my plans at the last minute. } \\
\text { I dislike unpredictable situations. } \\
\text { I enjoy having a clear and structured mode of life. } \\
\text { I find that establishing a consistent routine enables me to enjoy life more. } \\
\text { I feel uncomfortable when I don't understand the reason why an event occurred in my life. }\end{array}$ & 0.864 & $\begin{array}{l}\text { Original measure: Kruglanski, A. W., Atash, M. N., De } \\
\text { Grada, E., Mannetti, L., and Pierro, A. (2013). Need for } \\
\text { Closure Scale (NFC). Measurement instrument database } \\
\text { for the social science. } \\
9 \text { Point adapted measure: Kashima, E. S., \& Loh, E. (2006). }\end{array}$ \\
\hline SBC & $\begin{array}{l}\text { The brand in the commercial that I just saw is part of me and who I am. } \\
\text { I do not feel personally connected to the brand in the commercial that I just saw. } \\
\text { I feel emotionally bonded with the brand in the commercial that I just saw. } \\
\text { The brand in the commercial that I just saw says something to other people about who I am. }\end{array}$ & 0.797 & $\begin{array}{l}\text { Original measure: Kruglanski, A. W., Atash, M. N., De } \\
\text { Grada, E., Mannetti, L., and Pierro, A. (2013). Need for } \\
\text { Closure Scale (NFC). Measurement instrument database } \\
\text { for the social science. }\end{array}$ \\
\hline
\end{tabular}


Figure 2: Full Logarithmic Spectral Frequency Display for Clips used in Exp1

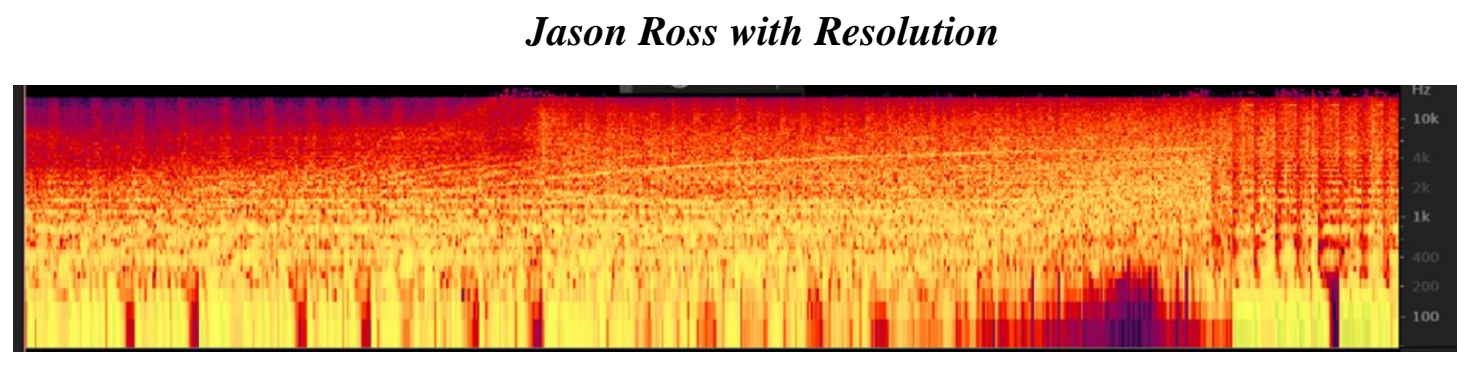

Jason Ross without Resolution

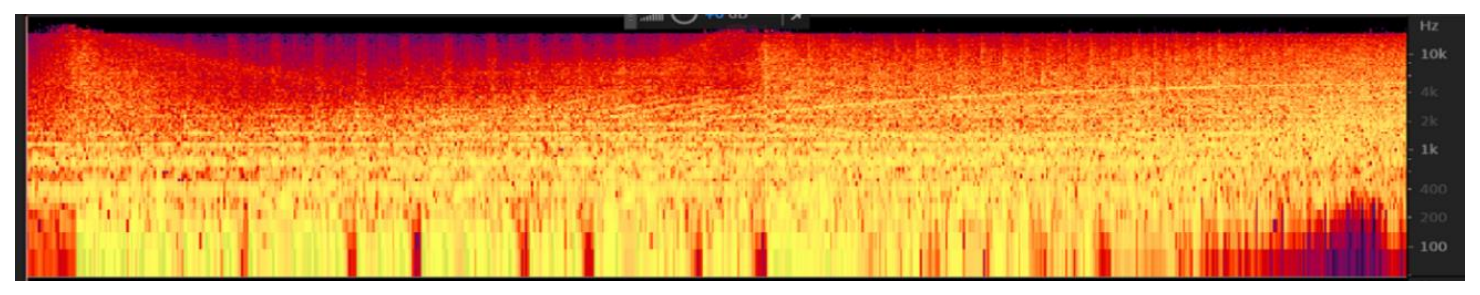


Figure 3: Mediation of the Effect of Tension Resolution Structure on Advertisement Likeability by Curiosity for Experiment 1

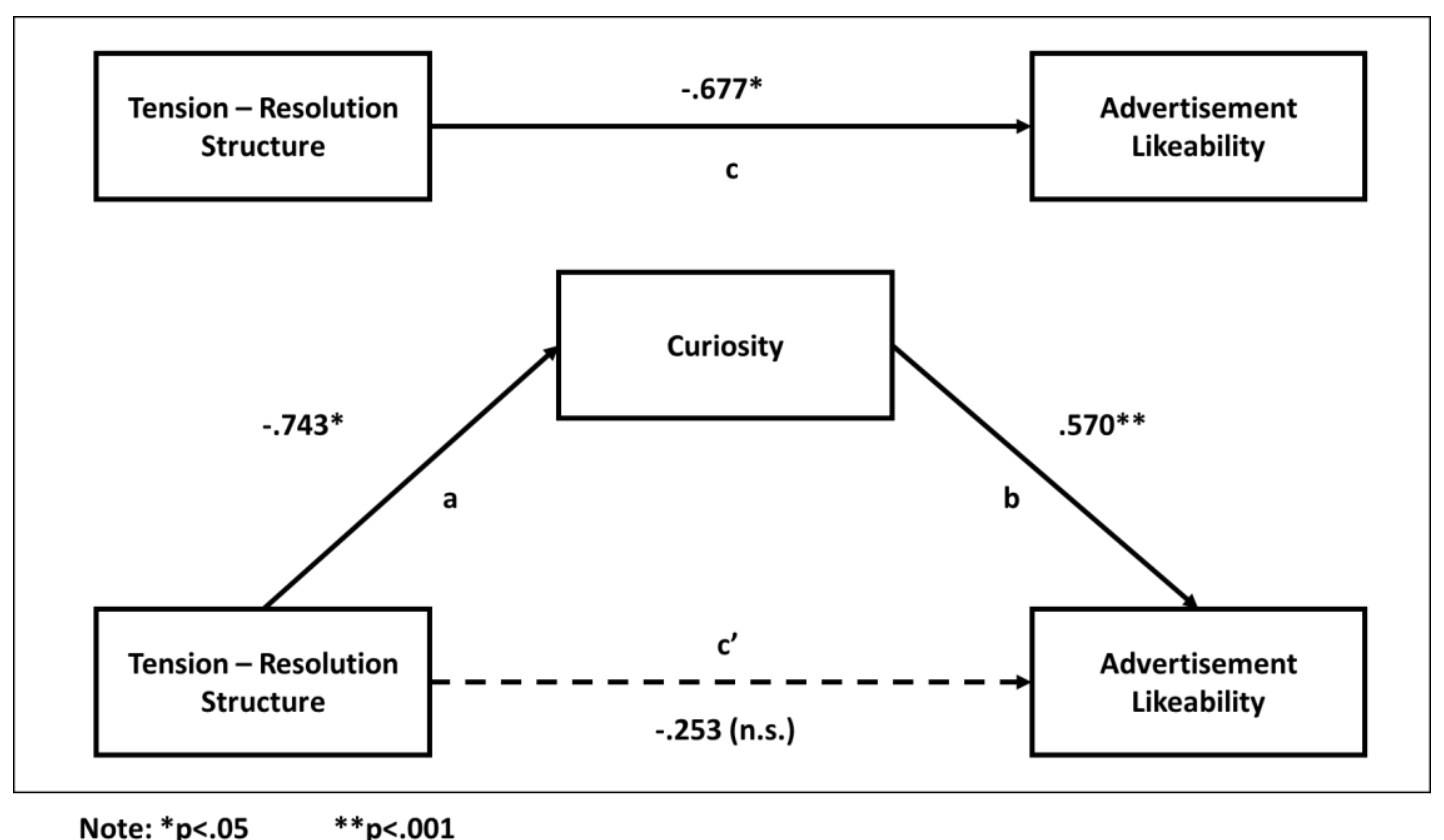


Table 2: Full Results of Experiment 1

\begin{tabular}{|c|c|c|c|c|c|c|c|c|c|}
\hline \multirow{2}{*}{ Dependent Variable } & \multicolumn{8}{|c|}{$95 \%$ Confidence Interval } & \multirow[b]{2}{*}{$\eta^{2}$} \\
\hline & Mean & Std. Error & $\beta$ & Lower BoundUpper & r Bound & $\mathrm{t}$ & $\mathrm{F}$ & Sig. & \\
\hline \multicolumn{10}{|c|}{ ANCOVA (Controlling for Involvement and Mood) } \\
\hline Curiosity & & & & & & & 9.974 & 0.002 & 0.123 \\
\hline With Resolution & 3.298 & 0.205 & & 2.889 & 3.708 & & & & \\
\hline Without Resolution & 2.345 & 0.222 & & 1.907 & 2.783 & & & & \\
\hline Satisfaction & & & & & & & 11.702 & 0.001 & 0.014 \\
\hline With Resolution & 3.254 & 0.199 & & 2.857 & 3.65 & & & & \\
\hline Without Resolution & 2.253 & 0.213 & & 1.829 & 2.677 & & & & \\
\hline Advertisement Likeability & & & & & & & 10.395 & 0.002 & 0.128 \\
\hline With Resolution & 4.676 & 0.174 & & 4.329 & 5.023 & & & & \\
\hline Without Resolution & 3.852 & 0.186 & & 3.481 & 4.223 & & & & \\
\hline \multicolumn{10}{|l|}{ Mediation } \\
\hline Tension -> Curiosity & & & -0.743 & -1.449 & -0.037 & -2.097 & & 0.040 & \\
\hline Curiosity -> Ad Likeability & & & 0.570 & 0.422 & 0.718 & 7.672 & & 0.000 & \\
\hline Tension -> Ad Likeability & & & -0.253 & -0.715 & 0.209 & -1.092 & & 0.278 & \\
\hline Indirect Effect & & & -0.424 & -0.844 & -0.014 & & & & \\
\hline
\end{tabular}


Figure 4: Temporal Slider Scale Output paired with Full Logarithmic Spectral Frequency Display for clips used in Pretest 2

Foo Fighters “All My Life” 1st Half Resolution

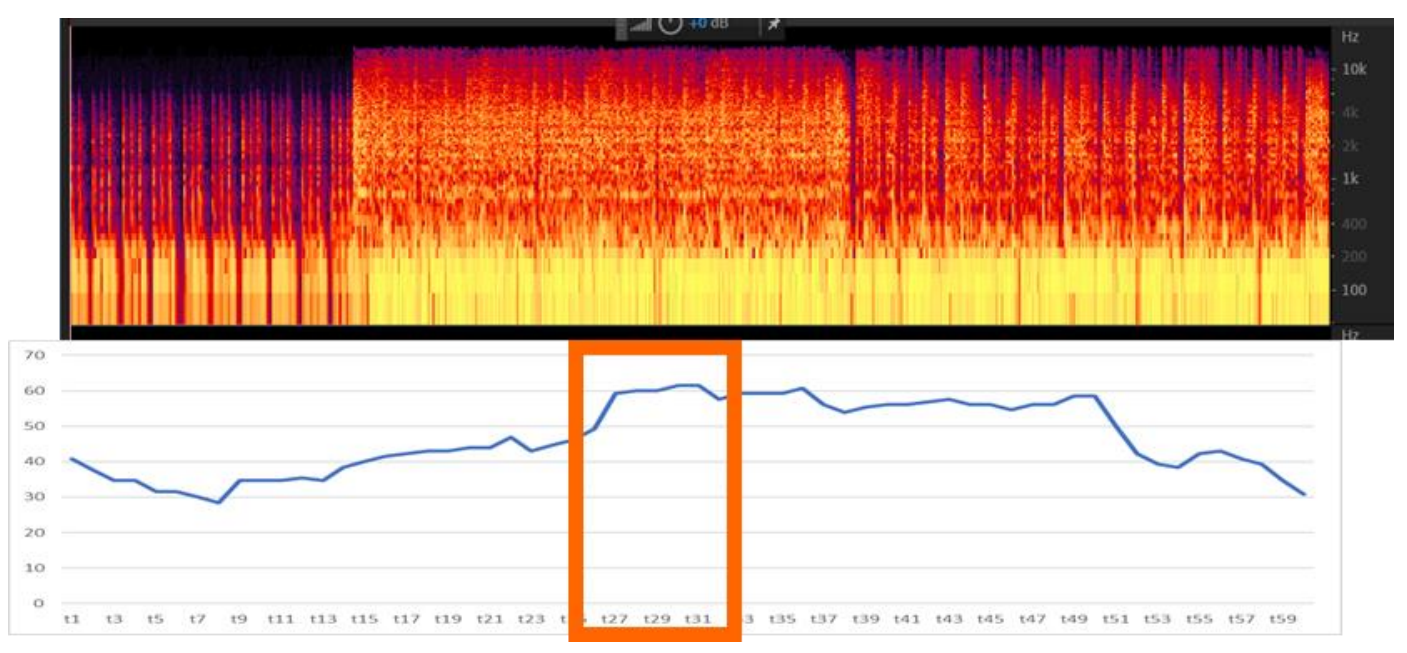

Foo Fighters “All My Life” 2nd Half Resolution

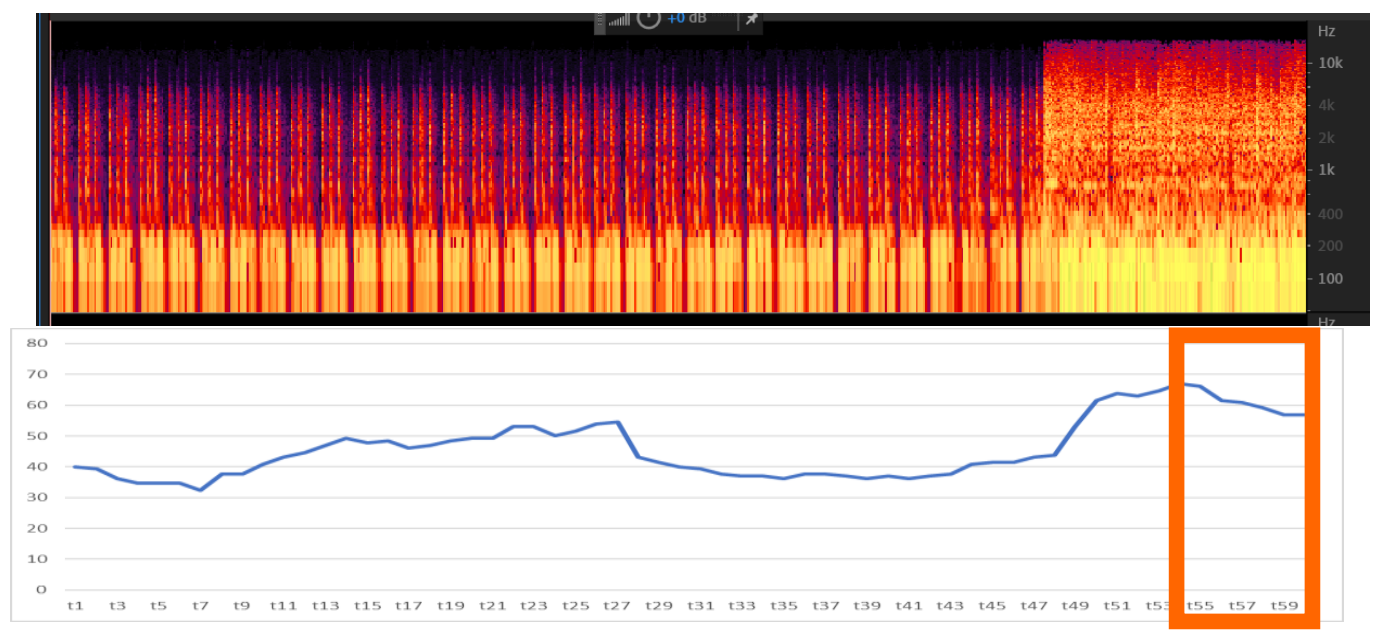


Skrillex “Bangarang” 1st Half Resolution
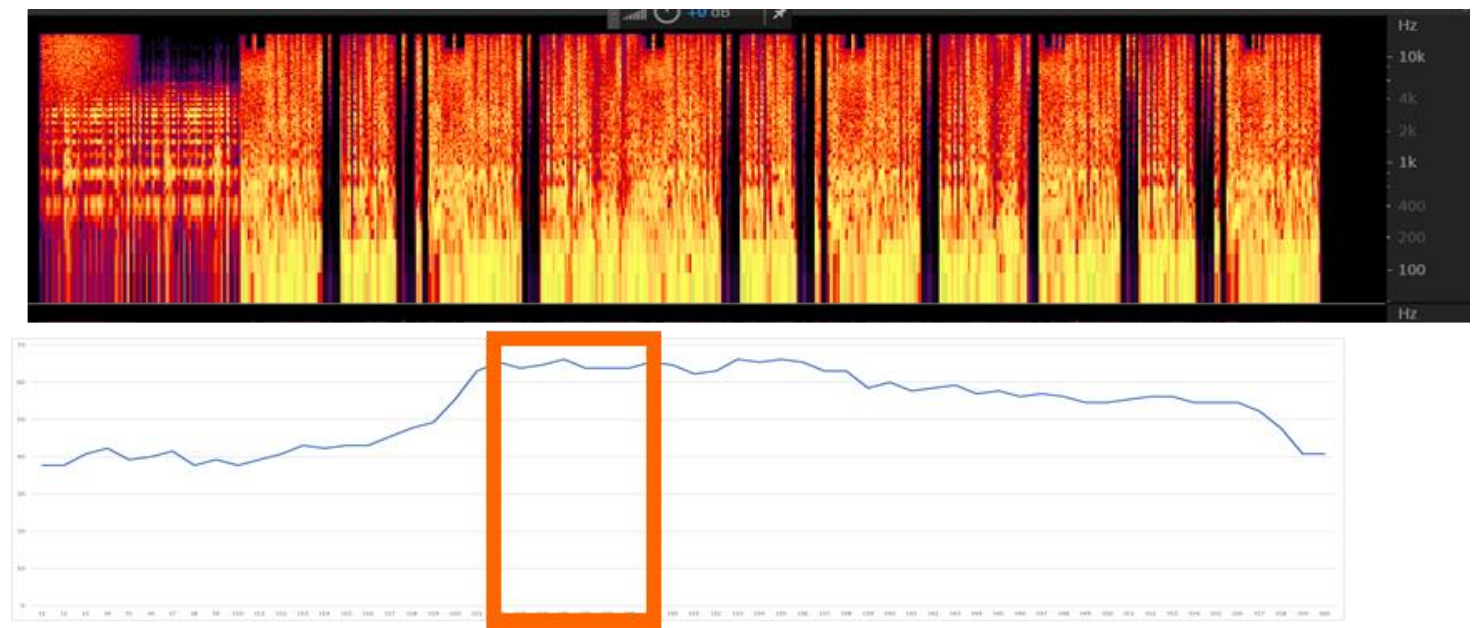

Skrillex “Bangarang” 2nd Half Resolution

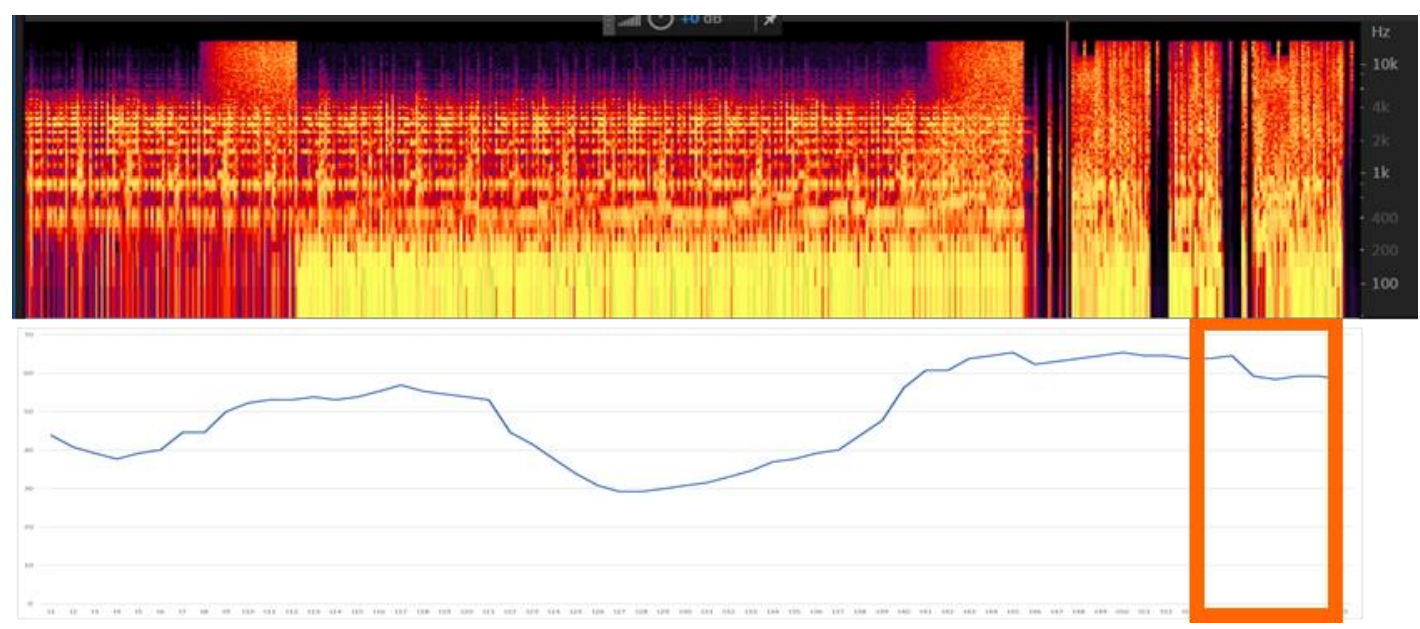


Figure 5: Temporal Slider Scale Output for Experiment 2

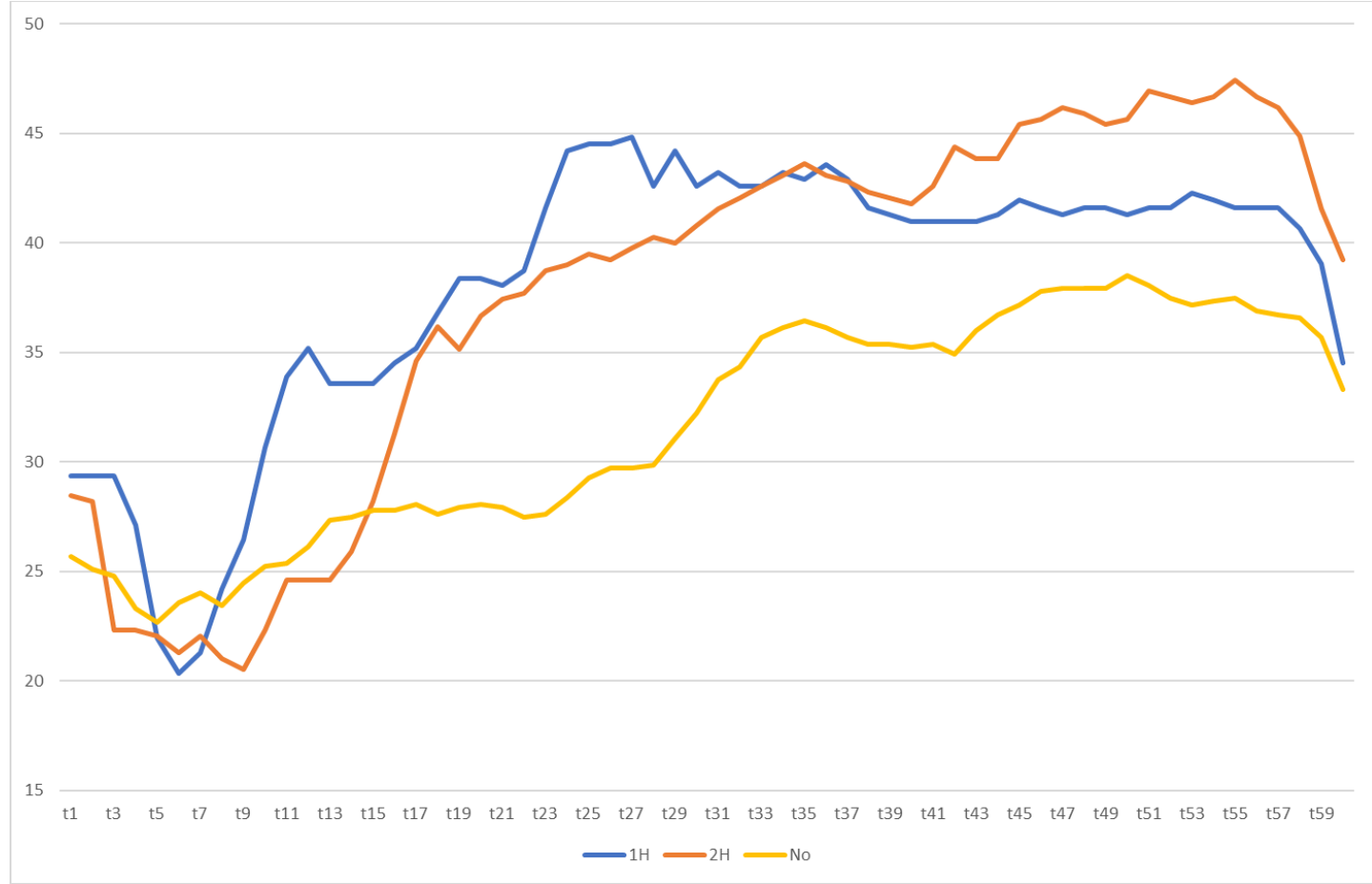


Figure 6: Full Mediation of the Effect of Tension Resolution Structure on Advertisement Likeability by Curiosity for Experiment 2
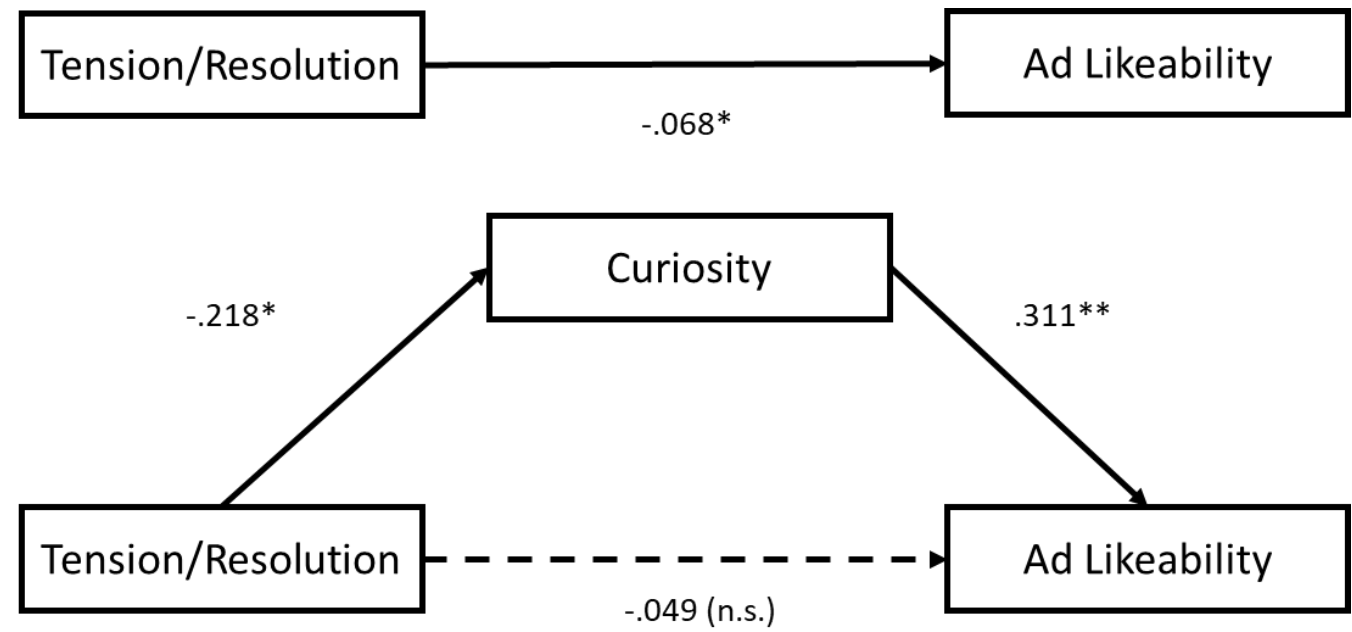

Note: $*=p<0.5 \quad * * p<.001$ 
Table 3: Full Results of Experiment 2

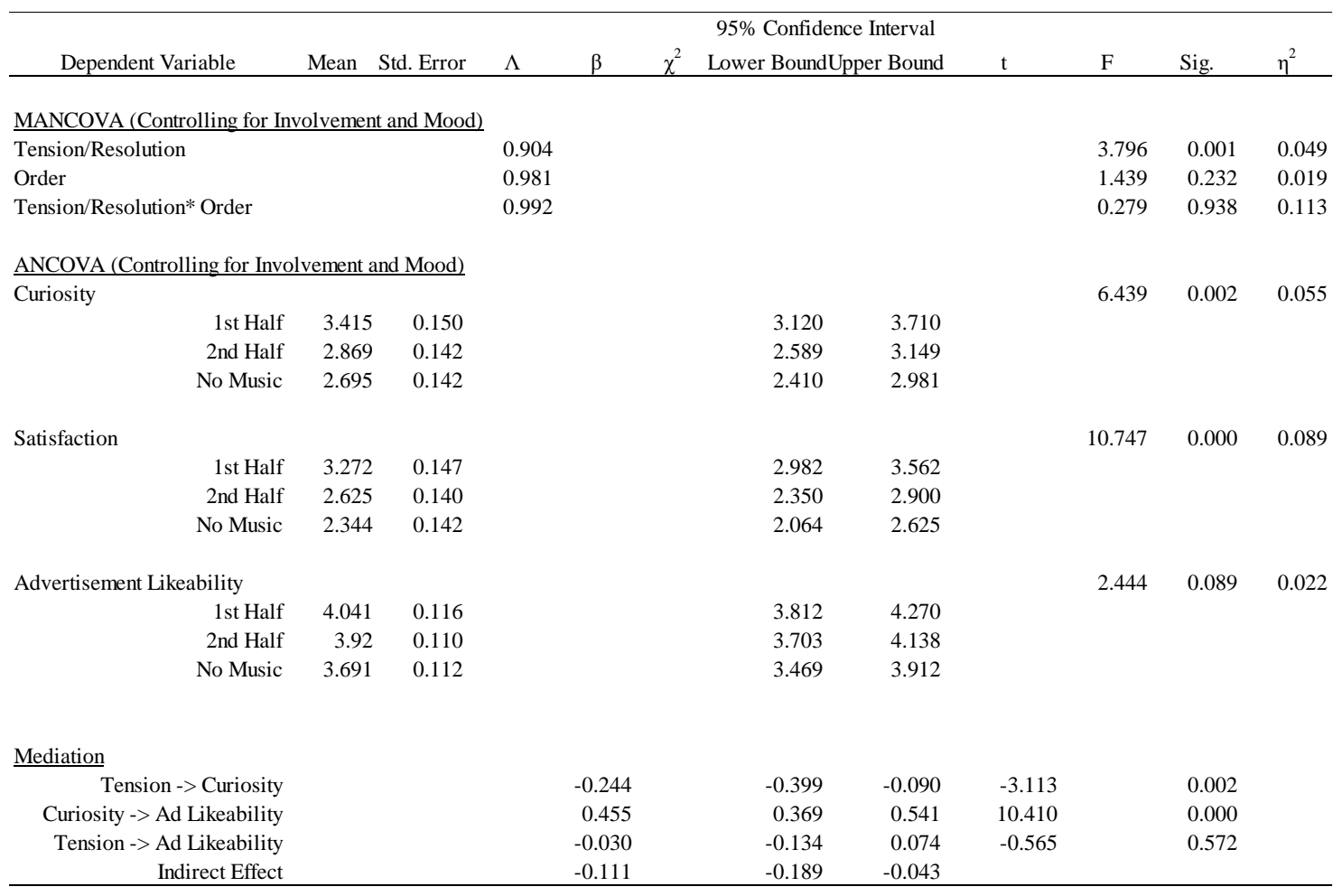




\section{Table 4: Full Results of Experiment 3}

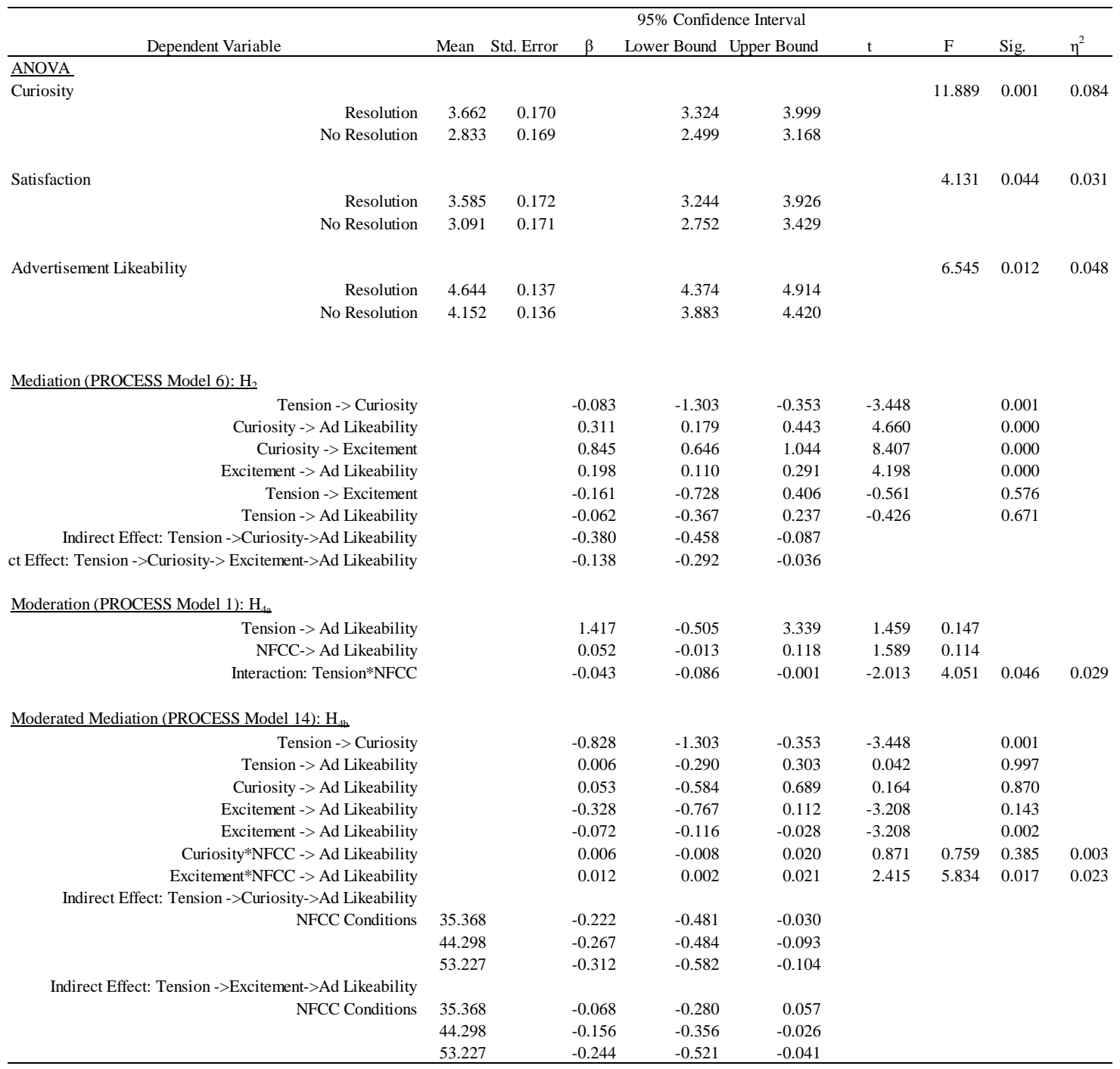


Table 5: Johnson-Nevman Output: Conditional Effect at Values of the Moderator NFCC on the relationship of the tension resolution structure and ad likeability

\begin{tabular}{|r|r|r|r|r|r|r|}
\hline NFCC_Tot & Effect & se & t & p & LLCl & ULCI \\
\hline 23.000 & -0.063 & 0.117 & -0.541 & 0.589 & -0.295 & 0.169 \\
\hline 25.000 & -0.040 & 0.108 & -0.373 & 0.710 & -0.255 & 0.174 \\
\hline 27.000 & -0.017 & 0.100 & -0.175 & 0.862 & -0.215 & 0.180 \\
\hline 29.000 & 0.006 & 0.092 & 0.060 & 0.952 & -0.176 & 0.187 \\
\hline 31.000 & 0.029 & 0.083 & 0.342 & 0.733 & -0.137 & 0.194 \\
\hline 33.000 & 0.052 & 0.076 & 0.681 & 0.497 & -0.098 & 0.201 \\
\hline 35.000 & 0.074 & 0.068 & 1.091 & 0.278 & -0.061 & 0.210 \\
\hline 37.000 & 0.097 & 0.062 & 1.584 & 0.116 & -0.024 & 0.219 \\
\hline 38.386 & 0.113 & 0.057 & 1.979 & 0.050 & 0.000 & 0.227 \\
\hline 39.000 & 0.120 & 0.056 & 2.168 & 0.032 & 0.011 & 0.230 \\
\hline 41.000 & 0.143 & 0.051 & 2.829 & 0.006 & 0.043 & 0.244 \\
\hline 43.000 & 0.166 & 0.047 & 3.520 & 0.001 & 0.073 & 0.260 \\
\hline 45.000 & 0.189 & 0.046 & 4.152 & 0.000 & 0.099 & 0.280 \\
\hline 47.000 & 0.212 & 0.046 & 4.626 & 0.000 & 0.121 & 0.303 \\
\hline 49.000 & 0.235 & 0.048 & 4.891 & 0.000 & 0.140 & 0.330 \\
\hline 51.000 & 0.258 & 0.052 & 4.967 & 0.000 & 0.155 & 0.361 \\
\hline 53.000 & 0.281 & 0.057 & 4.916 & 0.000 & 0.168 & 0.394 \\
\hline 55.000 & 0.304 & 0.063 & 4.796 & 0.000 & 0.179 & 0.430 \\
\hline 57.000 & 0.327 & 0.070 & 4.648 & 0.000 & 0.188 & 0.466 \\
\hline 59.000 & 0.350 & 0.078 & 4.495 & 0.000 & 0.196 & 0.504 \\
\hline 61.000 & 0.373 & 0.086 & 4.349 & 0.000 & 0.203 & 0.543 \\
\hline 63.000 & 0.396 & 0.094 & 4.214 & 0.000 & 0.210 & 0.582 \\
\hline & & & & & & \\
\hline
\end{tabular}




\section{Figure 7: Serial Mediation Model from Experiment 3}

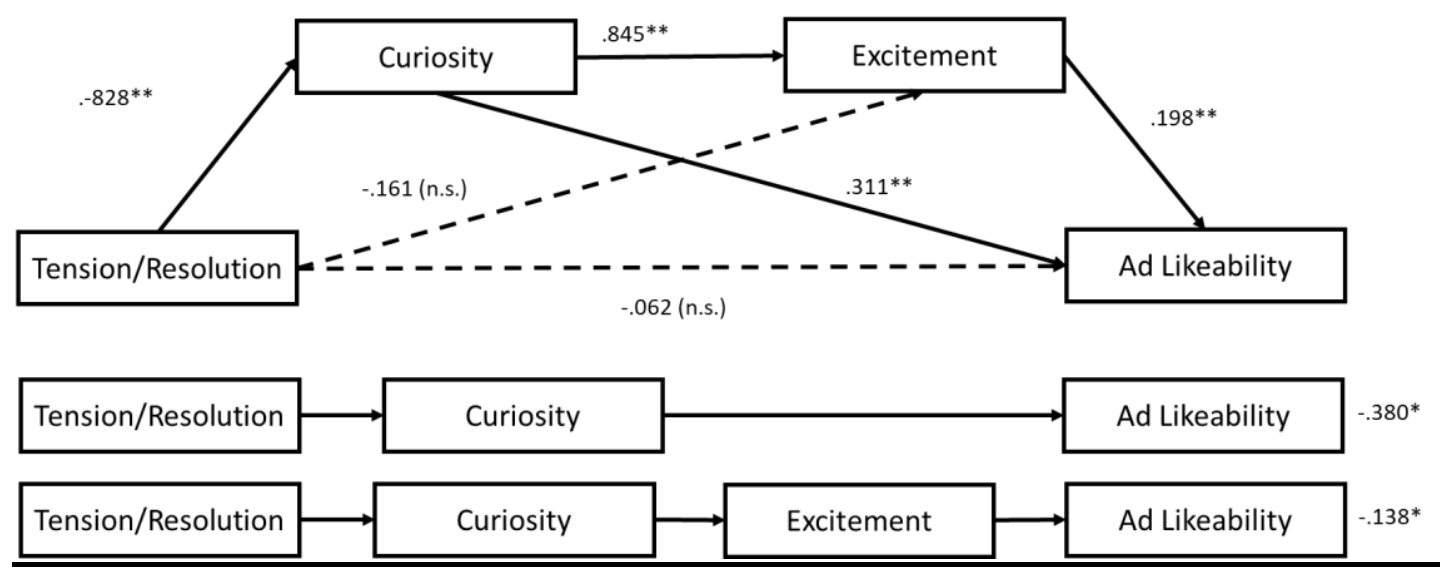


Figure 8: Moderation Mediation Models from Experiment 3

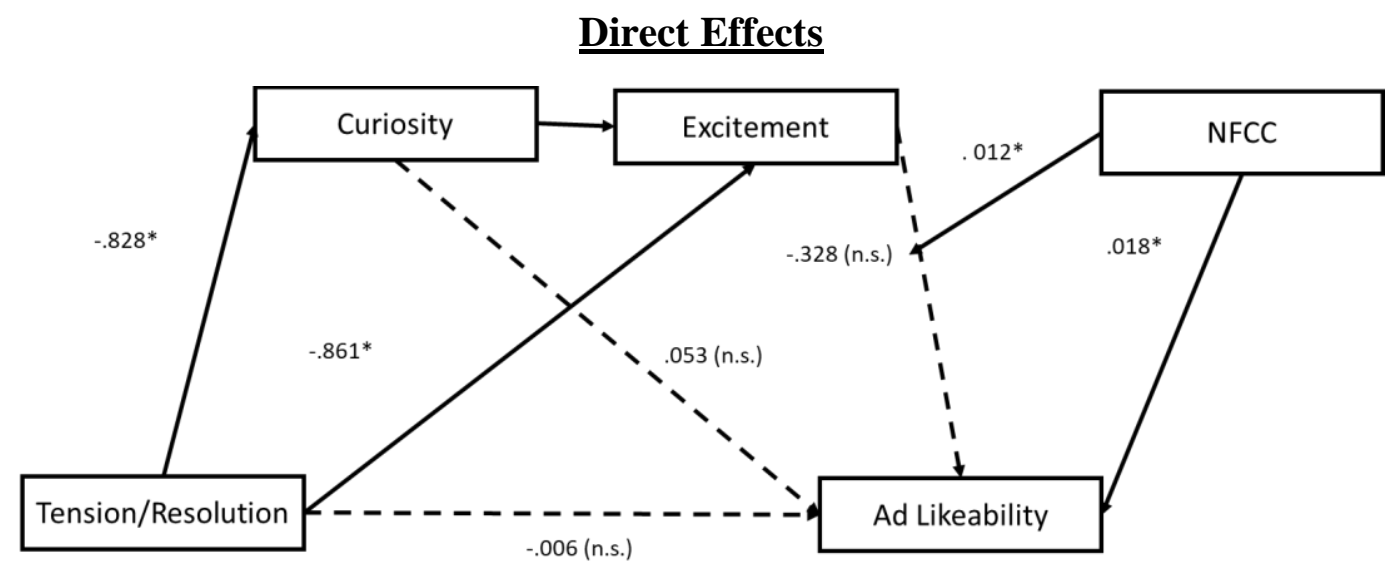

Note: $* \mathrm{p}<.05 \quad * * \mathrm{p}<.001$

Indirect Effects

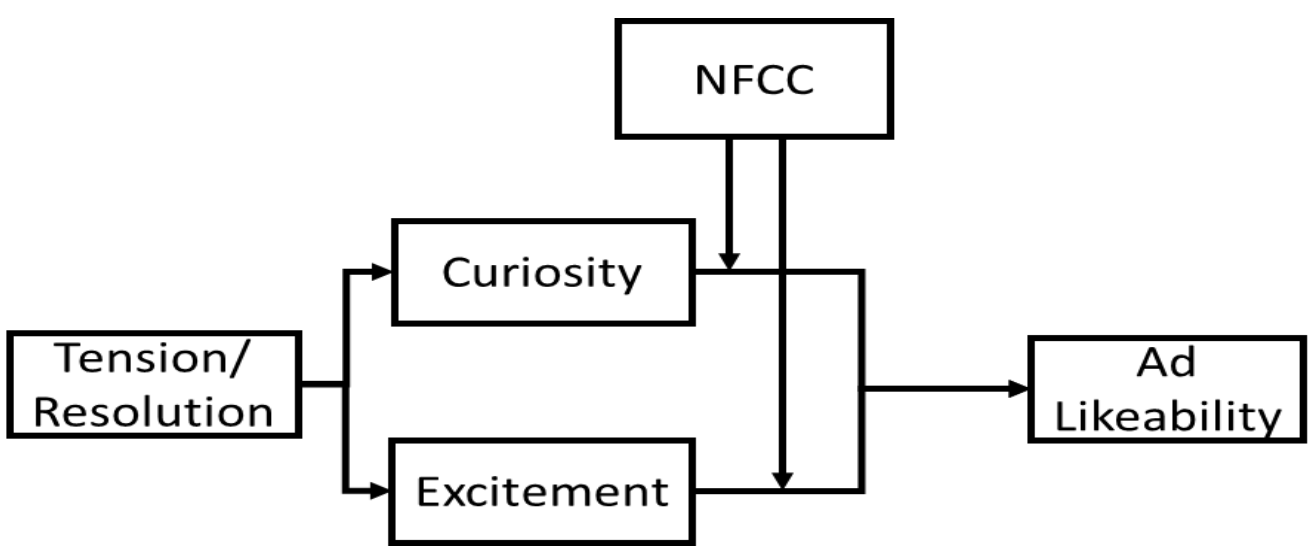


Table 6: Johnson-Nevman Output: Conditional Effect at Values of the Moderator NFCC for Moderated Mediation

\begin{tabular}{rrrrrrr}
\hline & & & & \multicolumn{3}{c}{$95 \%$ Confidence Interval } \\
NFCC Total & $\beta$ & Std. Error & $\mathrm{t}$ & \multicolumn{1}{l}{ Sig. } & Lower Bound Upper Bound \\
\hline 23.000 & -0.063 & 0.117 & -0.541 & 0.589 & -0.295 & 0.169 \\
25.000 & -0.040 & 0.108 & -0.373 & 0.710 & -0.255 & 0.174 \\
27.000 & -0.017 & 0.100 & -0.175 & 0.862 & -0.215 & 0.180 \\
29.000 & 0.006 & 0.092 & 0.060 & 0.952 & -0.176 & 0.187 \\
31.000 & 0.029 & 0.083 & 0.342 & 0.733 & -0.137 & 0.194 \\
33.000 & 0.052 & 0.076 & 0.681 & 0.497 & -0.098 & 0.201 \\
35.000 & 0.074 & 0.068 & 1.091 & 0.278 & -0.061 & 0.210 \\
37.000 & 0.097 & 0.062 & 1.584 & 0.116 & -0.024 & 0.219 \\
38.386 & 0.113 & 0.057 & 1.979 & 0.050 & 0.000 & 0.227 \\
39.000 & 0.120 & 0.056 & 2.168 & 0.032 & 0.011 & 0.230 \\
41.000 & 0.143 & 0.051 & 2.829 & 0.006 & 0.043 & 0.244 \\
43.000 & 0.166 & 0.047 & 3.520 & 0.001 & 0.073 & 0.260 \\
45.000 & 0.189 & 0.046 & 4.152 & 0.000 & 0.099 & 0.280 \\
47.000 & 0.212 & 0.046 & 4.626 & 0.000 & 0.121 & 0.303 \\
49.000 & 0.235 & 0.048 & 4.891 & 0.000 & 0.140 & 0.330 \\
51.000 & 0.258 & 0.052 & 4.967 & 0.000 & 0.155 & 0.361 \\
53.000 & 0.281 & 0.057 & 4.916 & 0.000 & 0.168 & 0.394 \\
55.000 & 0.304 & 0.063 & 4.796 & 0.000 & 0.179 & 0.430 \\
57.000 & 0.327 & 0.070 & 4.648 & 0.000 & 0.188 & 0.466 \\
59.000 & 0.350 & 0.078 & 4.495 & 0.000 & 0.196 & 0.504 \\
61.000 & 0.373 & 0.086 & 4.349 & 0.000 & 0.203 & 0.543 \\
63.000 & 0.396 & 0.094 & 4.214 & 0.000 & 0.210 & 0.582 \\
\hline & & & & & &
\end{tabular}




\section{Table 7: Full Results of Experiment 4}

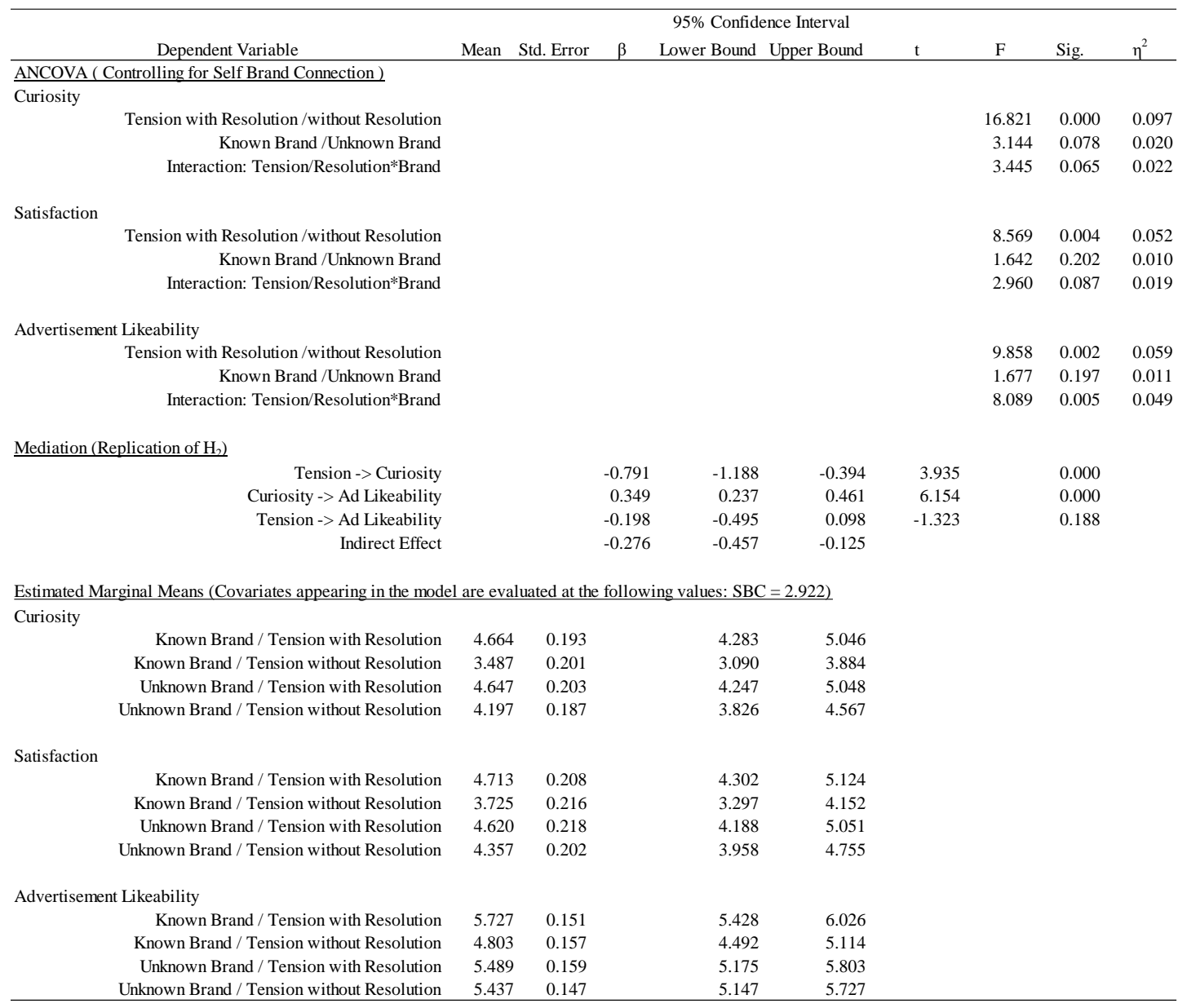




\section{Figure 9: Means Differences Between Conditions in Experiment 4}
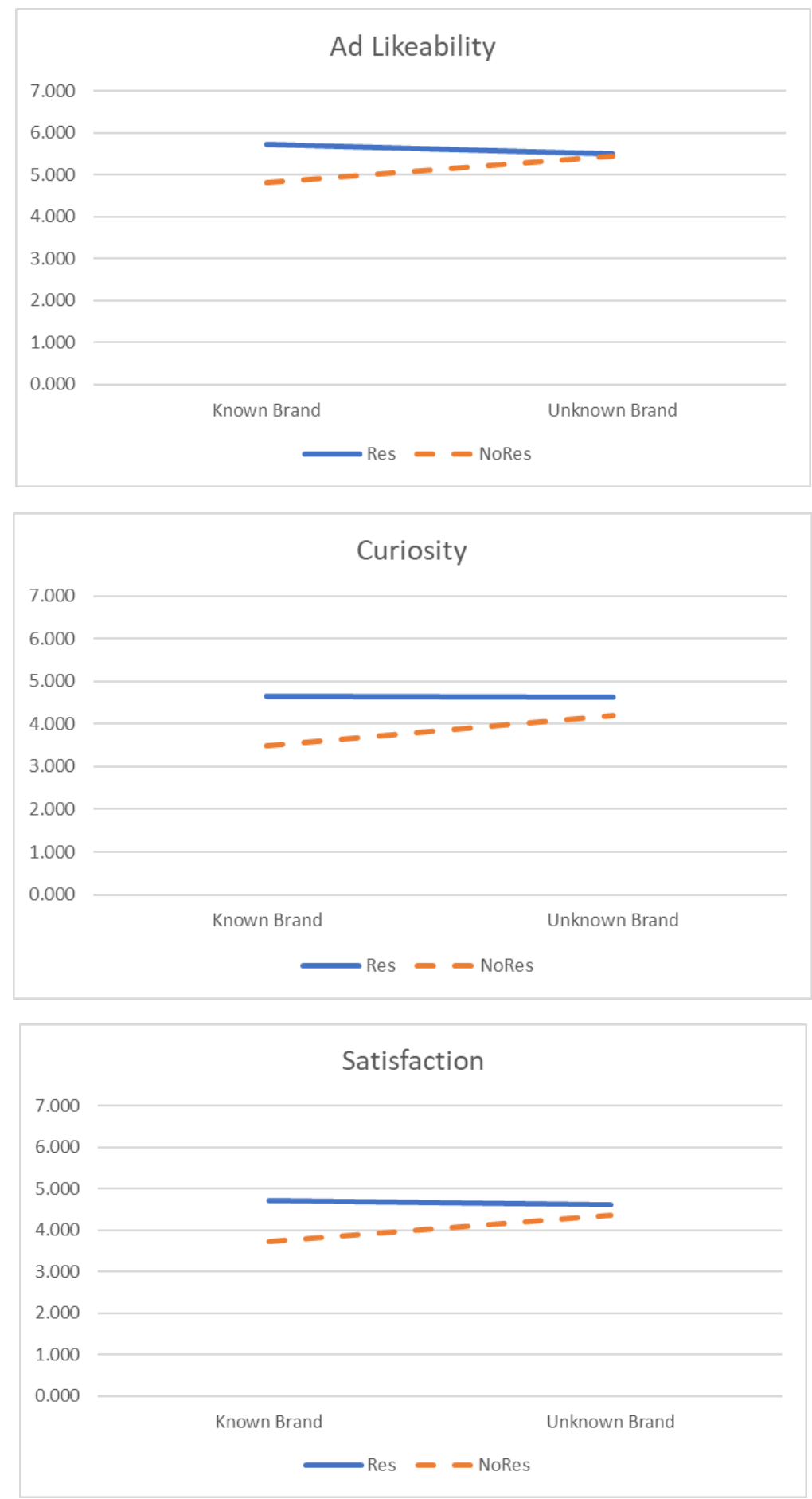


\section{APPENDIX C}

Table 8: Key Musical Terminology, and Associated Current and Future Research

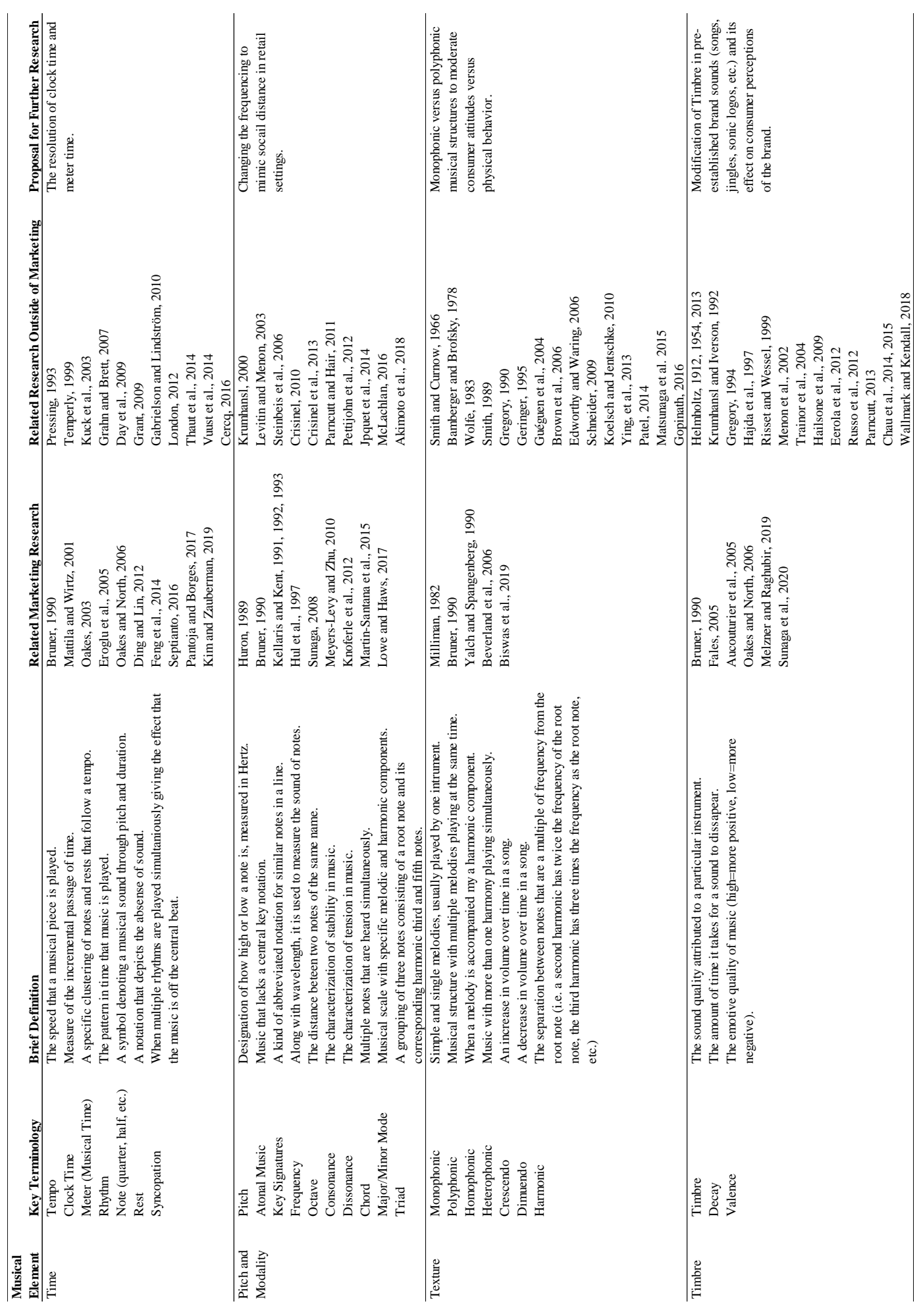




\section{BIBLIOGRAPHY}

Akimoto, K., Hu, A., Yamaguchi, T., \& Kobayashi, H. (2018). Effect of 528 Hz Music on the Endocrine System and Autonomic Nervous System. Health, 10(09), 1159.

All Ears: 27 (2019). Surprising statistics about headphones. (June 29). Retrieved from https://3dinsider.com/headphone-statistics/.

Allan, D. (2006). Effects of popular music in advertising on attention and memory. Journal of Advertising Research, 46(4), 434-444.

Alpers, S. L. (1967). Manner and meaning in some Rubens mythologies. Journal of the Warburg and Courtauld Institutes, 272-295.

Alpert, J. I., and Alpert, M. I. (1989). Background music as an influence in consumer mood and advertising responses. ACR North American Advances.

Alpert, M. I., Alpert, J. I., \& Maltz, E. N. (2005). Purchase occasion influence on the role of music in advertising. Journal of Business Research, 58(3), 369-376.

Anderson, Monica. "Mobile Technology and Home Broadband 2019.” Pew Research Center: Internet, Science \& Tech, Pew Research Center, 23 June 2020, www.pewresearch.org/internet/2019/06/13/mobile-technology-and-homebroadband-2019/.

Anderson, N. H., \& Hubert, S. (1963). Effects of concomitant verbal recall on order effects in personality impression formation. Journal of Verbal Learning and Verbal Behavior, 2(5-6), 379-391.

Anglada-Tort, M., Keller, S., Steffens, J., \& Müllensiefen, D. (2020). The Impact of Source Effects on the Evaluation of Music for Advertising: Are there Differences 
in How Advertising Professionals and Consumers Judge Music?. Journal of Advertising Research.

Areni, C. S., \& Kim, D. (1993). The influence of background music on shopping behavior: classical versus top-forty music in a wine store. ACR North American Advances.

Argo, J. J., Popa, M., \& Smith, M. C. (2010). The sound of brands. Journal of Marketing, 74(4), 97-109.

Art-Numeric Mazy Réginald. (2010, April 4). Godiva Chocolatier [Video]. YouTube. https://youtu.be/kU-7m1zZ3Eo

Aucouturier, J. J., Pachet, F., \& Sandler, M. (2005). "The way it sounds:" Timbre models for analysis and retrieval of music signals. IEEE Transactions on Multimedia, 7(6), 1028-1035.

Bakker, D. R., \& Martin, F. H. (2015). Musical chords and emotion: Major and minor triads are processed for emotion. Cognitive, Affective, \& Behavioral Neuroscience, 15(1), 15-31.

Bamberger, J. S. and Brofsky, H. (1978). The art of listening: Developing musical perception (5th ed.). New York: Harper \& Row.

Berlyne, D. E. (1954). A theory of human curiosity. British Journal of Psychology. General Section, 45(3), 180-191.

Beverland, M., Lim, E. A. C., Morrison, M., \& Terziovski, M. (2006). In-store music and consumer-brand relationships: Relational transformation following experiences of (mis) fit. Journal of Business Research, 59(9), 982-989. 
Bigand, E., Parncutt, R., \& Lerdahl, F. (1996). Perception of musical tension in short chord sequences: The influence of harmonic function, sensory dissonance, horizontal motion, and musical training. Perception \& Psychophysics, 58(1), 125 141.

Bijsterveld, K. (2010). Acoustic cocooning: How the car became a place to unwind. The Senses and Society, 5(2), 189-211.Biswas, D., Grewal, D., \& Roggeveen, A. (2009). How the Order of Sampled Experiential Goods Affects Choice. ACR Asia-Pacific Advances.

Biswas, D. (2019). Sensory aspects of retailing: Theoretical and practical implications.

Biswas, D., Grewal, D., \& Roggeveen, A. (2010). How the order of sampled experiential products affects choice. Journal of Marketing Research, 47(3), 508-519.

Biswas, D., Lund, K., \& Szocs, C. (2019). Sounds like a healthy retail atmospheric strategy: effects of ambient music and background noise on food sales. Journal of the Academy of Marketing Science, 47(1), 37-55.

Biswas, D., Szocs, C., \& Abell, A. (2019). Extending the boundaries of sensory marketing and examining the sixth sensory system: Effects of vestibular sensations for sitting versus standing postures on food taste perception. Journal of Consumer Research, 46(4), 708-724.

Bonin, T., \& Smilek, D. (2016). Inharmonic music elicits more negative affect and interferes more with a concurrent cognitive task than does harmonic music. Attention, Perception, \& Psychophysics, 78(3), 946-959.

Brackett, D. (2016). Categorizing sound: Genre and twentieth-century popular music. Univ of California Press. 
Brattico, E., \& Pearce, M. (2013). The neuroaesthetics of music. Psychology of Aesthetics, Creativity, and the Arts, 7(1), 48.

Bronner, K. (2008). Jingle all the way? Basics of audio branding. Paper presented at the Audio Branding, 76-89.

Brown, S., Martinez, M. J., \& Parsons, L. M. (2006). Music and language side by side in the brain: a PET study of the generation of melodies and sentences. European journal of neuroscience, 23(10), 2791-2803.

Bruner, G. C. (1990). Music, mood, and marketing. Journal of Marketing, 54(4), 94-104.

Carah, N., \& Shaul, M. (2016). Brands and Instagram: Point, tap, swipe, glance. Mobile Media \& Communication, 4(1), 69-84.

Chau, C. J., Wu, B., \& Horner, A. (2014, September). Timbre Features and Music Emotion in Plucked String, Mallet Percussion, and Keyboard Tones. In ICMC.

Chau, C., Wu, B., \& Horner, A. (2015). The Emotional Characteristics and Timbre of Nonsustaining Instrument Sounds. Journal of the Audio Engineering Society. Audio Engineering Society. 63. 228-244. 10.17743/jaes.2015.00016.

Chebat, J. C., Chebat, C. G., \& Vaillant, D. (2001). Environmental background music and in-store selling. Journal of Business Research, 54(2), 115-123.

Clercq, T. D. (2016). Measuring a measure: absolute time as a factor for determining bar lengths and meter in pop/rock music. Music Theory Online, 22(3).

Cohen, A. J., Thorpe, L. A., \& Trehub, S. E. (1987). Infants' perception of musical relations in short transposed tone sequences. Canadian Journal of Psychology/Revue canadienne de psychologie, 41(1), 33-47. 
Coulter, R. A., Price, L. L., \& Feick, L. (2003). Rethinking the origins of involvement and brand commitment: Insights from postsocialist central Europe. Journal of consumer research, 30(2), 151-169.

Crisinel, A. S. (2010). As bitter as a trombone: Synesthetic correspondences in nonsynesthetes between tastes/flavors and musical notes. Attention, Perception, \& Psychophysics, 72(7), 1994-2002.

Crisinel, A. S., Jacquier, C., Deroy, O., \& Spence, C. (2013). Composing with crossmodal correspondences: Music and odors in concert. Chemosensory Perception, 6(1), 45-52.

Dainow, E. (1977). Physical effects and motor responses to music. Journal of Research in Music Education, 25(3), 211-221.

Dalla Bella, S., Peretz, I., \& Aronoff, N. (2003). Time course of melody recognition: A gating paradigm study. Perception \& Psychophysics, 65(7), 1019-1028.

Day, R. F., Lin, C. H., Huang, W. H., \& Chuang, S. H. (2009). Effects of music tempo and task difficulty on multi-attribute decision-making: An eye-tracking approach. Computers in Human Behavior, 25(1), 130-143.

Dijksterhuis, A. P., Van Knippenberg, A. D., Kruglanski, A. W., and Schaper, C. (1996). Motivated social cognition: Need for closure effects on memory and judgment. Journal of Experimental Social Psychology, 32(3), 254-270.

Ding, C. G., \& Lin, C. H. (2012). How does background music tempo work for online shopping?. Electronic Commerce Research and Applications, 11(3), 299-307. 
Dowling, W. J. (1994). Melodic contour in hearing and remembering melodies, in Aiello, R. and Sloboda, J.A. (Eds), Musical perceptions, Oxford University Press, Oxford, 173-90.

Edison Research. (2019). The podcast consumer 2019. Retrieved October 10, 2019, from https://www.edisonresearch.com/the-podcast-consumer-2019/.

Edworthy, J., \& Waring, H. (2006). The effects of music tempo and loudness level on treadmill exercise. Ergonomics, 49(15), 1597-1610.

Eerola, T., Ferrer, R., \& Alluri, V. (2012). Timbre and affect dimensions: Evidence from affect and similarity ratings and acoustic correlates of isolated instrument sounds. Music Perception: An Interdisciplinary Journal, 30(1), 49-70.

Elliot, A. J., \& Aarts, H. (2011). Perception of the color red enhances the force and velocity of motor output. Emotion, 11(2), 445.

Eroglu, S. A., Machleit, K. A., \& Chebat, J. C. (2005). The interaction of retail density and music tempo: Effects on shopper responses. Psychology \& Marketing, 22(7), 577-589.

Evans, B. (2005). Foundations of a visual music. Computer Music Journal, 29(4), 11-24.

Fales, C. (2005). Short-circuiting perceptual systems. Timbre in ambient and techno music, in Greene, P. D. \& Porcello, T. (Eds), Wired for sound. Engineering and technologies in sonic cultures, Wesleyan University Pres, Middletown, Connecticut, 156-180.

Feng, S., Suri, R., \& Bell, M. (2014). Does classical music relieve math anxiety? Role of tempo on price computation avoidance. Psychology \& Marketing, 31(7), 489-499.

Freytag, G. (1863). Freytag's pyramid. A dictionary of media communication. 
Gabrielsson, A., \& Lindström, E. (2010). The role of structure in the musical expression of emotions. Handbook of music and emotion: Theory, research, applications, 367-400.

Geringer, J. M. (1995). Continuous loudness judgments of dynamics in recorded music excerpts. Journal of Research in Music Education, 43(1), 22-35.

Gillard, J., \& Schutz, M. (December 2016). Composing alarms: Considering the musical aspects of auditory alarm design. Neurocase. 22 (6): 566576. doi: $\underline{10.1080 / 13554794.2016 .1253751 .}$ PMID 27869530.

Gorn, G. J. (1982). The effects of music in advertising on choice behavior: A classical conditioning approach. Journal of Marketing, 46(1), 94-101.

Gorn, G. J., Chattopadhyay, A., Yi, T., \& Dahl, D. W. (1997). Effects of color as an executional cue in advertising: They're in the shade. Management science, 43(10), 1387-1400.

Gopinath, S. (2016). Researching the Mobile Phone Ringtone: Towards and Beyond The Ringtone Dialectic. In 21st Century Perspectives on Music, Technology, and Culture (pp. 182-194). Palgrave Macmillan, London.

Grahn, J. A., \& Brett, M. (2007). Rhythm and beat perception in motor areas of the brain. Journal of Cognitive Neuroscience, 19(5), 893-906.

Grant, R. M. (2009). epistemologies of time and metre in the long eighteenth century. Eighteenth-Century Music, 6(1), 59-75.

Gregory, A. H. (1990). Listening to polyphonic music. Psychology of Music, 18(2), 163170. 
Gregory, A. H. (1994). Timbre and auditory streaming. Music Perception, 12(2), 161174.

Guéguen, N., Hélène, L. G., \& Jacob, C. (2004). Sound level of background music and alcohol consumption: An empirical evaluation. Perceptual and Motor Skills, 99(1), 34-38.

Hailstone, J. C., Omar, R., Henley, S. M., Frost, C., Kenward, M. G., \& Warren, J. D. (2009). It's not what you play, it's how you play it: Timbre affects perception of emotion in music. Quarterly journal of experimental psychology, 62(11), 21412155.

Hajda, J. M., Kendall, R. A., Carterette, E. C., \& Harshberger, M. L. (1997). Methodological issues in timbre research. In I. Deliège \& J. Sloboda (Eds.), Perception and cognition of music (p. 253-306). Psychology Press/Erlbaum (UK) Taylor \& Francis.

Hayes, A. F. (2017). Introduction to mediation, moderation, and conditional process analysis: A regression-based approach. Guilford publications.

Helmholtz, H. (1912, 2013). On the sensations of tone. Courier Corporation.

Homer, P. M. (1990). The mediating role of attitude toward the ad: Some additional evidence. Journal of Marketing research, 27(1), 78-86.

Howard, D., Rosen, S., \& Broad, V. (1992). Major/minor triad identification and discrimination by musically trained and untrained listeners. Music Perception, 10(2), 205-220.

jHul, M. K., Dube, L., \& Chebat, J. C. (1997). The impact of music on consumers' reactions to waiting for services. Journal of retailing, 73(1), 87-104. 
Huron, D. (1989). Music in advertising: An analytic paradigm. The Musical Quarterly, 73(4), 557-574.

Huron, D. B. (2006). Sweet anticipation: Music and the psychology of expectation. MIT press.

Hwang, I., and Kim, H. K. (2015). The Effect of Congruency and Familiarity of Background Music in TV Advertising on the Music's Role as a Retrieval Cue. Asia Marketing Journal, 16(4), 1-18.

Jaquet, L., Danuser, B., \& Gomez, P. (2014). Music and felt emotions: How systematic pitch level variations affect the experience of pleasantness and arousal. Psychology of Music, 42(1), 51-70.

Kaltcheva, V. D., \& Weitz, B. A. (2006). When should a retailer create an exciting store environment?. Journal of marketing, 70(1), 107-118.

Kallinen, K., \& Ravaja, N. (2007). Comparing speakers versus headphones in listening to news from a computer-individual differences and psychophysiological responses. Computers in Human Behavior, 23(1), 303-317.

Kang, M. J., Hsu, M., Krajbich, I. M., Loewenstein, G., McClure, S. M., Wang, J. T. Y., \& Camerer, C. F. (2009). The wick in the candle of learning: Epistemic curiosity activates reward circuitry and enhances memory. Psychological science, 20(8), 963-973.

Kashdan, T. B., Stiksma, M. C., Disabato, D. J., McKnight, P. E., Bekier, J., Kaji, J., \& Lazarus, R. (2018). The five-dimensional curiosity scale: Capturing the bandwidth of curiosity and identifying four unique subgroups of curious people. Journal of Research in Personality, 73, 130-149. 
Kashima, E. S., \& Loh, E. (2006). International students' acculturation: Effects of international, conational, and local ties and need for closure. International journal of intercultural relations, 30(4), 471-485.

Keil, C., \& Feld, S. (1994). Music grooves. Chicago: University of Chicago Press.

Kellaris, J. J., \& Cox, A. D. (1989). The effects of background music in advertising: A reassessment. Journal of Consumer Research, 16(1), 113-118.

Kellaris, J. J., \& Kent, R. J. (1991). Exploring tempo and modality effects, on consumer responses to music. ACR North American Advances.

Kellaris, J. J., \& Kent, R. J. (1992). The influence of music on consumers' temporal perceptions: Does time fly when you're having fun?. Journal of consumer psychology, 1(4), 365-376.

Kellaris, J. J., \& Kent, R. J. (1993). An exploratory investigation of responses elicited by music varying in tempo, tonality, and texture. Journal of Consumer Psychology, 2(4), 381-401.

Kidd, C., \& Hayden, B. Y. (2015). The psychology and neuroscience of curiosity. Neuron, 88(3), 449-460.

Kim, K., \& Zauberman, G. (2019). The effect of music tempo on consumer impatience in intertemporal decisions. European Journal of Marketing.

Klimmt, C., Rizzo, A., Vorderer, P., Koch, J., \& Fischer, T. (2009). Experimental evidence for suspense as determinant of video game enjoyment. Cyberpsychology \& behavior, 12(1), 29-31. 
Knobloch-Westerwick, S., David, P., Eastin, M. S., Tamborini, R., \& Greenwood, D. (2009). Sports spectators' suspense: Affect and uncertainty in sports entertainment. Journal of Communication, 59(4), 750-767.

Knoferle, K. M., Spangenberg, E. R., Herrmann, A., \& Landwehr, J. R. (2012). It is all in the mix: The interactive effect of music tempo and mode on in-store sales. Marketing Letters, 23(1), 325-337.

Koelsch, S., Fritz, T., Schulze, K., Alsop, D., \& Schlaug, G. (2005). Adults and children processing music: An fMRI study. Neuroimage, 25(4), 1068-1076.

Koelsch, S., \& Jentschke, S. (2010). Differences in electric brain responses to melodies and chords. Journal of cognitive neuroscience, 22(10), 2251-2262.

Krishnan, V., Kellaris, J. J., \& Aurand, T. W. (2012). Sonic logos: Can sound influence willingness to pay? The Journal of Product and Brand Management, 21(4), 275.

Kruglanski, A. W., Atash, M. N., De Grada, E., Mannetti, L., and Pierro, A. (2013). Need for Closure Scale (NFC). Measurement instrument database for the social science.

Krumhansl, C. L., \& Iverson, P. (1992). Perceptual interactions between musical pitch and timbre. Journal of Experimental Psychology: Human Perception and Performance, 18(3), 739.

Krumhansl, C. L. (1996). A perceptual analysis of Mozart's Piano Sonata K. 282: Segmentation, tension, and musical ideas. Music Perception: An Interdisciplinary Journal, 13(3), 401432.

Krumhansl, C. L. (2000). Rhythm and pitch in music cognition. Psychological Bulletin, 126(1), 159. 
Kuck, H., Grossbach, M., Bangert, M., \& Altenmüller, E. (2003). Brain processing of meter and rhythm in music: electrophysiological evidence of a common network. Annals of the New York Academy of Sciences, 999(1), 244-253.

Kunst, Alexander. “Devices Used with Headphones US 2017.” Statista, 3 Sept. 2019, www.statista.com/statistics/696835/devices-headphones-are-used-for-in-the-us/.

Lehne, M., \& Koelsch, S. (2015). Toward a general psychological model of tension and suspense. Frontiers in Psychology, 6, 79.

Lehne, M., Rohrmeier, M., \& Koelsch, S. (2013). Tension-related activity in the orbitofrontal cortex and amygdala: An fMRI study with music. Social Cognitive And Affective Neuroscience, 9(10), 1515-1523.

Lerdahl, F. (1996). Calculating tonal tension. Music Perception: An Interdisciplinary Journal, 13(3), 319-363.

Lerdahl, F., and Krumhansl, C. L. (2007). Modeling tonal tension. Music Perception: An Interdisciplinary Journal, 24(4), 329-366.

Levitin, D. J., \& Menon, V. (2003). Musical structure is processed in "language" areas of the brain: A possible role for Brodmann Area 47 in temporal coherence. Neuroimage, 20(4), 2142-2152.

Lewis, J. W., Beauchamp, M. S., \& DeYoe, E. A. (2000). A comparison of visual and auditory motion processing in human cerebral cortex. Cerebral Cortex, 10(9), 873-888.

Liberman, N., Trope, Y., \& Wakslak, C. (2007). Construal level theory and consumer behavior. Journal of consumer psychology, 17(2), 113-117. 
Licoppe, C. (2008). The mobile phone's ring. In J. E. Katz (Ed.), Handbook of mobile communication studies (p. 139-152). MIT

Press. https://doi.org/10.7551/mitpress/9780262113120.003.0011

Lieberman, A. J., Amir, O., \& Schroeder, J. (2016). “Coming Alive” Through Headphones: Listening to Messages Via Headphones Vs. Speakers Increases Immersion, Presence, and Liking. ACR North American Advances.

Lisjak, M., Bonezzi, A., Kim, S., \& Rucker, D. D. (2015). Perils of compensatory consumption: Within-domain compensation undermines subsequent selfregulation. Journal of Consumer Research, 41(5), 1186-1203.

Li, H., Edwards, S. M., \& Lee, J. H. (2002). Measuring the intrusiveness of advertisements: Scale development and validation. Journal of Advertising, 31(2), $37-47$.

Loewenstein, G. (1994). The psychology of curiosity: A review and reinterpretation. Psychological bulletin, 116(1), 75.

London, J. (2012). Hearing in time: Psychological aspects of musical meter. Oxford University Press.

Lowe, M. L., \& Haws, K. L. (2017). Sounds big: the effects of acoustic pitch on product perceptions. Journal of Marketing Research, 54(2), 331-346.

MacKenzie, S. B. (1986). The role of attention in mediating the effect of advertising on attribute importance. Journal of Consumer Research, 13(2), 174-195.

Magala, S., Mantere, S., Sillince, J. A., \& Hämäläinen, V. (2007). Music as a metaphor for organizational change. Journal of Organizational Change Management. 
Manchón, L. M. (2019). Sonic logos: An Experimental Design on Sound Features and Brand Personality. Disertaciones: Anuario electrónico de estudios en Comunicación Social, 12(2), 125-141.

Martín-Santana, J. D., Muela-Molina, C., Reinares-Lara, E., \& Rodríguez-Guerra, M. (2015). Effectiveness of radio spokesperson's gender, vocal pitch and accent and the use of music in radio advertising. BRQ Business Research Quarterly, 18(3), 143-160.

Matsunaga, R., Hartono, P., \& Abe, J. I. (2015). The acquisition process of musical tonal schema: implications from connectionist modeling. Frontiers in psychology, 6, 1348.

Mattila, A. S., \& Wirtz, J. (2001). Congruency of scent and music as a driver of in-store evaluations and behavior. Journal of Retailing, 77(2), 273-289.

McLachlan, N. (2016, June 02). Timbre, Pitch, and Music. Oxford Handbooks Online.

Melzner, J., \& Raghubir, P. (2019). The Sound of Music: the Influence of Timbre on Product Perception. ACR North American Advances.

V. Menon, D.J. Levitin, B.K. Smith, A. Lembke, B.D. Krasnow, D. Glazer, G.H. Glover, S. McAdams. (2002). Neural correlates of timbre change in harmonic sounds. Neuroimage, 17(4), 1742-1754.

Meyers-Levy, J., \& Zhu, R. J. (2010). Gender differences in the meanings consumers infer from music and other aesthetic stimuli. Journal of Consumer Psychology, 20(4), 495-507.

Milliman, R. E. (1982). Using background music to affect the behavior of supermarket shoppers. Journal of Marketing, 46(3), 86-91. 
Möckel, M., Röcker, L., Störk, T., Vollert, J., Danne, O., Eichstädt, H., ... \& Hochrein, H. (1994). Immediate physiological responses of healthy volunteers to different types of music: Cardiovascular, hormonal and mental changes. European Journal of Applied Physiology and Occupational Physiology, 68(6), 451-459.

Morrison, M., \& Beverland, M. (2003). In search of the right in-store music. Business Horizons, 46(6), 77-82.

Mulcahy, R. F., \& Riedel, A. S. (2020). 'Touch it, swipe it, shake it': Does the emergence of haptic touch in mobile retailing advertising improve its effectiveness?. Journal of Retailing and Consumer Services, 54.

Murphy, J., Hofacker, C., \& Mizerski, R. (2006). Primacy and recency effects on clicking behavior. Journal of Computer-Mediated Communication, 11(2), 522-535.

NBC News (2015, June 11). The fourth chime: Why NBC's familiar signal changed on D-Day. Retrieved August 19, 2019 from https://www.nbcnews.com/storyline/dday-70th-anniversary/fourth-chime-why-nbcs-familiar-signal-changed-d-day$\underline{\mathrm{n} 123906}$

Nelson, L. D., Meyvis, T., \& Galak, J. (2009). Enhancing the television-viewing experience through commercial interruptions. Journal of Consumer Research, 36(2), 160-172.

Nielsen Music 360 (2017). Time with tunes: How technology is driving music consumption (February 11). Retrieved November 9, 2019, from https://www.nielsen.com/us/en/insights/article/2017/time-with-tunes-howtechnology-is-driving-music-consumption/

North, A. C., Sheridan, L. P., and Areni, C. S. (2016). Music congruity effects on product memory, perception, and choice. Journal of Retailing, 92(1), 83-95. 
Oakes, S. (2003). Musical tempo and waiting perceptions. Psychology \& Marketing, 20(8), 685-705.

Oakes, S. (2007). Evaluating empirical research into music in advertising: A congruity perspective. Journal of Advertising Research, 47(1), 38-50.

Oakes, S., \& North, A. C. (2006). The impact of background musical tempo and timbre congruity upon ad content recall and affective response. Applied Cognitive Psychology: The Official Journal of the Society for Applied Research in Memory and Cognition, 20(4), 505-520.

Olsen, G. D. (1995). Creating the contrast: The influence of silence and background music on recall and attribute importance. Journal of Advertising, 24(4), 29-44.

Pantoja, F., \& Borges, A. (2017, June). Is It a Matter of Tempo? Music Tempo Effects on Food's Purchase Intentions and Perceived Taste: An Abstract. In Academy of Marketing Science World Marketing Congress (pp. 27-27). Springer, Cham.

Park, C. W., \& Young, S. M. (1986). Consumer response to television commercials: The impact of involvement and background music on brand attitude formation. Journal of Marketing Research, 23(1), 11-24.

Parncutt, R., \& Hair, G. (2011). Consonance and dissonance in music theory and psychology: Disentangling dissonant dichotomies. Journal of Interdisciplinary Music Studies, 5(2).

Parncutt, R. (2013). Piano touch, timbre, ecological psychology, and cross-modal interference. In Proceedings of the International Symposium on Performance Science 2013 (pp. 763-768). Belgium: Association Européenne des Conservatoires, Brussels. 
Patel, A. D. (2014). Can nonlinguistic musical training change the way the brain processes speech? The expanded OPERA hypothesis. Hearing research, 308, 98108.

Pearce, M. T., \& Wiggins, G. A. (2012). Auditory expectation: The information dynamics of music perception and cognition. Topics in Cognitive Science, 4(4), 625-652.

Percy, L., \& Rossiter, J. R. (1992). A model of brand awareness and brand attitude advertising strategies. Psychology \& Marketing, 9(4), 263-274.

Pettijohn, T. F., Eastman, J. T., \& Richard, K. G. (2012). And the beat goes on: popular Billboard song beats per minute and key signatures vary with social and economic conditions. Current Psychology, 31(3), 313-317.

Petty, R. E., \& Cacioppo, J. T. (1986). The elaboration likelihood model of persuasion. In Communication and persuasion (pp. 1-24). Springer, New York, NY.

Pressing, J. (1993). Relations between musical and scientific properties of time. Contemporary Music Review, 7(2), 105-122.

Raja, M. W., Anand, S., \& Allan, D. (2019). Advertising music: An alternative atmospheric stimulus to retail music. International Journal of Retail \& Distribution Management.

Risset, J. C., \& Wessel, D. L. (1999). Exploration of timbre by analysis and synthesis. In The psychology of music (pp. 113-169). Academic Press.

Roehm, M. L. (2001). Instrumental vs. vocal versions of popular music in advertising. Journal of Advertising Research, 41(3), 49-58.

Rozin, A., Rozin, P., \& Goldberg, E. (2004). The feeling of music past: How listeners remember musical affect. Music perception, 22(1), 15-39. 
Ruan, B., Hsee, C. K., \& Lu, Z. Y. (2018). The teasing effect: An underappreciated benefit of creating and resolving an uncertainty. Journal of Marketing Research, 55(4), 556-570.

Russo, F. A., Ammirante, P., \& Fels, D. I. (2012). Vibrotactile discrimination of musical timbre. Journal of Experimental Psychology: Human Perception and Performance, 38(4), 822.

Sayin, E., Krishna, A., Ardelet, C., Decré, G. B., \& Goudey, A. (2015). “Sound and safe:" The effect of ambient sound on the perceived safety of public spaces. International Journal of Research in Marketing, 32(4), 343-353.

Schneider, C.J. (2009), "The music ringtone as an identity management device: a research note", Denzin, N.K. (Ed.) Studies in Symbolic Interaction (Studies in Symbolic Interaction, Vol. 33), Emerald Group Publishing Limited, Bingley, pp. $35-45$.

Smith, D. S. (1989). Preferences for differentiated frequency loudness levels in older adult music listening. Journal of Music Therapy, 26(1), 18-29.

Smith, K. T. (2011). Digital marketing strategies that millennials find appealing, motivating, or just annoying. Journal of Strategic Marketing, 19(6), 489-499.

Smith, P. C., \& Curnow, R. (1966). "Arousal hypothesis" and the effects of music on purchasing behavior. Journal of Applied Psychology, 50(3), 255.

Spence, C. (2011). Crossmodal correspondences: A tutorial review. Attention, Perception, \& Psychophysics, 73(4), 971-995. 
Steinbeis, N., Koelsch, S., \& Sloboda, J. A. (2006). The role of harmonic expectancy violations in musical emotions: Evidence from subjective, physiological, and neural responses. Journal of cognitive neuroscience, 18(8), 1380-1393.

Stewart, K., \& Koh, H. E. (2017). Hooked on a feeling: The effect of music tempo on attitudes and the mediating role of consumers' affective responses. Journal of Consumer Behaviour, 16(6), 550-564.

Sunaga, T. (2018). How the sound frequency of background music influences consumers' perceptions and decision making. Psychology \& Marketing, 35(4), 253-267.

Sunaga, T., Meng, Y., \& Zhuang, X. (2020). Interactions between instrumental timbre and consumers' regulatory focus. Journal of Business Research, 121, 1-12.

Sung, Y. S., Choi, M. J., Chung, S. J., \& Kim, C. Y. (2011). Neural responses to sonic branding: an fMRI study. Science of Emotion and Sensibility, 14(1), 93-100.

Tajadura-Jiménez, A., Pantelidou, G., Rebacz, P., Västfjäll, D., \& Tsakiris, M. (2011). Ispace: the effects of emotional valence and source of music on interpersonal distance. PloS one, 6(10), e26083.

Taylor, C. R. (2013). Hot topics in advertising research.

Temperley, D. (1999). Syncopation in rock: A perceptual perspective. Popular Music, 18(1), 19-40.

Thaut, M., Trimarchi, P., \& Parsons, L. (2014). Human brain basis of musical rhythm perception: Common and distinct neural substrates for meter, tempo, and pattern. Brain Sciences, 4(2), 428-452. 
Toiviainen, P., and Krumhansl, C. L. (2003). Measuring and modeling real-time responses to music: The dynamics of tonality induction. Perception, 32(6), 741766.

Trainor, L. J., \& Trehub, S. E. (1993). What mediates infants' and adults' superior processing of the major over the augmented triad?. Music Perception, 11(2), 185196.

Trainor, L. J., Wu, L., \& Tsang, C. D. (2004). Long-term memory for music: Infants remember tempo and timbre. Developmental science, 7(3), 289-296.

van Leeuwen, T. (2017). Sonic logos. Music as multimodal discourse. Semiotics, power and protest, 119-134.

Vermeir, I., and Geuens, M. (2008). Need for closure and media use and preference of young adults. ACR North American Advances.

Vermeulen, I., \& Beukeboom, C. J. (2016). Effects of music in advertising: Three experiments replicating single-exposure musical conditioning of consumer choice (Gorn 1982) in an individual setting. Journal of Advertising, 45(1), 53-61.

Von Helmholtz, H. (1912). On the sensations of tone as a physiological basis for the theory of music. Longmans, Green.

Vuust, P., Gebauer, L. K., \& Witek, M. A. (2014). Neural underpinnings of music: the polyrhythmic brain. In Neurobiology of interval timing (pp. 339-356). Springer, New York, NY.

Wallmark, Z., \& Kendall, R. A. (2018). Describing sound: The cognitive linguistics of timbre. The Oxford handbook of timbre. Advance online publication. New York, 
NY: Oxford University Press. http://dx. doi.

org/10.1093/oxfordhb/9780190637224.013, 14.

Webster, D. M., and Kruglanski, A. W. (1994). Individual differences in need for cognitive closure. Journal of personality and social psychology, 67(6), 1049.

Wolfe, D. E. (1983). Effects of music loudness on task performance and self-report of college-aged students. Journal of Research in Music Education, 31(3), 191-201.

Yalch, R., \& Spangenberg, E. (1990). Effects of store music on shopping behavior. Journal of Consumer Marketing, 7(2), 55-63.

Ying, L. F., Lung, L. C., Chiat, L. F., \& Hee, T. F. (2013). Preferences in musical elements in ringtone selection: Comparison between music and non-music undergraduate student. International Journal of Asian Social Sciences, 3(4), 913 920.

Zelechowska, A., Gonzalez-Sanchez, V. E., Laeng, B., \& Jensenius, A. R. (2020). Headphones or speakers? An exploratory study of their effects on spontaneous body movement to rhythmic music. Frontiers in Psychology, 11 . 